\title{
WestVirginiaUniversity
}

THE RESEARCH REPOSITORY @ WVU

Graduate Theses, Dissertations, and Problem Reports

2004

\section{Frictional resistance of concrete on a geocomposite material}

Joshua Bryan Cook

West Virginia University

Follow this and additional works at: https://researchrepository.wvu.edu/etd

\section{Recommended Citation}

Cook, Joshua Bryan, "Frictional resistance of concrete on a geocomposite material" (2004). Graduate Theses, Dissertations, and Problem Reports. 1420.

https://researchrepository.wvu.edu/etd/1420

This Thesis is protected by copyright and/or related rights. It has been brought to you by the The Research Repository @ WVU with permission from the rights-holder(s). You are free to use this Thesis in any way that is permitted by the copyright and related rights legislation that applies to your use. For other uses you must obtain permission from the rights-holder(s) directly, unless additional rights are indicated by a Creative Commons license in the record and/ or on the work itself. This Thesis has been accepted for inclusion in WVU Graduate Theses, Dissertations, and Problem Reports collection by an authorized administrator of The Research Repository @ WVU. For more information, please contact researchrepository@mail.wvu.edu. 


\title{
FRICTIONAL RESISTANCE OF \\ CONCRETE ON A GEOCOMPOSITE MATERIAL
}

by

\section{Joshua Bryan Cook}

Thesis submitted to the College of Engineering and Mineral Resources

at West Virginia University

in partial fulfillment of the requirements

for the degree of

Master of Science

in

Civil Engineering

\author{
Roger H.L.Chen, Ph.D.,Chair \\ Hota V. GangaRao, Ph.D. \\ Robert N. Eli, Ph.D. \\ Department of Civil and Environmental Engineering
}

Morgantown, West Virginia

2004

Keywords: concrete, frictional resistance, geocomposite, slab on ground, Tendrain, drainage 


\section{ABSTRACT \\ Frictional Resistance of Concrete on a Geocomposite Material}

Joshua B. Cook

The frictional resistance provided by the underlying layers of a concrete slabs on ground has a large influence on the cracking behavior. To adequately judge the quality of performance of the slabs, it is imperative to investigate the frictional resistance to movement and other relations of the concrete and sub-layer system. It's also crucial to understand exactly how to introduce a drainage layer to the slab without adversely affecting the cracking pattern of the concrete by dramatically altering the resistance provided by the underlying layers.

Frictional resistance of sub-grade systems which incorporate the geocomposite material Tendrain were tested in a laboratory setting. The testing scenario included a predetermined number of blocks which were cast on top of Tendrain and then tested at varying ages of the concrete. Some additional tests were also conducted to determine any changes in the concrete shrinkage or compressive strength due to water seepage before setting of concrete.

Results from this study show: Tendrain has no significant affect on the compressive strength of the concrete, it some what reduces the amount of concrete shrinkage due to seepage and its frictional behavior is comparable to other sublayer systems. The connections between concrete and Tendrain found in these study are the preliminary steps to formulating slab design which utilizes the material as a sublayer. This study, along with future subgrade reaction analysis, can be used to predict elastic deflections and stresses for concrete slabs on ground. 


\section{ACKNOWLEDGEMENT}

I would like to thank my advisor, Dr. Roger H.L. Chen for providing me with this opportunity and for guidance and knowledge throughout its progression. I would also like to express my gratitude to my Advisory Committee members, Dr. GangaRao and Dr. Eli, for reviewing this work and for their helpful suggestions. Appreciation is extended to the Tenax Corporation for their financial support of this work.

A special note of appreciation goes to Dr. Alejandro C. Kiriakidis for his motivation and great help throughout this study. I would also like to thank my office mates Mr. Jeong-Hoon Choi, Mr. Joseph Sweet, Mr. Ryan Arnold and Mr. Tuan-Chun Fu for their assistance.

My deep appreciation goes to my family and those close to my heart. This includes my

parents Harold and Sharon Cook, and my siblings Andy, Kristin, and Catherine. All of what I accomplish comes from their presence in my life. I would also like to thank my grandparents Harold Cook and Edith Snidow, along with my extended family for there unending love. Another special note of appreciation goes to Kim Sliger, for her love and motivation throughout this work.

This work also constitutes the final report presented to the Tenax Corporation. 


\section{TABLE OF CONTENTS}

$\begin{array}{ll}\text { ABSTRACT } & \text { ii }\end{array}$

ACKNOWLEDGEMENT

TABLE OF CONTENTS iv

LIST OF TABLES vii

LIST OF FIGURES viii

\section{CHAPTER 1 INTRODUCTION}

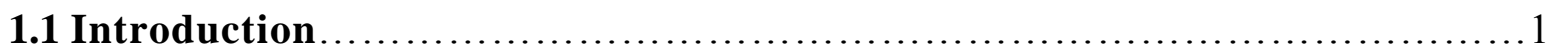

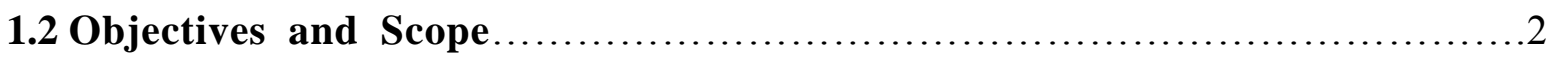

\section{CHAPTER 2 LITERATURE REVIEW}

2.1 Tenax Tendrain

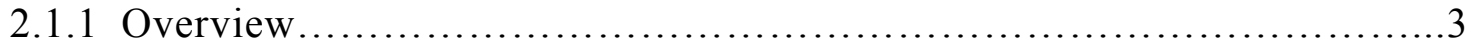

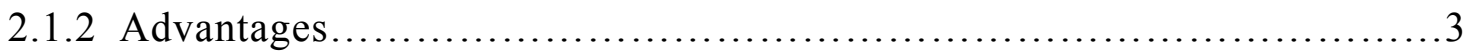

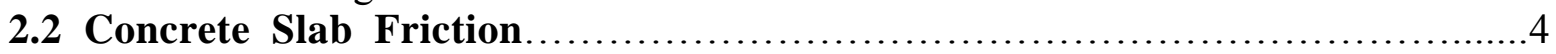

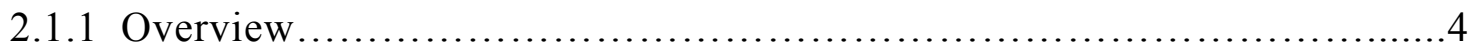

2.1.2 Method for Determination of Frictional Resistance...........................5

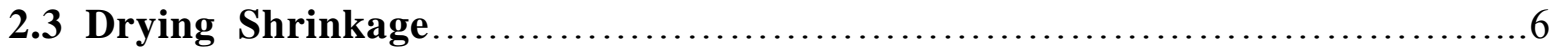

\section{CHAPTER 3 FRICTIONAL RESISTANCE}

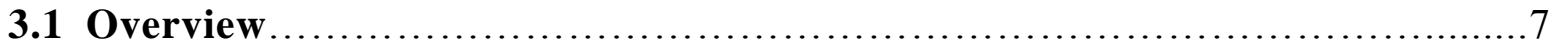

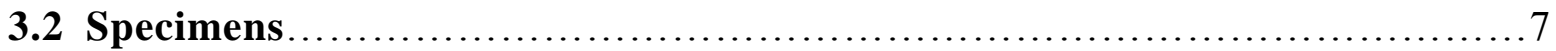

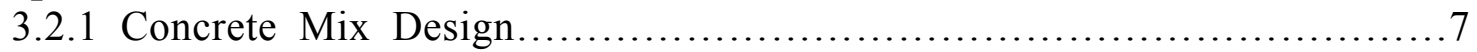

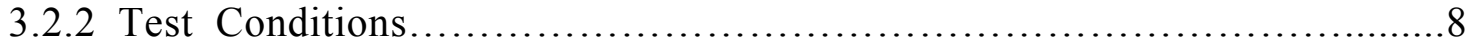

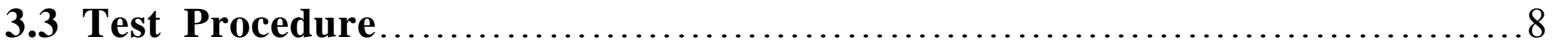

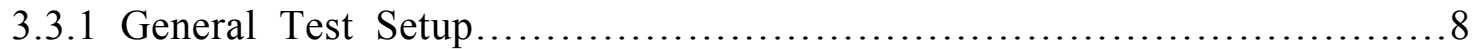

3.3.2 Specimen Casting and Preparation............................................ 9

3.3.3 General Push Test Procedure...............................................10

3.3.4 Push Test 1 to 6 Specifics..................................................... 10

3.3.5 Friction Test Procedure...................................................11

3.3.6 Peel Test Procedure .......................................................... 12

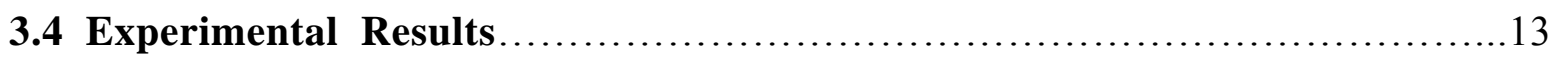

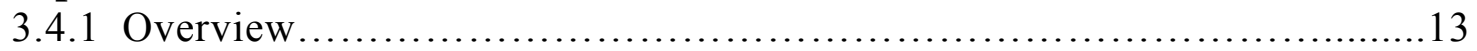

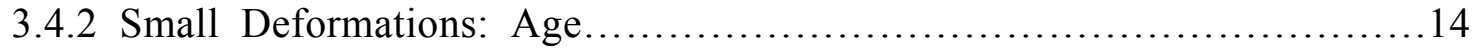

3.4.3 Small Deformations: Load Reloading..................................14

3.4.4 Resistance Trend..................................................... 15

3.4.5 Large Deformations: w/c ratios........................................15 
3.4.7 Friction Results.................................................. 16

3.4.6 Peel Tests and Tendrain Removal Results...............................17

\section{CHAPTER 4 COMPRESSIVE STRENGTH TESTS}

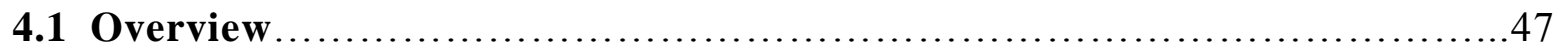

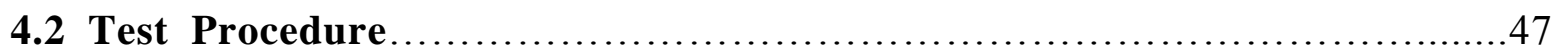

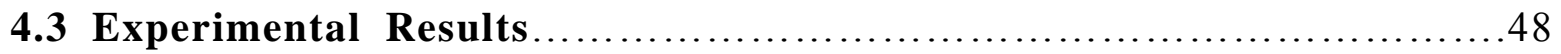

\section{CHAPTER 5 DRYING SHRINKAGE TESTS}

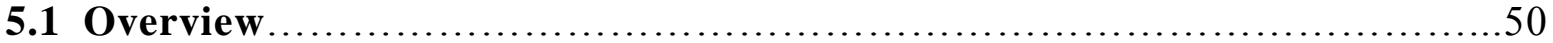

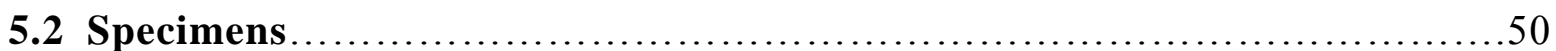

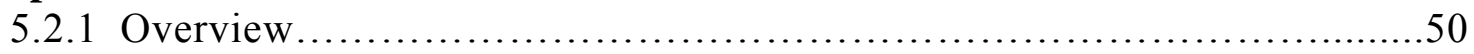

5.2 .2 Concrete Mix Design...............................................51

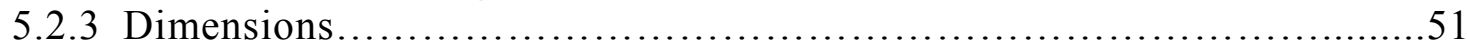

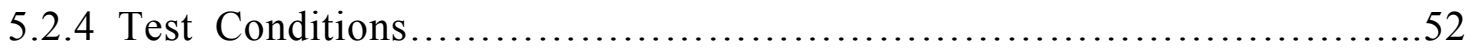

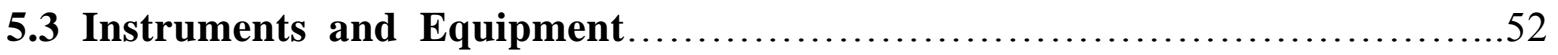

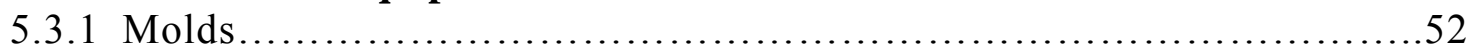

5.3.2 Apparatus for Measurement of Length Change.............................52

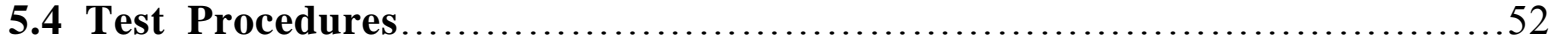

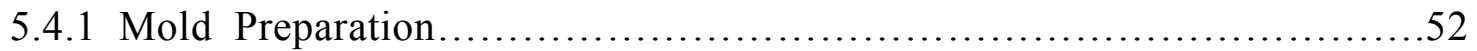

5.4.2 Specimen Casting, Curing and Storage.....................................53

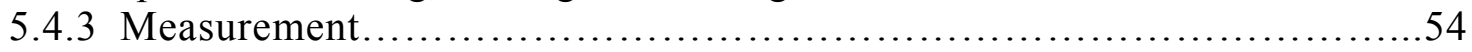

5.4.4 Calculation of Length Change........................................54

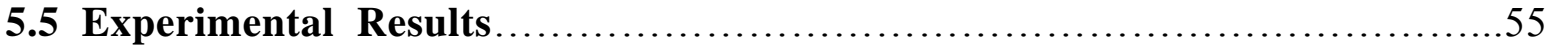

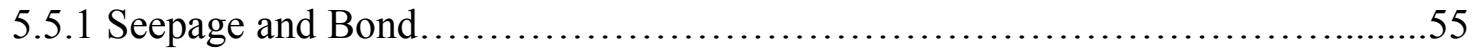

5.5.2 Shrinkage Comparison: Tendrain vs. Free-base Specimens.....................55

\section{CHAPTER 6 WATER LOSS TESTS}

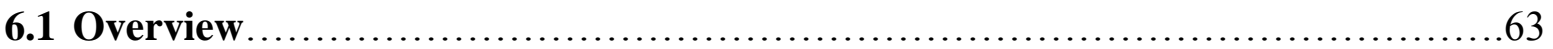

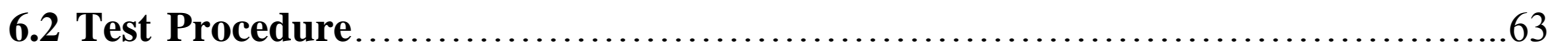

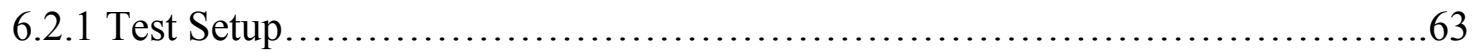

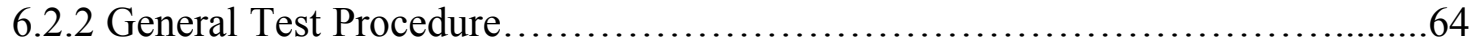

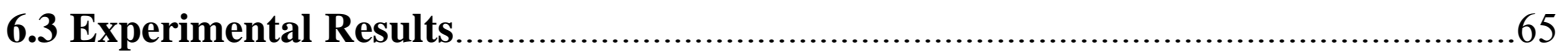

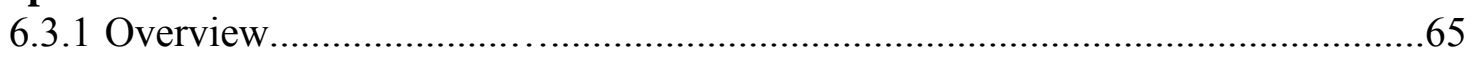

6.3.2 Shrinkage Tests Comparison ….........................................66

\section{CHAPTER 7 CONCLUSIONS AND APPLICATIONS}

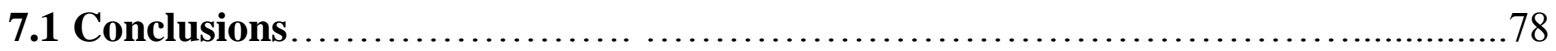

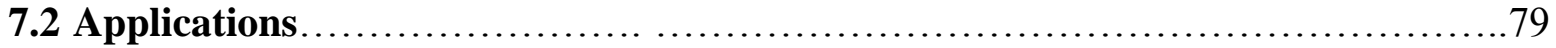

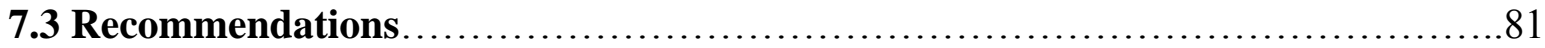

REFERENCES

APPENDIX A Geocomposite Properties 85 


\section{LIST OF TABLES}

Table 3.1 Push Test Parameters / Friction Results

Table 3.2 Material Strength Comparison

Table 3.3 Peel Test Results

Table 4.1 Compressive Strength Test Results

Table 5.1 Shrinkage Test Properties

Table 5.2 Average Shrinkage Results Comparison

Table 6.1 Experiment Properties

Table 6.2 Experimental Results

Table 6.3 Water Loss Exp 1 Results

Table 6.4 Water Loss Exp 2 Results

Table 7.1 Push-Off Test Results Comparison 


\section{LIST OF FIGURES}

Figure 3.1 Push Test 1 Setup

Figure 3.2 (a) Dial Gage Setup (b) Test Setup Cross-Section

Figure 3.3 Tendrain Section Cut

Figure 3.4 Friction Test Setup

Figure 3.5 Friction Test

Figure 3.6 Peel Test Specimens

Figure 3.7 Peel Test Setup

Figure 3.8 Tendrain Removal

Figure 3.9 Fabric Remains on Push Test Blocks

Figure 3.10 Dry Seepage on Push Test Blocks

Figure 3.9 Push Test 1 Load vs. Strain Plot

Figure 3.10 Push Test 2 Load vs. Strain Plot

Figure 3.11 Push Test 3 Load vs. Strain Plot

Figure 3.12 Push Test 4 Load vs. Strain Plot

Figure 3.13 Push Test 5 Load vs. Strain Plot

Figure 3.14 Push Test 6 Load vs. Strain Plot

Figure 3.15 Push Test 6 (Ages Comparison)

Figure 3.16 Push Test 5 (Load-Reload)

Figure 3.17 Push Test 6 (Load-Unload)

Figure 3.18 Push Test 2 (Load-Unload)

Figure 3.19 Push 5 and 6 (Small Displacement)

Figure 3.20 Push Tests 5 and 6 (Slope Change)

Figure 3.21 Push Test 2 and 3 (w/c Ratio Comparison)

Figure 3.22 Push Test 2 to 6 (Comparison)

Figure 3.23 Frictional Resistance (Tendrain - 2 in Gravel; Test 2 and 3)

Figure 3.24 Frictional Resistance (Tendrain - 3 in Soil; Test 4)

Figure 3.25 Frictional Resistance (Tendrain - 12 in Gravel; Test 6-1a)

Figure 3.26 Frictional Resistance (Tendrain - 12 in Gravel; Test 6-1a)

Figure 3.27 Frictional Resistance (Tendrain - 3 in Soil; Test 6-1b) 
Figure 3.28 Frictional Resistance (Tendrain - 3 in Soil; Test 6-1b)

Figure 3.29 Plastic Frictional Resistance on Tendrain (Test 5 and 6)

Figure 3.30 Frictional Resistance on Tendrain (Comparison)

Figure 5.1 Shrinkage Specimens

Figure 5.2 Apparatus for Measurement of Length Change

Figure 5.3 Shrinkage Specimens Removed from Tendrain

Figure 5.4 Cement Paste Residues from Shrinkage Specimens

Figure 5.5 Test 1: Shrinkage vs. Time (w/c ratio 0.47)

Figure 5.6 Test 2: Shrinkage vs. Time (w/c ratio 0.47)

Figure 5.7 Test 3: Shrinkage vs. Time (w/c ratio 0.57)

Figure 5.8 Test 4: Shrinkage vs. Time (w/c ratio 0.47)

Figure 5.9 Test 5: Shrinkage vs. Time (w/c ratio 0.47)

Figure 6.1 Experiment Setup

Figure 6.2 Weight Loss vs. Time (a) averages (b) individual

Figure 6.3 Weight Loss (w/ initial loss) vs. Time (a) averages (b) individual

Figure 6.4 Water Loss vs. Time (a) averages (b) individual

Figure 6.5 Water Loss (w/ out initial loss) vs. Time (a) averages (b) individual

Figure 7.1 Plots of push-off test data from example slabs 


\section{CHAPTER 1}

\section{INTRODUCTION}

\subsection{Introduction}

The frictional resistance provided by the underlying layers of a concrete slabs on ground has a large influence on the cracking behavior. To adequately judge the quality of performance of the slabs, it is imperative to investigate the frictional resistance to movement and other relations of the concrete - sublayer system. Concrete pavements and slabs will inevitably undergo some cracking as the concrete matures, due to stresses induced by temperature fluctuations and drying shrinkage in the slab. Crack spacing and crack width are controlled in Jointed Plain Concrete Pavement (JPCP) highways by imposing transverse saw cuts at every 15 or $20 \mathrm{ft}$ joint to promote cracking at these locations. Continuously Reinforced Concrete Pavements (CRCP) use reinforcement to achieve the desired crack spacing and crack width at the appropriate locations, while other structural concrete slabs on ground use various types of joints for this purpose. The manner in which the concrete slabs crack will determine the quality of performance and the life span for that member. Large crack widths in the pavement not only pose serviceability issues with respect to comfort level of travelers, but they also lead to premature localized deterioration at those locations and a loss of shear transfer due to reduced aggregate interlock. It is therefore crucial to understand exactly how to introduce a drainage layer to the highway without adversely affecting the cracking pattern of the slab by dramatically altering the resistance provided by the underlying layers.

Frictional resistance of sub-base systems which incorporate Tendrain drainage systems was tested in a laboratory setting. The testing scenario included a predetermined number of concrete blocks which are poured and cured on top of Tendrain. The frictional resistance was 
measured at varying age of concrete. Since the amount of seepage of cement paste into the underlying layers, or bleed zone, will increase with an increase in water content inside the concrete, the w/c ratio influence will be studied. These blocks will be tested using a hydraulic jack to apply a known force to the side of each slab until certain displacements are obtained. These test results can be used for comparison of the frictional resistance development provided by other subbase systems, for example, free-drain-base (asphalt coated aggregates). Some additional testing was also conducted to determine changes in the concrete shrinkage and compressive strength due to the presence of

Tendrain.

\subsection{Objectives and Scope}

The objective of this study is to analyze concrete's behavior when Tendrain is utilized as the subbase. This is to be done using frictional resistance tests, shrinkage tests, compressive tests, and water loss tests to make connections between the concrete and the presence of the Tendrain material. This research will provide useful data for use in slab on ground and pavement design.

An investigation into the frictional relationship of concrete cast on Tendrain is described. Chapter 1 is in the Introduction and Chapter 2 gives a literature review on concrete slab drying shrinkage and friction behavior under slabs on ground. Chapter 3 describes the experimental push test setup and procedure that were under gone to find frictional relations. Chapter 4 is an investigation into the effect of Tendrain on the concrete compressive strength, while Chapter 5 focuses on the possible affects on drying shrinkage. Chapter 6 reviews the proceedings for 
water weight loss of concrete specimens cast on Tendrain compared to standard casts. Conclusions and applications formulated from the study are described in Chapter 7. 


\section{CHAPTER 2}

\section{LITERATURE REVIEW}

\subsection{Tenax Tendrain}

\subsubsection{Overview}

A geocomposite consists of a combination of geotextile and geogrid; or geogrid and geomembrane or a combination of these three materials with another material such as deformed plastic sheets, steel cables, or steel anchors. The application areas are numerous and increasing steadily with new research efforts. The major functions of geocomposites include: separation, reinforcement, filtration, drainage, and a liquid barrier.

The Tendrain drainage geocomposite is comprised of a tri-axial geonet structure consisting of thick supporting ribs with diagonally placed top and bottom ribs and with a thermally bonded, non-woven high UV resistant Ultra Vera geotextile on both sides. The material is capable of providing high transmissibility in a soil environment under high normal loads. The combination of geotextiles (filtering action), geomembranes (waterproofing properties) and geonets (drainage and load distribution) offers a complete system of filterdrainage-protection, which is very compact and easy to install.

\subsubsection{Advantages}

1. Elimination of graduated filters resulting in a considerable reduction of costs for the purchase and installation of such materials;

2. Flexibility and lightness;

3. Reduction of excavation costs; 
4. Easy to install, even under adverse environmental conditions, requiring no special tools and no specialized labor;

5. Resistant to soil pressures, distribution of concentrated forces, high filtering and drainage capacity;

6. Mechanical protection of insulating from shock (soil placement), and soil erosion due to water flow during soil placement;

7. Easy and temporary fixing since it gets permanently anchored by the soil pressure or by the material in contact.

\subsection{Concrete Slab Friction}

\subsubsection{Overview}

The forces which act on a concrete slab on ground tend to slide the slab over the underlying layer; thus subjecting the slab to internal compression and tension stresses, depending on the direction of the force. Interaction between concrete slab and subbase is an important component in design and construction of pavements and slabs on ground. Since the level of subbase restraint on a slab will directly affect its cracking behavior, and ultimately the life and performance of the slab, it is of great interest in many research studies to determine the frictional resistance provided by the subbase.

Frictional resistance needs to be quantified in an effective concrete pavement design. This resistance is caused by shrinkage and changes in the internal temperature of the slab. When concrete shrinks and expands, the end of the slab want to move in the corresponding direction. Friction will act to resist this movement which produces compression or tension within the slab. Although temperature changes are highly insignificant on small sections of concrete for longer 
slabs, such as in a concrete slab in highway systems, the expansion/contraction can cause great stress $^{5}$. If the resistance exceeds the concrete strength, cracking will result.

\subsubsection{Method for Determination of Frictional Resistance}

The first study on a slab-support restraint of rigid pavements was done by Goldbeck in ACI 1917, and a continuation of the study was done by Public Roads in 1924. This study explored the frictional resistance behavior of concrete on various subbases. Since then, there has been an increase in lime stabilized and asphalt materials in support designs, which have increased the need for testing of subbase restraint on rigid pavements ${ }^{5}$.

There came a need for a standardized method which could be used to determine the frictional resistance on concrete slabs. In 1987, The Texas Department of Transportation's (TxDOT) studies focused on rigid pavements of highway application where they developed a method which could be utilized on several subbase types for analyses of frictional restraint. This method, later termed the "push-off test", was added to the AASHTO

Guide for the Design of Pavement Structures for reinforcement design in 1986.

The push test setup and procedure within this paper was developed by taking into account the previous push-off test adopted by TxDOT for slab-support analysis. This standardized testing procedure has been found to be an effective method of determining the slab and subbase friction characteristics of concrete pavement. Within this procedure the slab is pushed from its starting position over the subbase utilizing a hydraulic jack. Frictional resistance between the slab and under layers can be determined by analyzing the displacements observed and loads applied. 


\subsection{Drying Shrinkage}

Shrinkage is a cement paste property related to the volume changes it undergoes. Drying Shrinkage generally refers to the contraction of hardened concrete caused by water loss in the capillaries of the slab. This event causes tensile stress within the slab, which may lead to cracking, warping, and displacement, even before the concrete is subjected to any external loads. Drying shrinkage is dependent on not only the humidity of the environment but also upon several factors which include the properties of the component, proportions of the components, mixing procedure, amount of moisture while curing, and size of the member ${ }^{7}$. Drying shrinkage occurs mainly because of the reduction of capillary water through evaporation of water in the cement paste. This means that greater amount of water in the fresh concrete, leads to greater drying shrinkage affects. Influences on the shrinkage magnitude include: the amount of mixing, the elapsed time after the addition of water, temperature fluctuation, slumping, placement, and curing. Aggregate size is of lesser importance, but has an indirect affect on the water content of concrete.

Inadequate allowance for the effects of drying shrinkage in a concrete member can cause failure due to the restraint on the volume change ${ }^{9}$. Though cracking within concrete slabs can not be prevented, it can be localized and confined with regular joint spacing. To understand how to design the spacing of the joints, one must determine how the concrete's shrinkage is affected by the presence of Tendrain. The emphasis of the drying shrinkage study in this paper is on the total water content in the concrete and any losses related to the material. Since the cement paste has the ability to bleed water into the Tendrain material, there is a potential for an effect on the drying shrinkage which needs to be examined. 


\section{CHAPTER 3 \\ FRICTIONAL RESISTANCE}

\subsection{Overview}

The frictional resistance between concrete and underlying layers is one of the principal components in pavement and slab design. To have enhanced control of cracking and therefore control of performance and lifespan, information on the frictional behavior of the concrete on the Tendrain drainage system is required. A push test was designed similar to TxDOT's push-off test to analyze the relationship between Tendrain, the concrete and the subbase as a horizontal force is applied to a concrete slab. For these tests, blocks of concrete are cast on Tendrain with a known length between them. After the concrete has reached a predetermined age, the blocks are forced apart (Figure 3.2b). The force will cause a combination of shearing between the concrete and Tendrain, tension within the Tendrain, and sliding of the concrete and Tendrain on the subbase material. By examining the magnitude of the loads, the relative displacements and the frictional resistance provided by the subbase and design parameters for concrete slabs can begin to be determined.

\subsection{Specimens}

\subsubsection{Concrete Mix Design}

To have a better understanding of Tendrain behavior in actual pavement and slabs, a widely used concrete structural mixture (WVDOT Class B Concrete Mix Design) was chosen for these tests. This mix is prepared in accordance with WVDOT, DOH MCS\&T MP 711.03.023 and coincides to applicable subarticles of Section 601 Structural Concrete "West Virginia Department of Transportation, Division of Highways Standard Specifications - Roads and 
Bridges". Having a w/c ratio of 0.47 , this batch has a targeted 28 day Compressive Strength of 4000 psi. The concrete mixes used for these tests coincide with those of the Shrinkage Tests. For example, Push Test 1 was cast with the same concrete batch as Shrinkage Test 1 and so on.

\subsubsection{Test Conditions}

Push Test 1 utilized a WVDOT Class B concrete mixture which was obtained from Arrow Concrete Company in Morgantown, WV. This batch had a design w/c ratio of 0.47 and a slump of $3 \mathrm{in}$. The cast was conducted with ambient temperature of $79.5^{\circ} \mathrm{F}$ and a humidity of 50 percent.

For Tests 2 to 6, Class B concrete mixtures were obtained from Hoy Redi-Mix Co. in Morgantown, WV. All batches had a design w/c ratio of 0.47 and slump of 3 in., except for Test 3 which possessed a w/c ratio of 0.57 and slump of 4 in. Casting of Test 2 was conducted with an ambient temperature of $73.6^{\circ} \mathrm{F}$ and a humidity of 52 percent, while Push Test 3 was conducted with an ambient temperature of $74.3^{\circ} \mathrm{F}$ and humidity of 61 percent. Casting of Test 4 was conducted with an ambient temperature of $77.4^{\circ} \mathrm{F}$ and a humidity of 57 percent. Casting of Test 5 was conducted with an ambient temperature of $62.3^{\circ} \mathrm{F}$ and a humidity of 62 percent, while casting of Test 6 was conducted with an ambient temperature of $67.4^{\circ} \mathrm{F}$ and a humidity of 67 percent.

\subsection{Test Procedure}

\subsubsection{General Test Setup}

All the push tests were conducted with the following setup description having variations in the subbase and block spacing. Upon a level concrete slab, a layer of plywood was laid, then a sheet of plastic or subbase material was placed and secured upon that. Sections of the Tendrain 
material were rolled out into place over the subbase and the setup was checked for overall levelness and adjusted accordingly. The Tendrain material was not secured in any way to the subbase, so it had the ability to slide if required forces were applied.

The testing setups include a predetermined number of wooden forms (2' $\mathrm{x} 2^{\prime}$ x $1^{\prime}$ ) which were placed and secured upon the Tendrain with the spacing called for by each test (Figure 3.1). They were aligned along the length of the core's ribs. These forms were firm, fitting and oiled to produce proper dimensions and quality of set for the concrete blocks. The forms were also horizontally aligned with great care so that no significant angle of misalignment during the pushes was noted.

\subsubsection{Specimen Casting and Preparation}

Upon the arrival of concrete, a portion was used to check for the proper slump before casting. The forms were filled with care not to misalign any part of the setup or allow for concrete leakage on to other parts of the Tendrain. Using a vibrating rod, the concrete was vibrated and two small reinforcement bar hooks were inserted for crane lifting purposes. Proper curing compound and wet burlap were then applied. The concrete aged for an amount of time, $8-24$ hours depending on the test, before the forms were removed.

For accurate measurements, four displacement dial gages were used to assure proper horizontal movement through the alignment of the jack and the load cell. Two gages were placed and secured upon the extreme edges of the blocks for measurements of relative horizontal displacement (Figure 3.2a). These gages allowed the operator to determine if the blocks were undergoing a twist, instead of balanced horizontal movement, so proper adjustments could be made. In addition to these gages, two more gages were positioned in an orientation which 
would allow the operator to adjust alignment for zero vertical displacement of the edges of the blocks.

\subsubsection{General Push Test Procedure}

Several of the tests were conducted at very early ages of the concrete, where it was still visibly wet. To ensure the jack or load cell didn't produce a punching affect on the blocks, 8 " $\mathrm{x}$ 7" $\mathrm{x} 0.5$ " steel bearing plates were placed on the inner sides of the blocks to better distribute the loading.

A small 10 kip hydraulic jack and a load cell were placed between the two blocks. A hydraulic pump was connected to the jack for load application, while a strain indicator was connected to the load cell for load readings (Figure 3.3). Care was taken in the jack and load cell for horizontal and vertical alignments. A gradually increasing force was then applied to the side of each block, pushing them apart along the length of the core's ribs. The relative displacement of the stretched section was recorded at various intervals of loading until the load or displacement reached a predetermined value.

\subsubsection{Push Test 1 to 6: Specifics}

Push Test 1's subbase consisted solely of a layer of $1 / 2$ in plywood. This test was conducted just to get familiar with the behavior of the material and gain a better overall understanding of the mechanics behind the pushes. Adjustments are then made for the setup (or procedure) before a legitimate subbase was introduced.

The interest in the tests following Push Test 1 was to see how varying the subbase layer would affect the overall frictional behavior. Three more tests (Test 2, 3 and 4) were setup exactly as the first, but the support layer was changed to 2 in. of \#57 limestone for the second 
and third tests and 3 in. of soil for the third test. Similar support layer materials are utilized in WVDOT pavement designs. Also, within the first testing, blocks which were not a part of the test were cast on the same sheet. Having the weight from these blocks acting on the Tendrain, the buckling and movements from the pushes may have been restrained, which would effect the relative displacement and therefore the total loading obtained. Each set of blocks was cast on separate sheets of the Tendrain. Hence, the Tendrain sides were not restrained by other blocks on the sheets. The following changes were also made for these tests: the length between the blocks was increased, the subbase was varied, times at which tests were conducted were changed and the $\mathrm{w} / \mathrm{c}$ ratios were varied.

For Test 5 and 6 , the setup was the same as above for these two tests, except rubber pads were introduced and the subbase was changed to plastic. The rubber pads were placed on both sides of the cell so the load would be distributed across the whole face of the cell producing more accurate readings. This decreased the bandwidth of the results curves and increased the smoothness, which indicates more precise readings. The subbase was switched to $6 \mathrm{~mm}$ plastic for further observation of the Tendrain behavior under loading with the new settings. Refer to Table 3.1 for a summary of individual test parameters.

\subsubsection{Friction Test Procedure}

After conducting the Push Test, the interest was now on the behavior of the Tendrain with subbase frictional forces only. Tests were done on the blocks from Push Tests 3, 4, 5, and 6 to determine the resistance provided by the subbase. Though test 6 blocks were on plastic during the push test, they were later cut and moved to soil/gravel subbase for additional friction testing. The Tendrain between the blocks was cut, allowing each block to be upon its own section of Tendrain (Figure 3.3). One of the blocks was then loaded with several others to produce a 
quasi-rigid wall, while the other was free to slide (Figures 3.4 and 3.5). The same procedure was adopted as for the Push Tests, but now only one of the blocks was free to slide (Figure 3.4). Load was applied slowly while measuring the small movement. Once the load reached the frictional resistance level of the subbase and Tendrain, the blocks began to slide under a constant force.

\subsubsection{Peel Test Procedure}

To grasp a better understanding of the bond strength, a "peel test" was designed to analyze the magnitude of force required to remove the Tendrain from the concrete. This analysis subjects a vertical load to the Tendrain and peels the materials from the concrete while a load indicator displays the magnitude.

The experiment consisted of six standard compression cylinders (12"x 6"dia) with their bottoms removed and six 1'x1'sections of Tendrain. Three of the modified cylinders were cast on dry gray Tendrain and three were cast on dry black Tendrain (Figure 3.6). Both Tendrain types posses the same core, though there fabric pieces vary in design. The WVDOT Class B highway mix was utilized for these tests. When the concrete was approximately 50 hours of age the corner of the Tendrain was wired to a tension indicator. The indicator was attached to the load application machine (Figure 3.7). After securing the concrete cylinder, a load was conducted, creating a peeling effect, until the maximum load value was obtained for each specimen (Figure 3.8). 


\subsection{Experimental Results}

\subsubsection{Overview}

One presumption before testing was that the bonding of the concrete and the Tendrain was negligible. If this were correct, the adhesion and coefficient of friction between the concrete and Tendrain could easily be determined through these tests. However, it was found that the bond between the two was very significant. Loading values within some tests reached two thousand pounds and still the concrete resisted detachment from the Tendrain material. The bond itself is created through cement paste bleeding water into the top layer of Tendrain composite, causing adhesion when the concrete sets. Since the interest of the tests was in smaller displacements and safety of the operator, loading values never overcame the bond strength during any magnitudes of the push forces. The adhesion restrains concrete from sliding over the Tendrain and causes the section of drainage composite to elongate between the two blocks as it's loaded. By examining the Tendrain material buckle behind the block, it's determined that the geonet core and the geotextile layers were included in the stretch.

The recorded displacements and loads were used to determine overall strain of the material. Figures 3.9 to 3.14 displays load vs. strain plots for the six push tests. The strain was calculated by dividing the displacement increment by the length between the two blocks (Table 3.1). All plots have very similar linear behavior after a particular strain value is reached $(0.007-0.009$ in/in), with the exception of the first test. Due to the unknown forces present within Test 1 , having multiple testing blocks on one sheet, the results for Test 1 seem to be inconclusive. The linear portion of these plots corresponds to the manufactured tensile strength (about 15 kip/in/in for $1 \mathrm{ft}$ width) of the material (Table 3.2). A $3.4 \mathrm{ft}$ section was used within Tests 2 to 6 , multiplying the above strength by the material length arrives at $51.0 \mathrm{kip} / \mathrm{in} / \mathrm{in}$. This compares 
with the average slopes of Test 2, 5 and 6, 50.2, 50.4, and $52.5 \mathrm{kip} / \mathrm{in} / \mathrm{in}$. (Tests 3 and 4 developed similar linear portions, but were stopped at lower displacement values.)

\subsubsection{Small Deformations: Age}

The bond between the concrete and the Tendrain is developed early in the concrete's setting stage. Referring to Figure 3.15, from Push Test 6, it is observed that after 8 hrs the age of the concrete has no significant influence on the resistance provided by the overall system. This is seen by the close bandwidth of the slopes displayed within the figures. It is also observed that slope change occurs when the frictional resistance value of around $270 \mathrm{lb}$ is met within these results (discussed later). Results from testing at varied concrete ages indicated insignificant differences, due to high early strength of bond between the concrete and Tendrain.

\subsubsection{Small Deformations: Load-Reload}

The stiffness of the Tendrain is observed to remain approximately the same when it's reloaded. Referring to Figure 3.16, it can be seen that only slight changes occur in the shifting of the slope locations during reloading, but slope values remain relatively constant within the first several pushes conducted. During the unloading of the blocks, after small displacement in Push Test 6, the displacement returned to 0.01 in. when the load returned to zero (Figure 3.17). Though this is about 40 percent return from total, contraction continued slowly close to initial length. For larger displacement returns in Push 2, the displacement reached 0.3 in. and returned to $0.08 \mathrm{in}$. (Figure 3.18). This is a return of 27 percent of the total displacement during loading. Contraction continued after load removal in this testing also. 


\subsubsection{Resistance Trend}

During small relative displacements of the blocks, the emphasis falls upon the friction between the Tendrain and subbase only. Figure 3.19 displays the small displacement results of Push Test 5 and 6 where Tendrain is on plastic. Figure 3.29 displays the load and displacement plot of the friction resistance on the plastic within Push Test 5 and 6, where static friction is overcome when the curve stops $(\sim 270 \mathrm{lb})$. Through comparison of the plots, it is observed that the slopes of each curve run parallel to one another before the ultimate static frictional value is met. Therefore, during the initial expansion of the Tendrain, all displacements are from the deformation of the material and not from translation along the subbase. Figure 3.20 is the expanded display of Figure 3.19. It is observed that once the static friction value is met, the slope changes and material slides along the subbase with further loading.

All the Push Tests result in the same behavior after the frictional values of each are met as shown in Figure 3.22. Regardless of the subbase material, Tendrain follows the same trend after loading surpasses the frictional value. By knowing the coefficient of friction between Tendrain and its subbase, one can predict the amount of total resistance which will be present.

\subsubsection{Large Deformations: w/c ratios}

In Figure 3.21, it is observed that w/c ratios $(0.47$ and 0.57$)$ seem to have no effect on the performance of the Tendrain. Large deformations were the focus of these two Push Tests, so slope change with the initial displacement is harder to determine than with the small deformation push test. Slopes among these two tests in the large deformations (Figure 3.21) have similar average slopes and are mixed in a manner which suggests no effect from the difference in w/c ratios. 


\subsubsection{Friction Results}

Push Test 2 and 3 had a 2 in. layer of gravel for a support layer. The average frictional force on these blocks was found to be $287 \mathrm{lb}$ (Figure 3.23), corresponding to a coefficient of frictional resistance of 0.48 between the Tendrain and the gravel ( $600 \mathrm{lb}$ block wt.). The second friction test was done with Tendrain upon 3 in. of soil using Push Test 4 blocks. The displacement at which sliding begins to occur can be observed to be approximately 0.05 in. (Figure 3.24). The force corresponding to this displacement is found to be $\sim 6601 \mathrm{~b}$. This produces a coefficient of friction equaling 1.0.

Push Tests 5 and 6 were upon a sheet of $3 \mathrm{~mm}$ plastic. When the friction tests were conducted these blocks displaced approximately 0.006 in. (Figure 3.29) before beginning to slide. The frictional resistance can be observed as $270 \mathrm{lb}$, producing of a coefficient of friction equaling 0.45. Since no abrasion was present between the Tendrain and plastic, three Test 6 blocks with material still attached were relocated to a 12 in gravel subbase. With the increase in gravel thickness, roll or slide of the gravel wasn't as likely as in the 2 in. subbase. Therefore an increase of resistance to $3851 \mathrm{bs}$ was observed. This increased the coefficient from 0.48 to 0.64 (Figure 3.26). The remaining three Test 6 blocks were relocated to the soil subbase and frictionally tested. The specimens resulted in very similar frictional values as the blocks on 3 in. soil of Push Test 4 (Figure 3.28). They were observed to have an average coefficient of 1.06. For the final test, smaller normal force blocks ( $\left.1^{\prime} \mathrm{x} 1^{\prime} \mathrm{x} 0.5^{\prime}\right)$ were used on the same 3 in soil support. Even with the reduction in weight, the coefficient of friction between the Tendrain and soil remained close to 1.0 (Figures $3.27 \mathrm{a}$ and $3.27 \mathrm{~b}$ ).

All friction tests result in similar initial load - displacement slopes as shown in Figure 3.30, suggesting initial displacement is from deformation of the Tendrain without slip along the 
subbase. The average shear force per unit displacement was found to be $133 \mathrm{psi} / \mathrm{in}$. which was calculated using the following equation:

$$
\text { Shear Force per Unit Displacement }(\mathrm{psi} / \mathrm{in})=\frac{(\mathrm{F} / \mathrm{A})}{\mathrm{x}}
$$

where,

$$
\begin{aligned}
& \mathrm{F}=\text { friction } \\
& \mathrm{A}=\text { slab area } \\
& \mathrm{X}=\text { displacement }
\end{aligned}
$$

This value represent the initial resistance provided (horizontal spring). The friction results have the same initial slopes suggesting that the initial deformation is within the Tendrain itself before the slide occurs between the Tendrain and subbase. The subbase has no effect on initial displacements until the loading reaches the friction resistance, where resistance then come from Tendrain's tensile property and a constant subbase friction.

\subsubsection{Peel Tests and Tendrain Removal Results}

The Tendrain with the continuously woven geotextile required on average about half the force of that required to remove the Tendrain with the staple geotextile fibers : $271 \mathrm{~b}$ versus $571 \mathrm{~b}$ force respectively (Table 3.3). The black Tendrain has a tighter weave of the fabric and short pieces of fabric available to bond with the Tendrain. As the section was removed from the cylinder, it was observed that shorter pieces of fabric were still attached to the concrete. On the other hand, the concrete which was cast upon the gray Tendrain had longer strands of material which remained connected to the concrete. 
After push and friction tests were concluded the Tendrain was removed from the bottom of the $2 \times 2 \times 1 \mathrm{ft}$. blocks. The blocks were flipped upside down and the lab crane was attached on to two places of the section of material. The self weight alone wasn't enough to start or continue the peel. The operator had to apply body weight to the corner of the block to hold it down for the removal to take place. Large amount of fabric remains were observed on the bottom of the block (Figure 3.9), along with a good amount of dry seepage (Figure 3.10). 


\begin{tabular}{|c|c|c|c|c|c|c|c|}
\hline Test & $\begin{array}{l}\text { Subbase / } \\
\text { Thickness }\end{array}$ & $\begin{array}{l}\text { Friction } \\
\quad(1 \mathrm{bs})\end{array}$ & $\begin{array}{l}\text { Coeff. } \\
\text { Friction }\end{array}$ & $\begin{array}{c}\text { Block } \\
\text { Spacing (in) }\end{array}$ & $\begin{array}{l}\mathrm{w} / \mathrm{c} \\
\text { ratio }\end{array}$ & $\begin{array}{l}\text { Tendrain } \\
\text { Width (ft) }\end{array}$ & $\begin{array}{c}\text { No. of } \\
\text { Specimen } \\
\text { Set }\end{array}$ \\
\hline 1 & $\begin{array}{c}\text { Plywood / } 0.5 \\
\text { in }\end{array}$ & $\mathrm{N} / \mathrm{A}$ & $\mathrm{N} / \mathrm{A}$ & 12 & 0.47 & 6.7 & 5 \\
\hline 2 & Gravel / 3 in & 260 & 0.48 & 27 & 0.47 & 3.4 & 2 \\
\hline 3 & Gravel / 3 in & 260 & 0.48 & 27 & 0.57 & 3.4 & 2 \\
\hline 4 & Soil / 3 in & 600 & 1.00 & 27 & 0.47 & 3.4 & 2 \\
\hline 5 & Plastic / 6mm & 270 & 0.45 & 19 & 0.47 & 3.4 & 5 \\
\hline 6 & Plastic / 6mm & 270 & 0.45 & 19 & 0.47 & 3.4 & 6 \\
\hline $6-\mathrm{a}$ & Grave1 / 12 in. & 385 & 0.68 & \multicolumn{4}{|c|}{$\mathrm{N} / \mathrm{A}$} \\
\hline $6-b$ & Soil / 3 in & 660 & 1.02 & \multicolumn{4}{|c|}{$\mathrm{N} / \mathrm{A}$} \\
\hline
\end{tabular}

Table 3.1 Push Test Parameters / Friction Results

\begin{tabular}{|c|c|c|}
\hline Test & Avg. Slope (kip/in/in) & $\begin{array}{c}\text { Manufactured } \\
\text { Strength* (kip/in/in) }\end{array}$ \\
\hline 2 & 50.2 & \multirow{2}{|c|}{51.0} \\
\hline 5 & 50.4 & \\
\hline 6 & 52.5 & \\
\hline
\end{tabular}

* $15 \mathrm{kip} / \mathrm{in} / \mathrm{in}$ tensile strength for $1 \mathrm{ft}$ (3.4' test sections)

Table 3.2 Material Strength Comparison

\begin{tabular}{|c|c|c|}
\cline { 2 - 3 } \multicolumn{1}{c|}{} & Black Tendrain (lb/in) & Gray Tendrain 770-2 (lb/in) \\
\hline $\mathbf{1}$ & 12.1 & 4.4 \\
\hline $\mathbf{2}$ & 8.7 & 4.5 \\
\hline $\mathbf{3}$ & 8.5 & - \\
\hline Average & $\mathbf{9 . 8}$ & $\mathbf{4 . 5}$ \\
\hline
\end{tabular}

*Total force divided 6 in. width strips

Table 3.3 Peel Test Results 


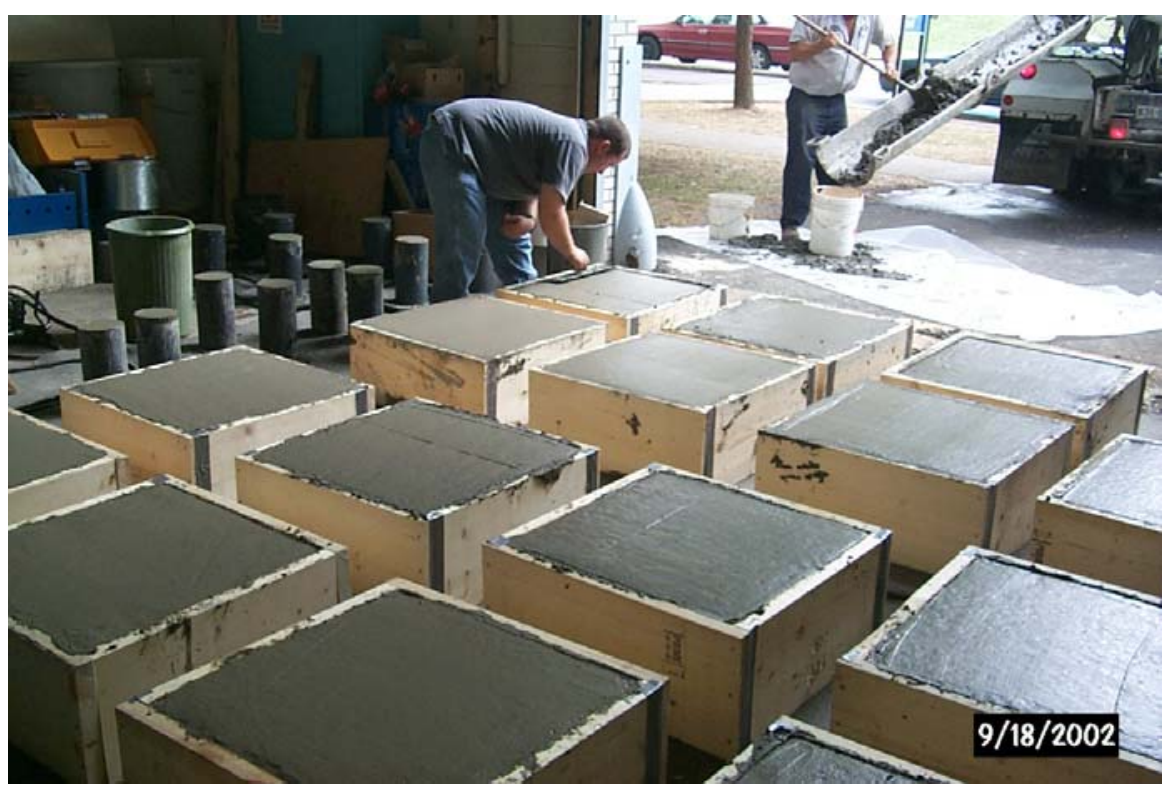

Figure 3.1 Push Test 1 Setup

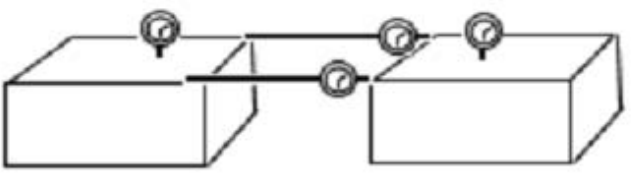

(a)

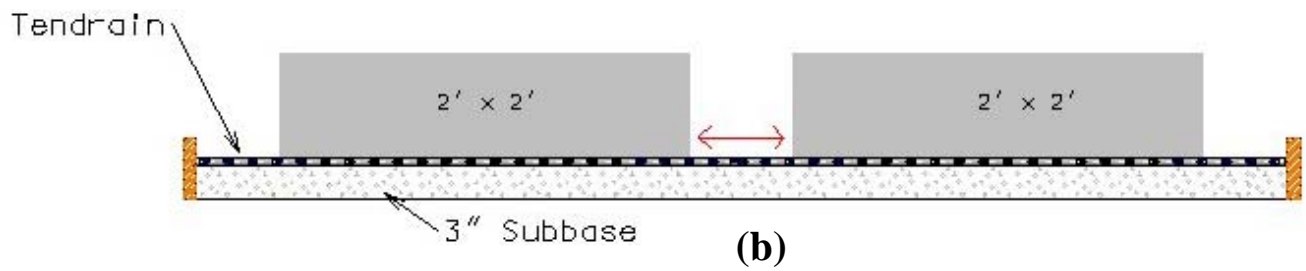

Figure 3.2 (a) Dial Gage Setup (b) Test Setup Cross-Section 


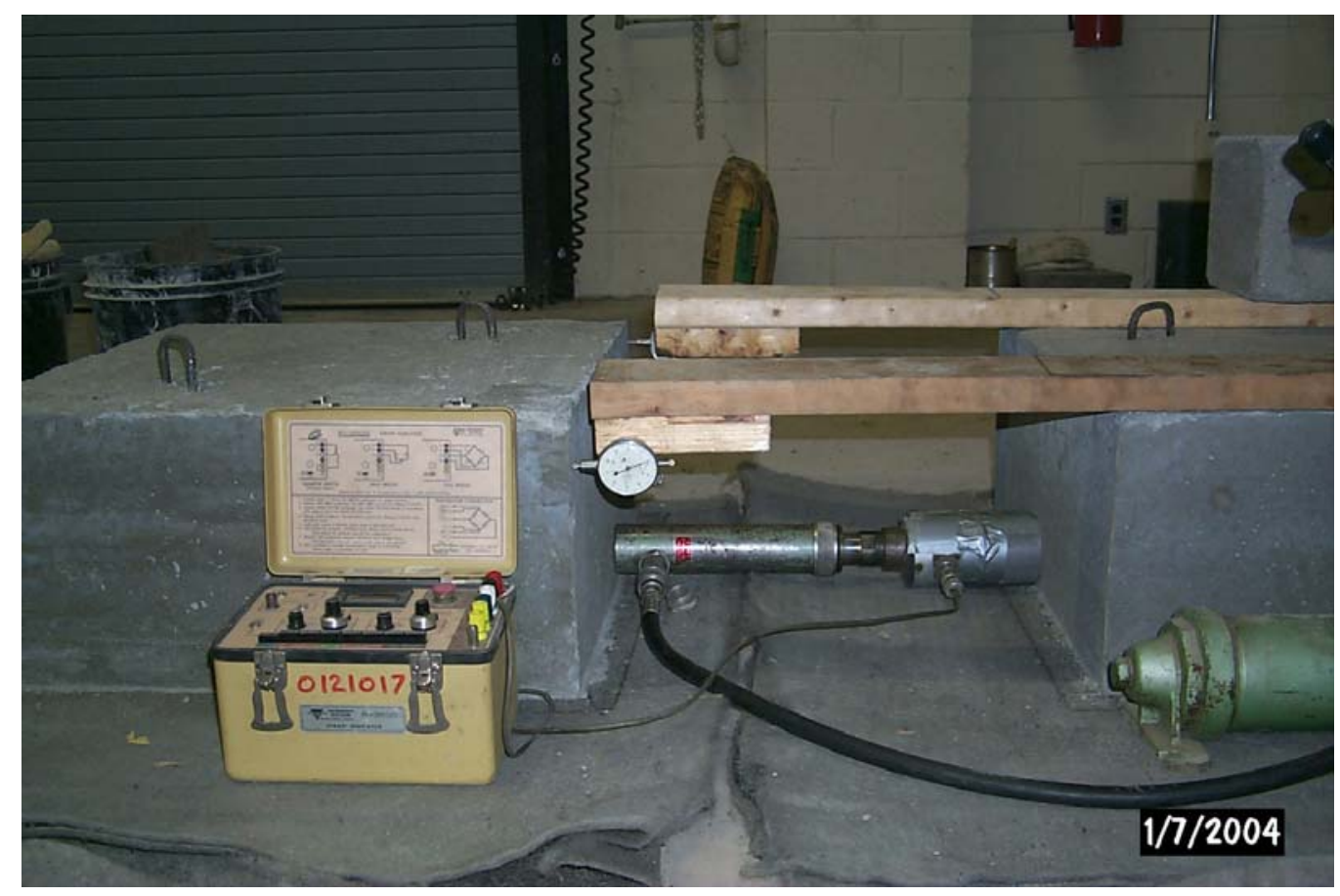

Figure 3 .3 Tendrain Section Cut

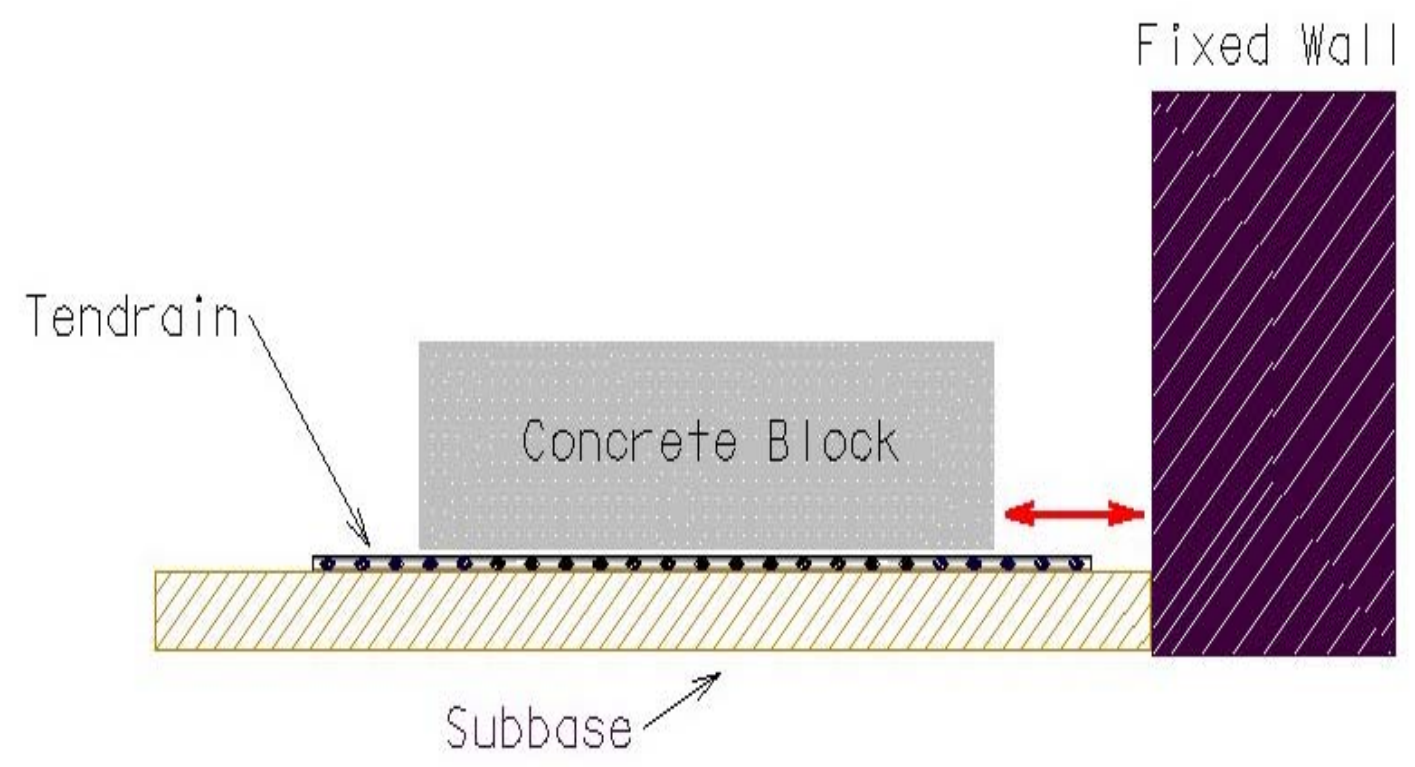

Figure 3.4 Friction Test Setup 


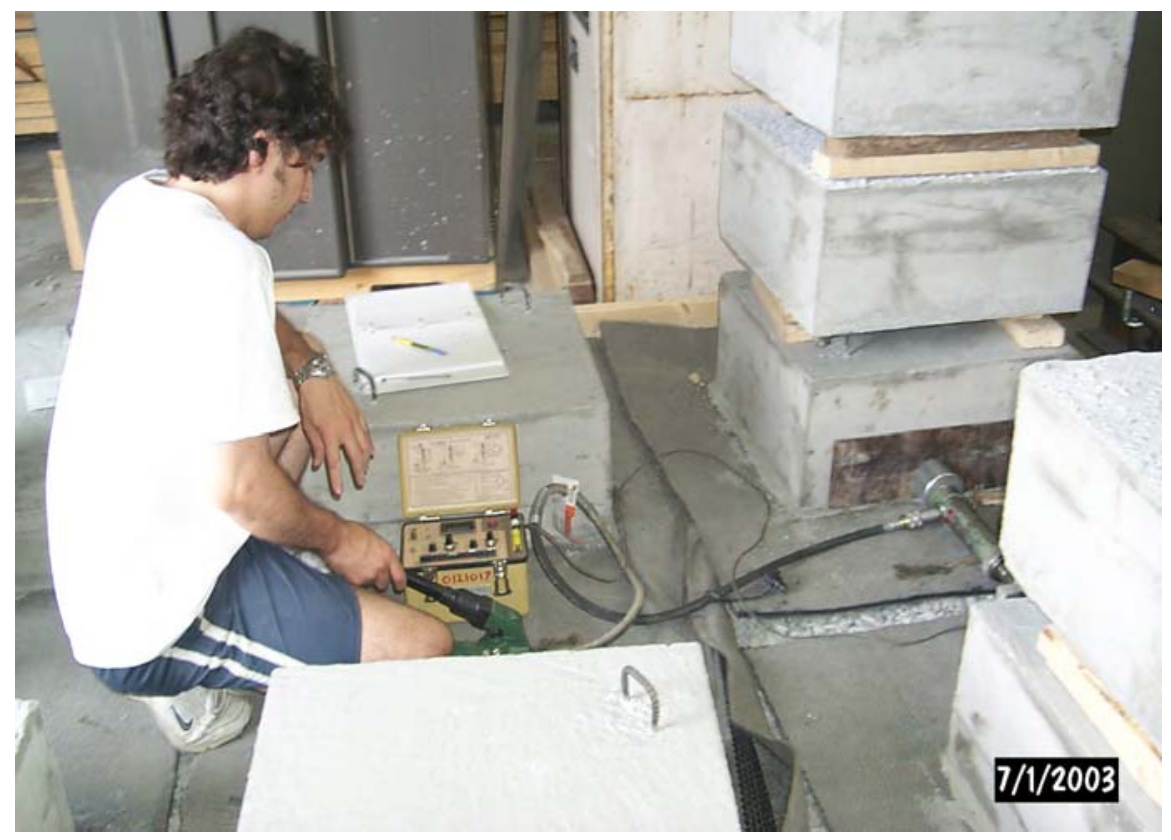

Figure 3.5 Friction Test

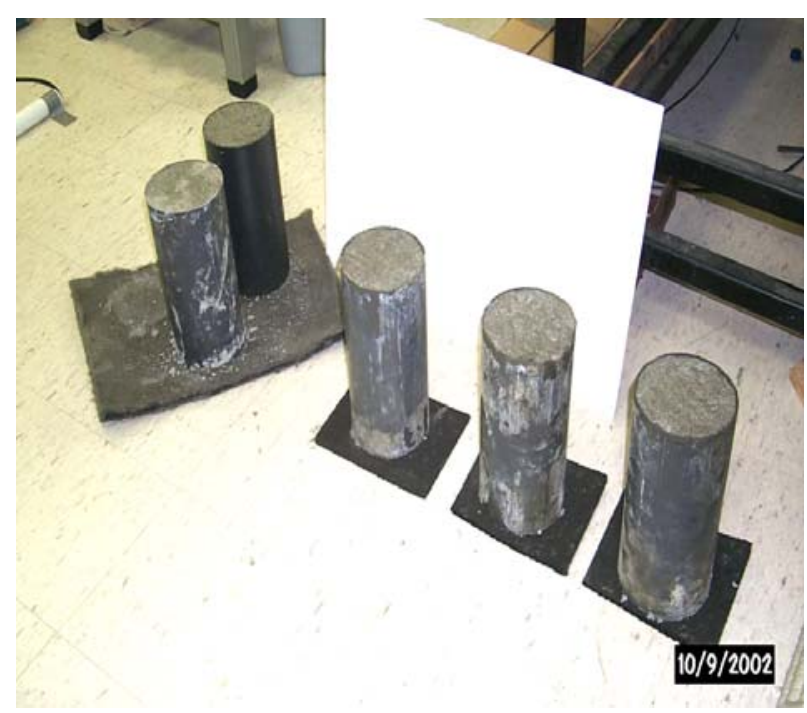

Figure 3.6 Peel Test Specimens 


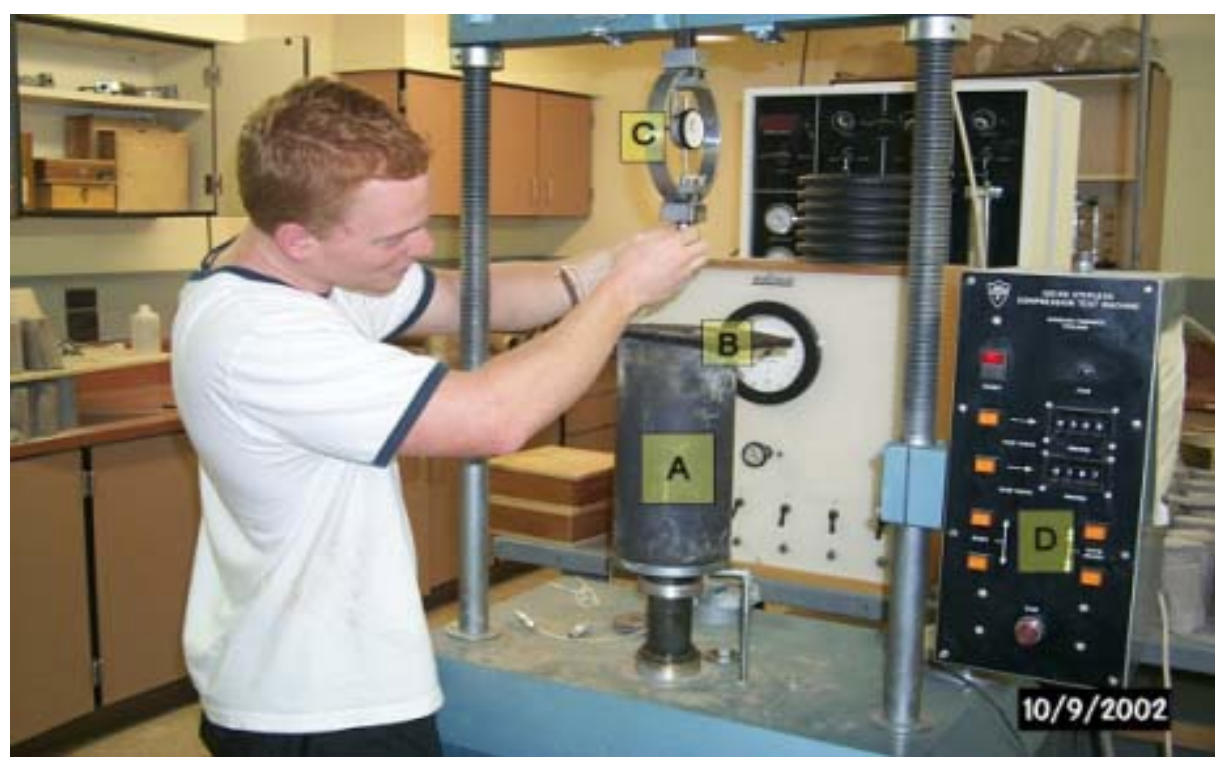

$$
\begin{aligned}
& \text { A - Concrete Cylinder } \\
& \text { B - Tendrain } \\
& \text { C - Load Indicator } \\
& \text { D - Load Application Machine }
\end{aligned}
$$

Figure 3.7 Peel Test Setup

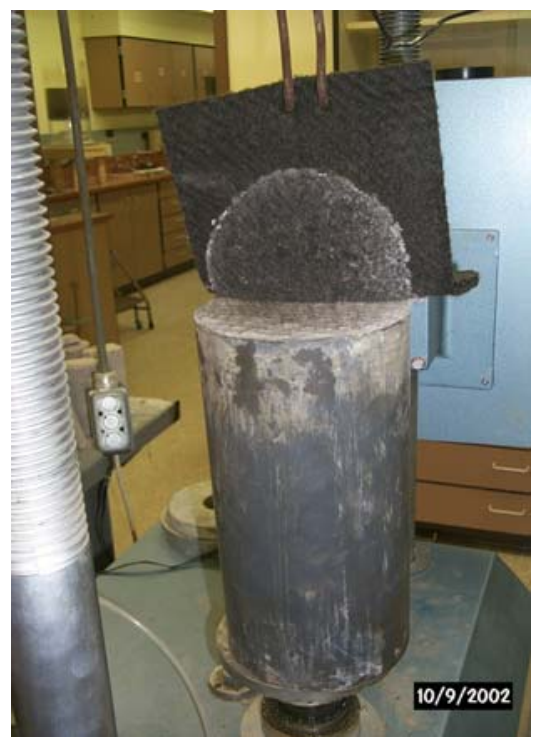

Figure 3.8 Tendrain Removal 
Figure 3.9 Fabric Remains on Push Test Blocks

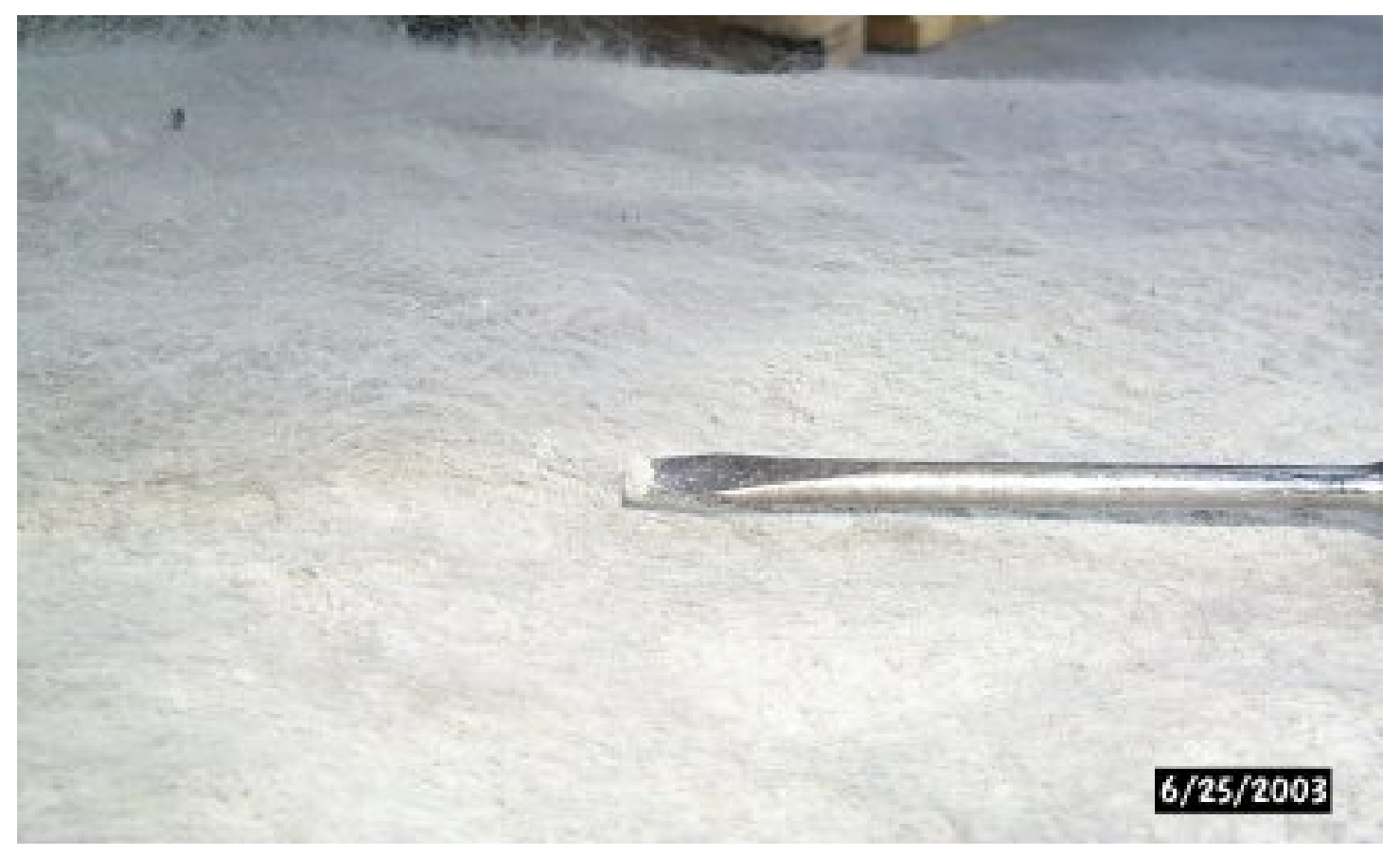

Figure 3.10 Dry Seepage on Push Test Blocks 


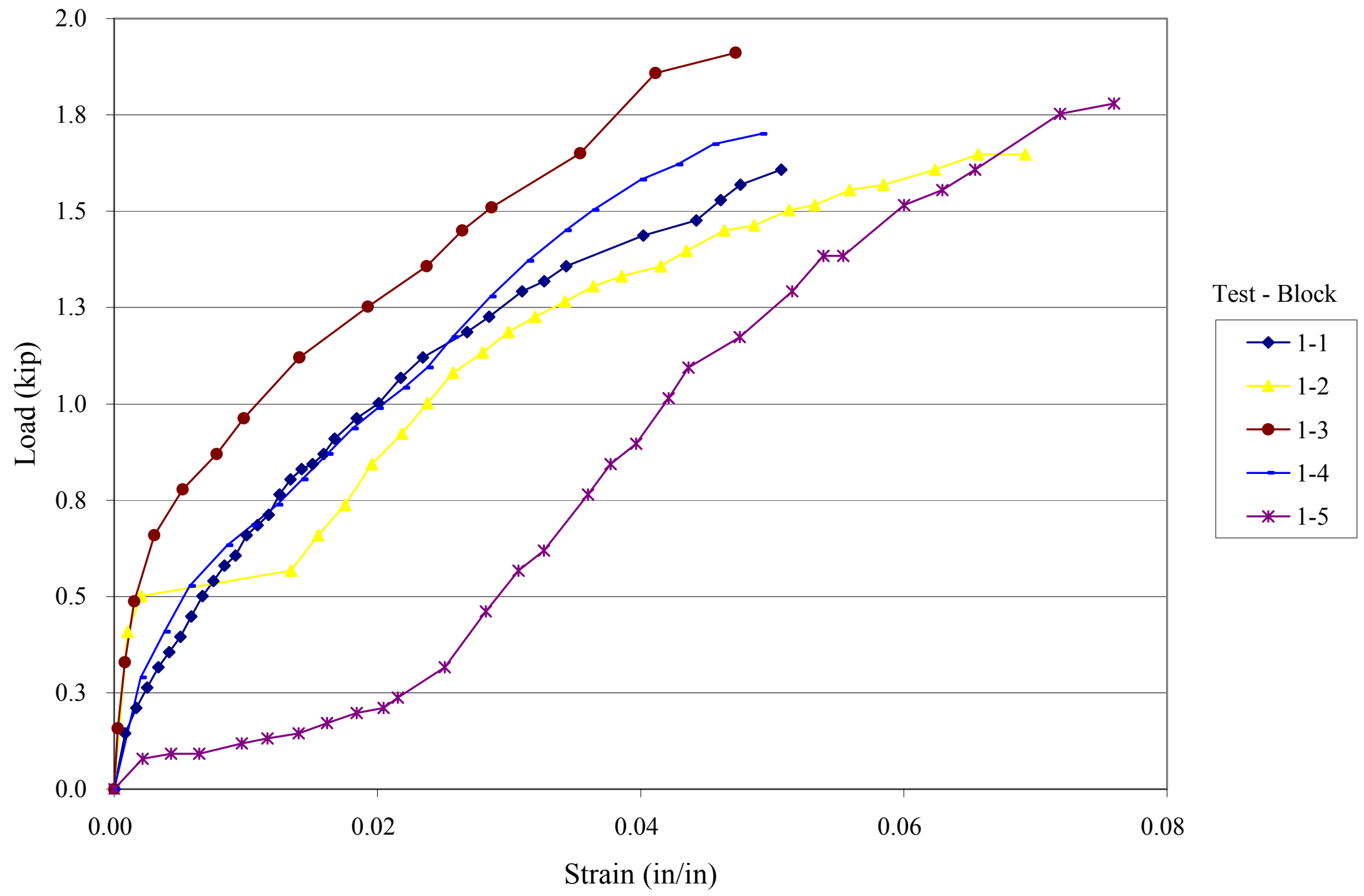

Figure 3.9 Push Test 1 Load vs. Strain Plot 


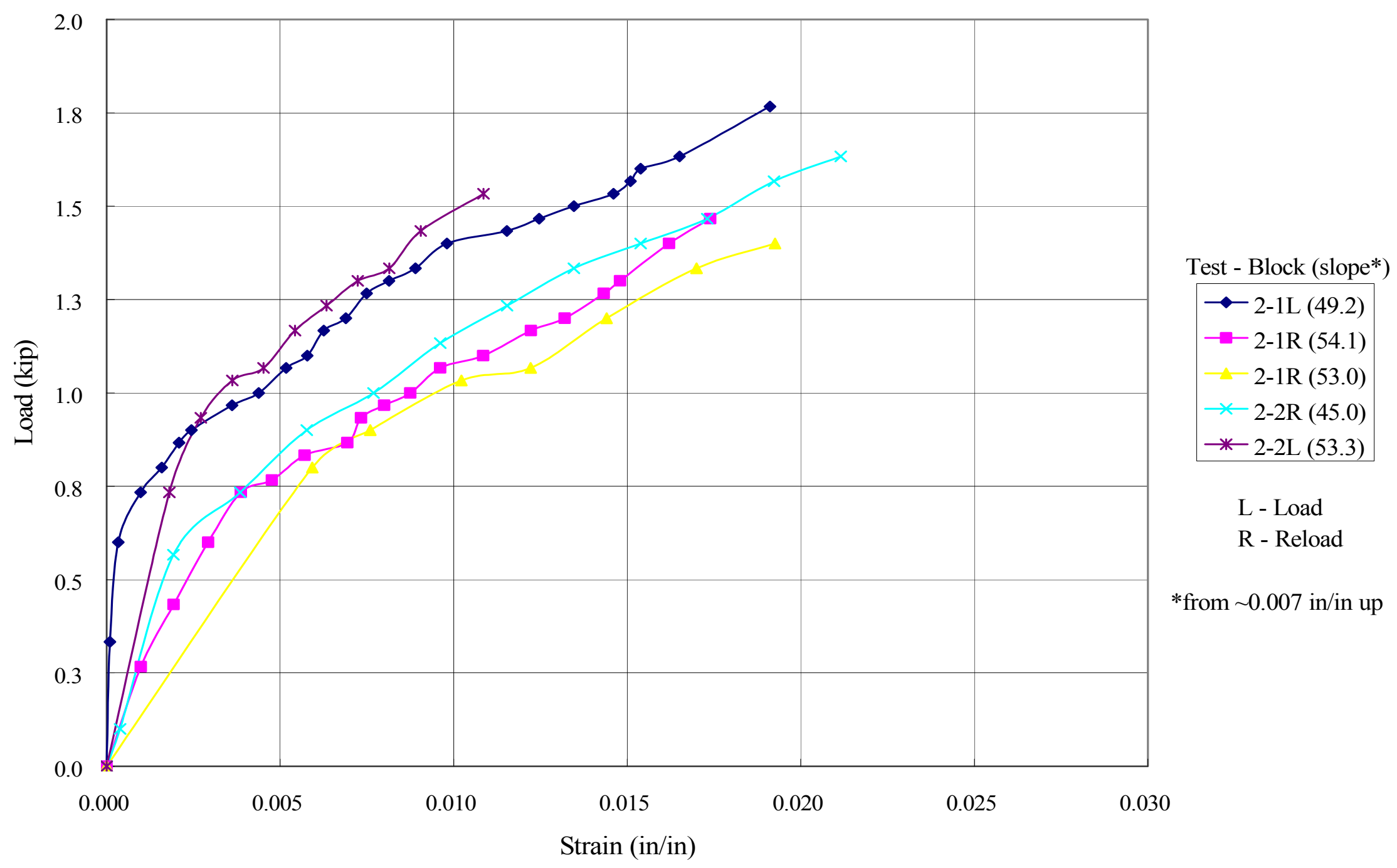

Figure 3.10 Push Test 2 Load vs. Strain Plot 


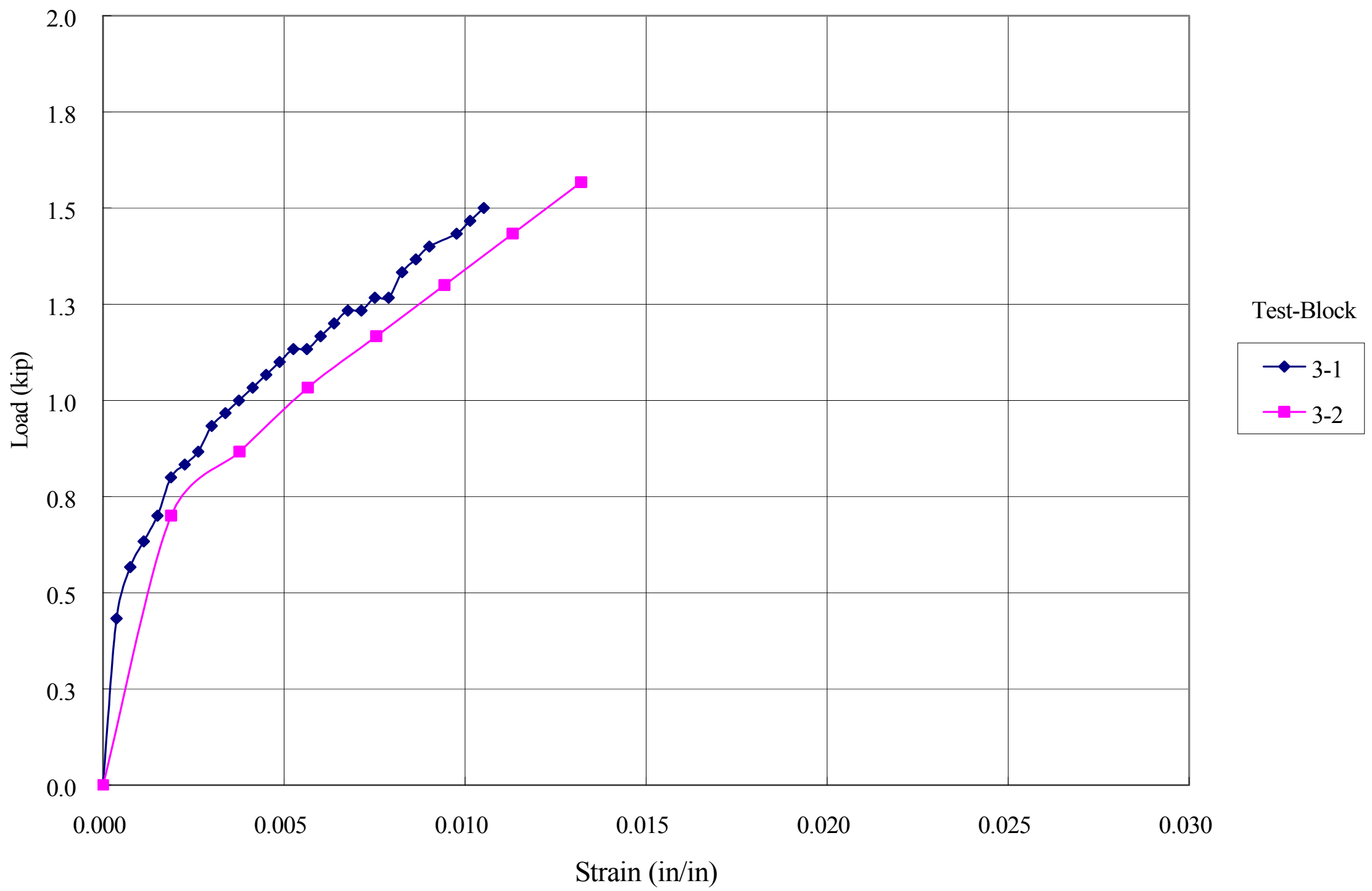

Figure 3.11 Push Test 3 Load vs. Strain Plot 


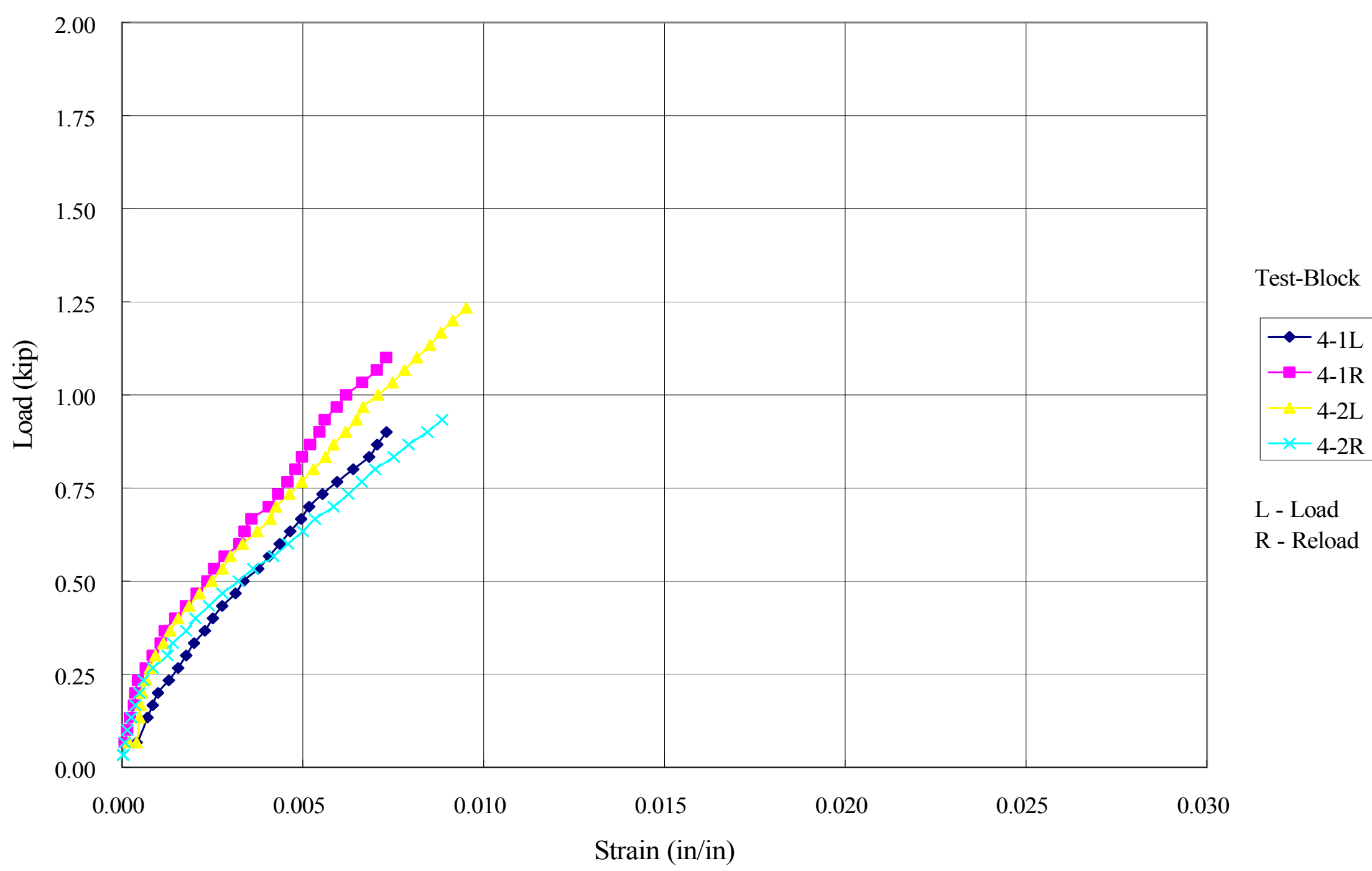

Figure 3.12 Push Test 4 Load vs. Strain Plot 


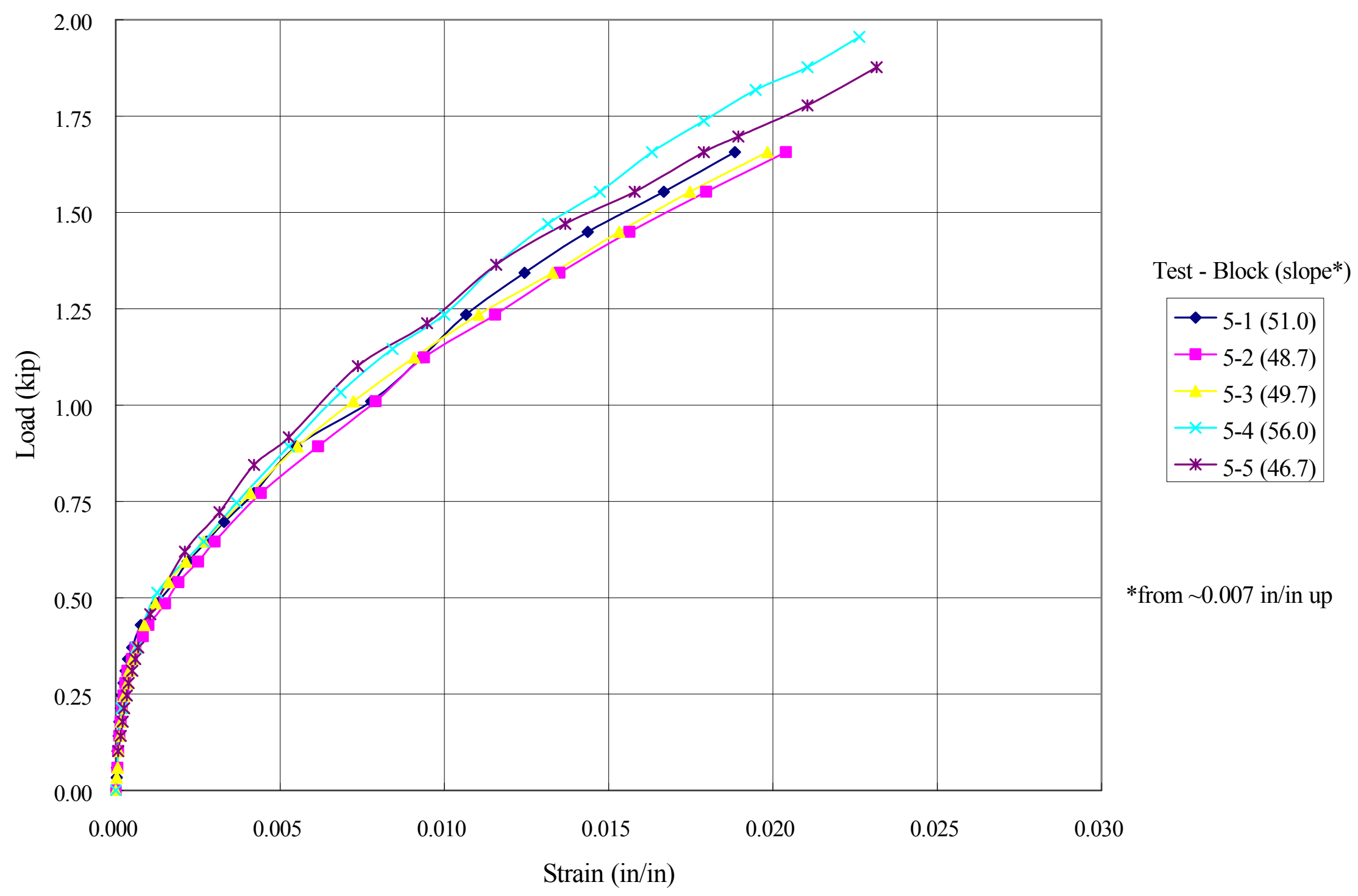

Figure 3.13 Push Test 5 Load vs. Strain Plot 


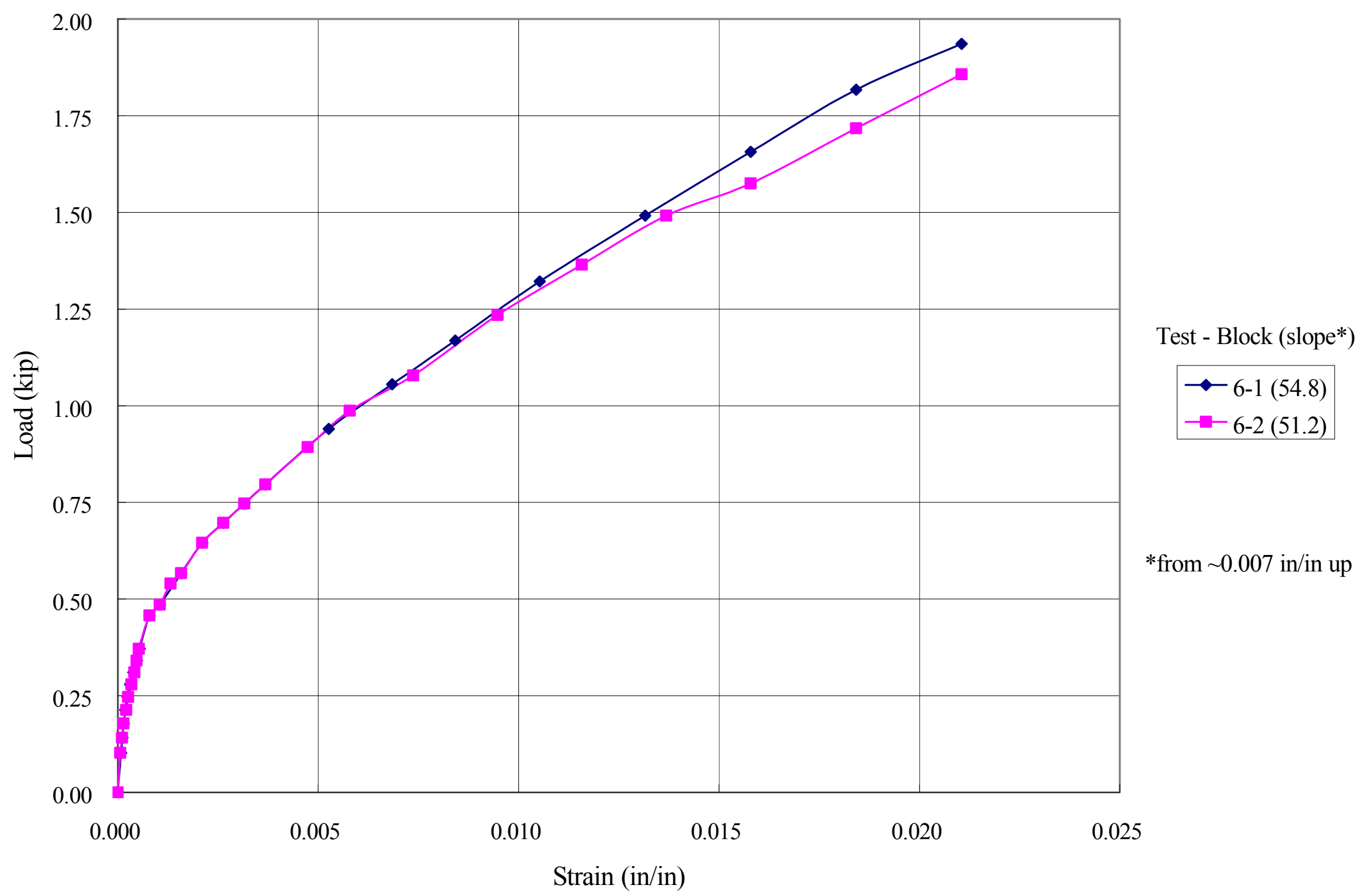

Figure 3.14 Push Test 6 Load vs. Strain Plot 


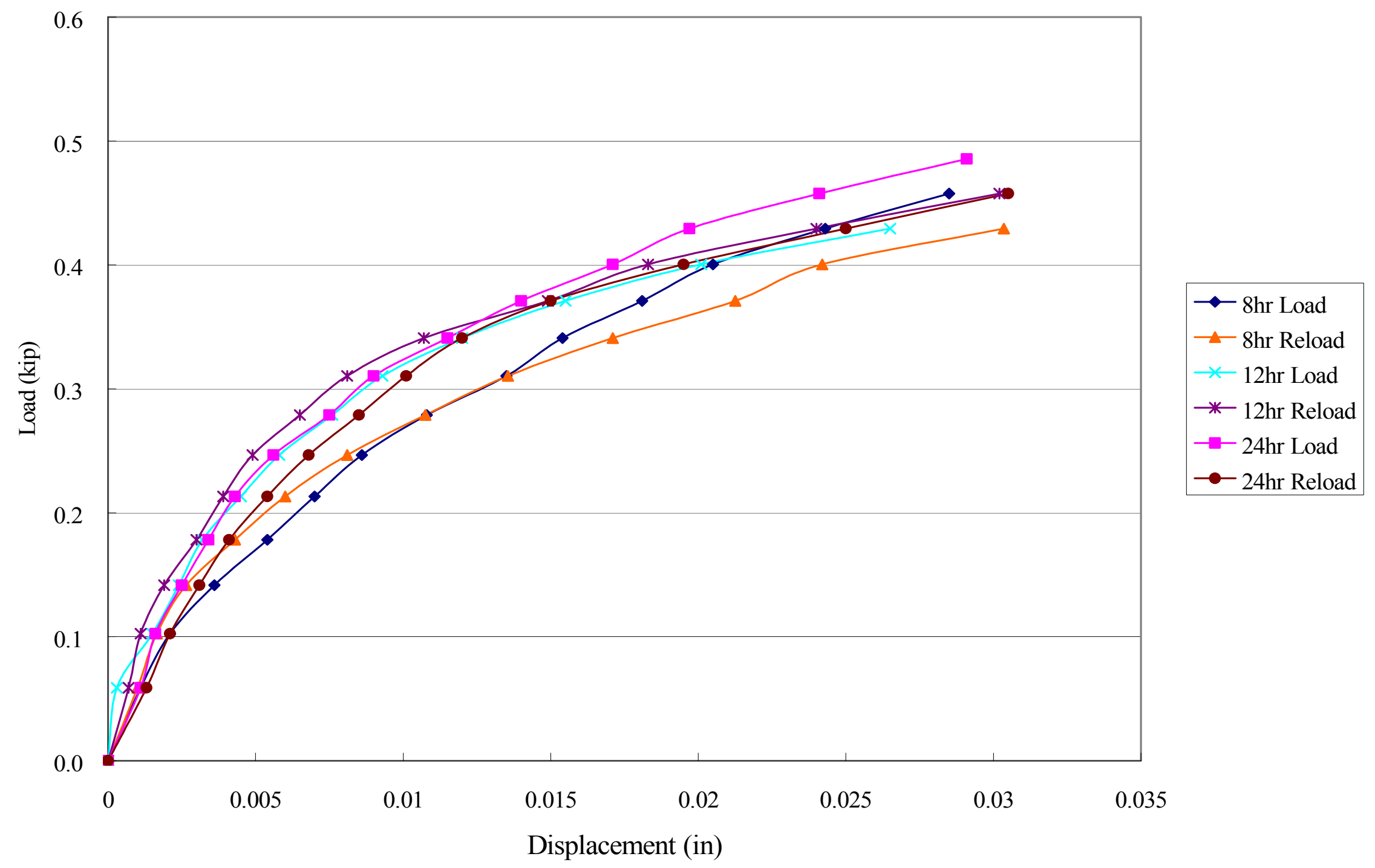

Figure 3.15 Push Test 6 (Ages Comparison) 


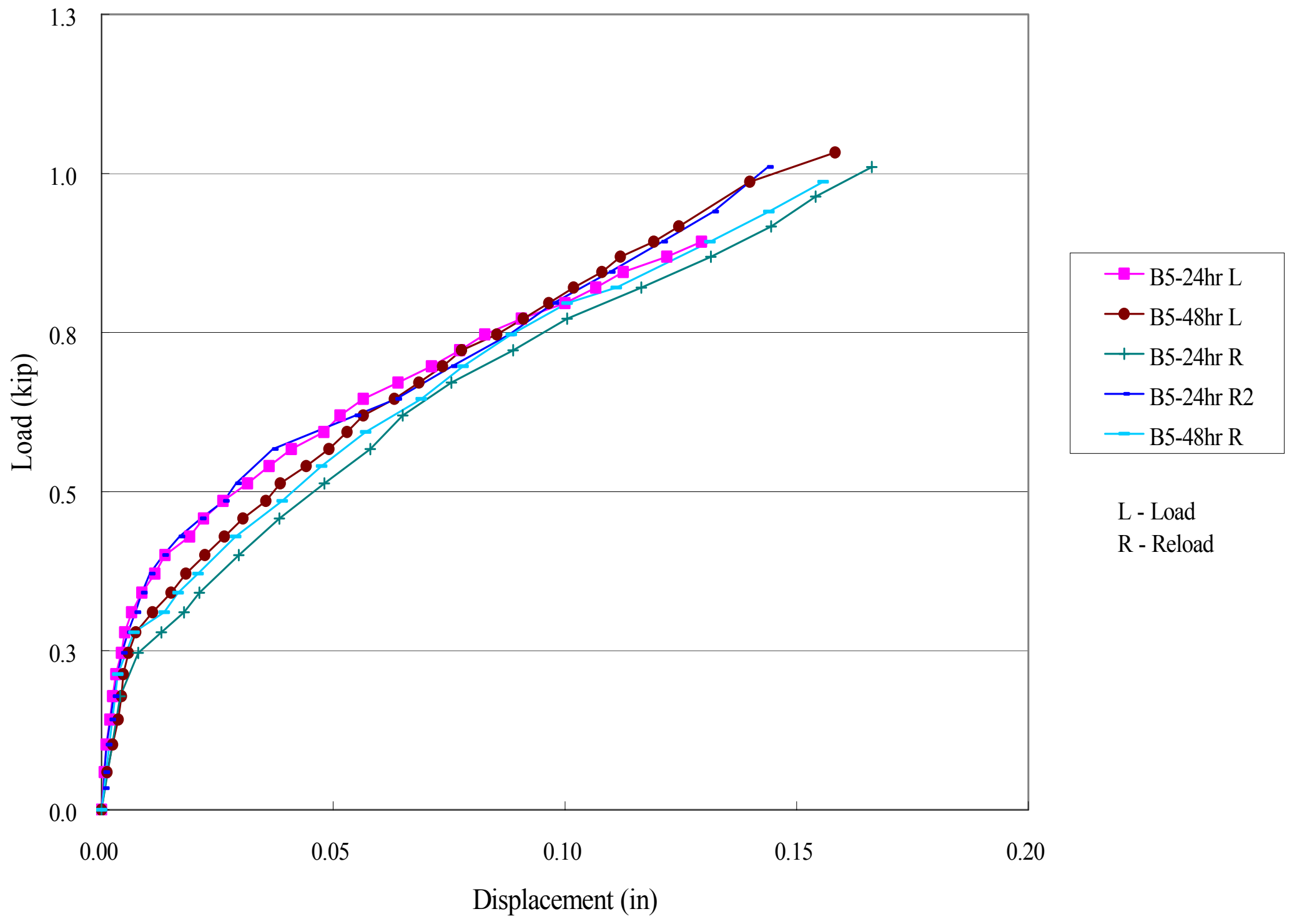

Figure 3.16 Push Test 5 (Load-Reload) 


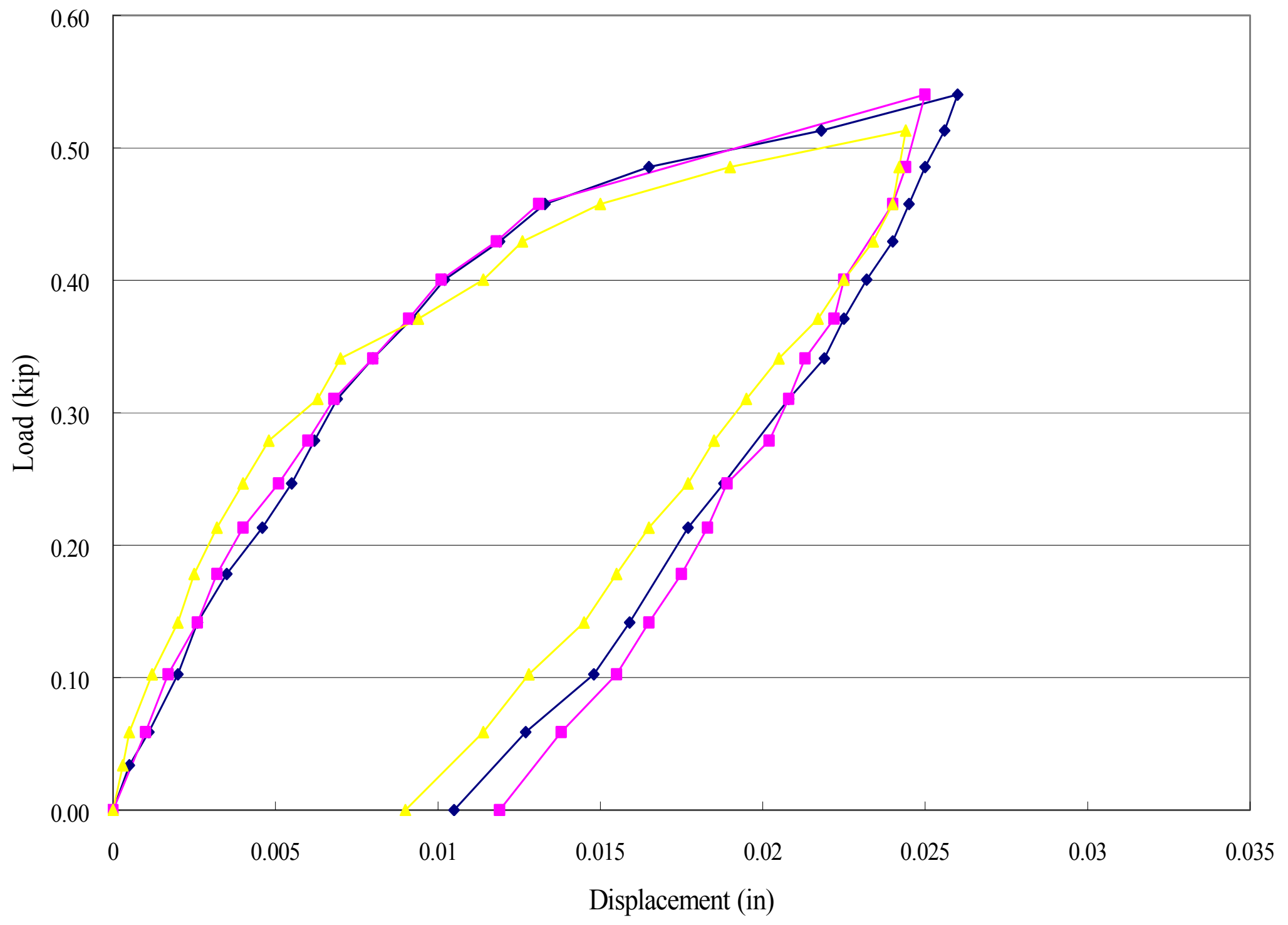

Figure 3.17 Push Test 6 (Load-Unload) 


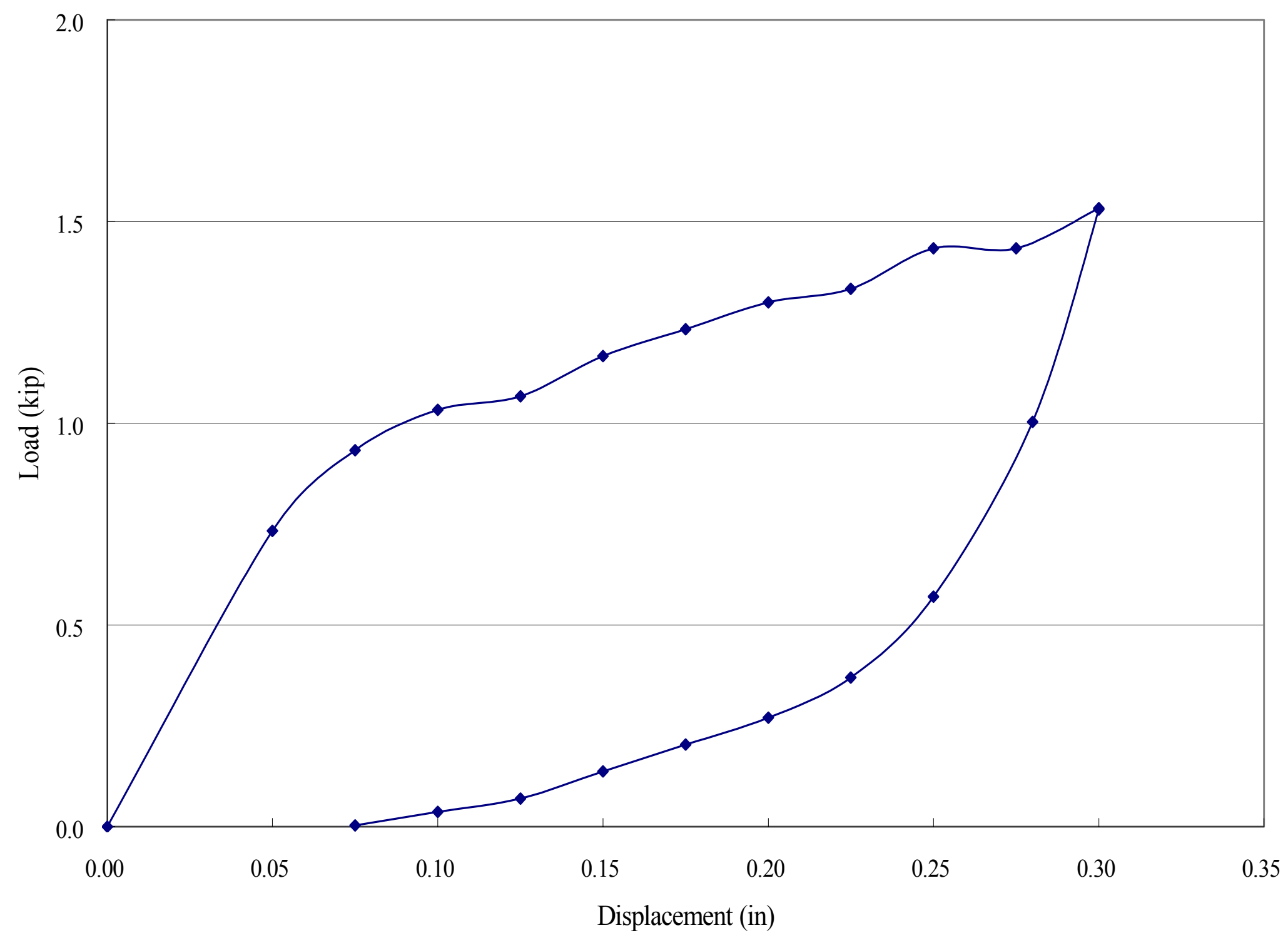

Figure 3.18 Push Test 2 (Load-Unload) 


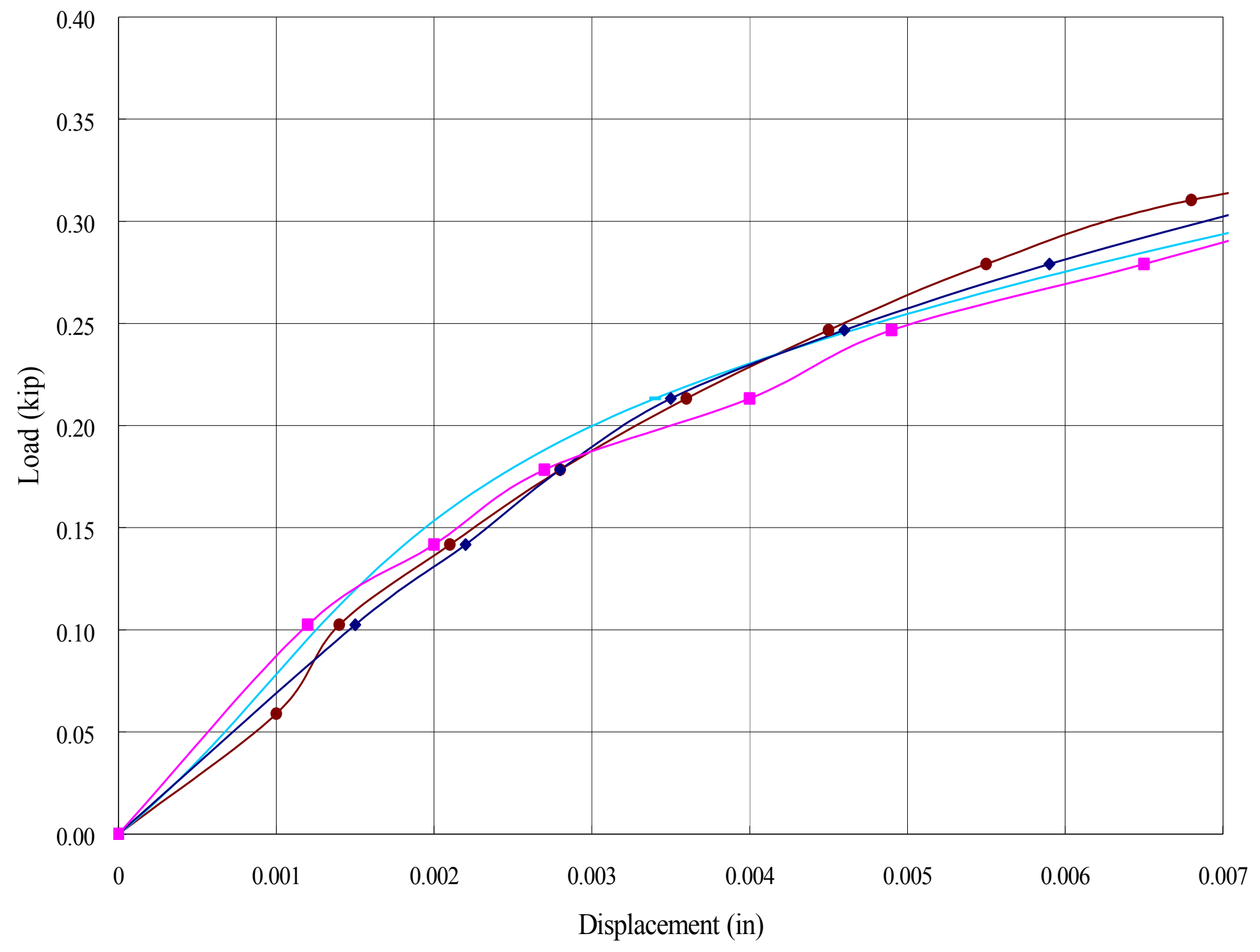

Figure 3.19 Push 5 and 6 (Small Displacement) 


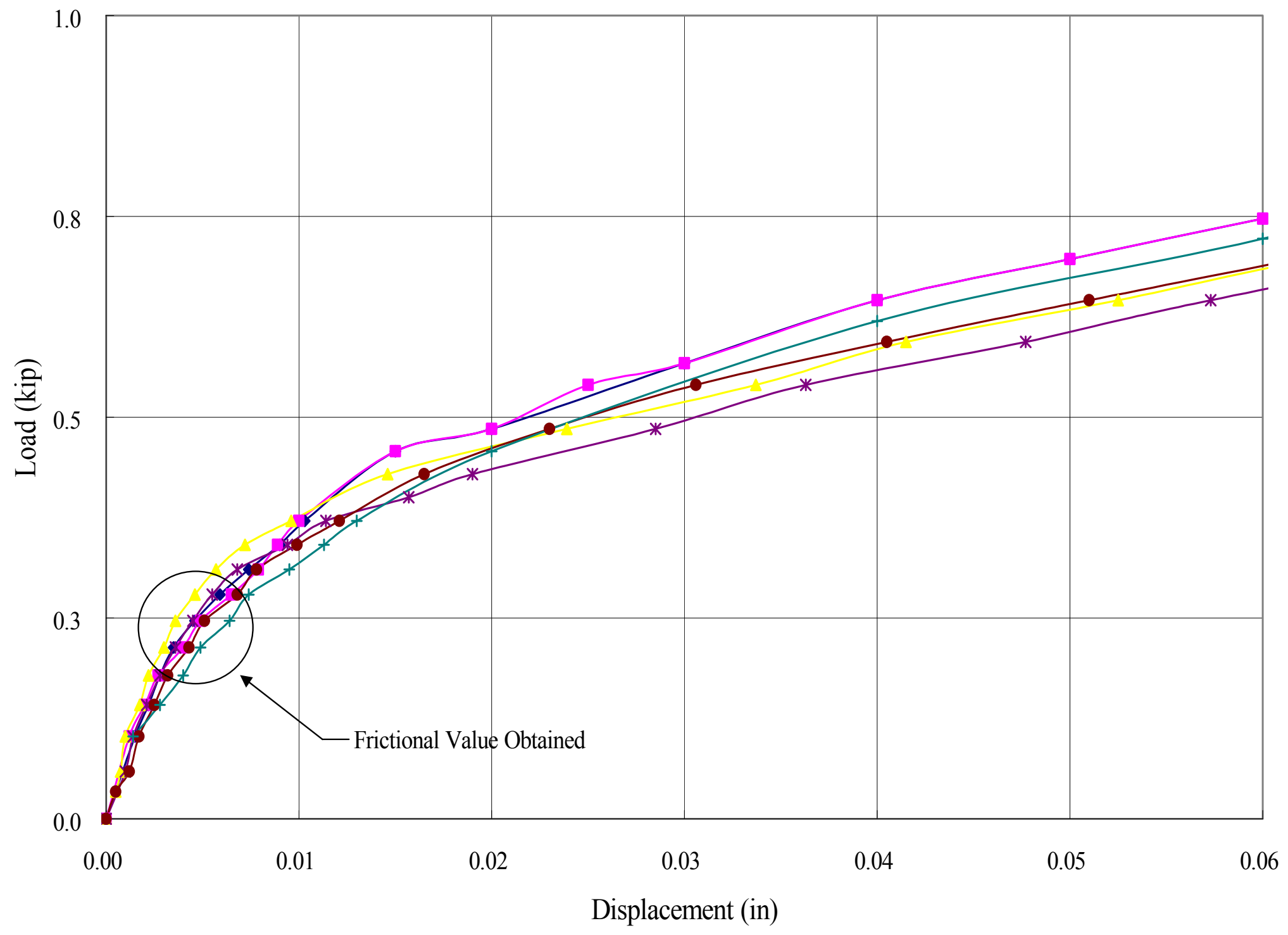

Figure 3.20 Push Tests 5 and 6 (Slope Change) 


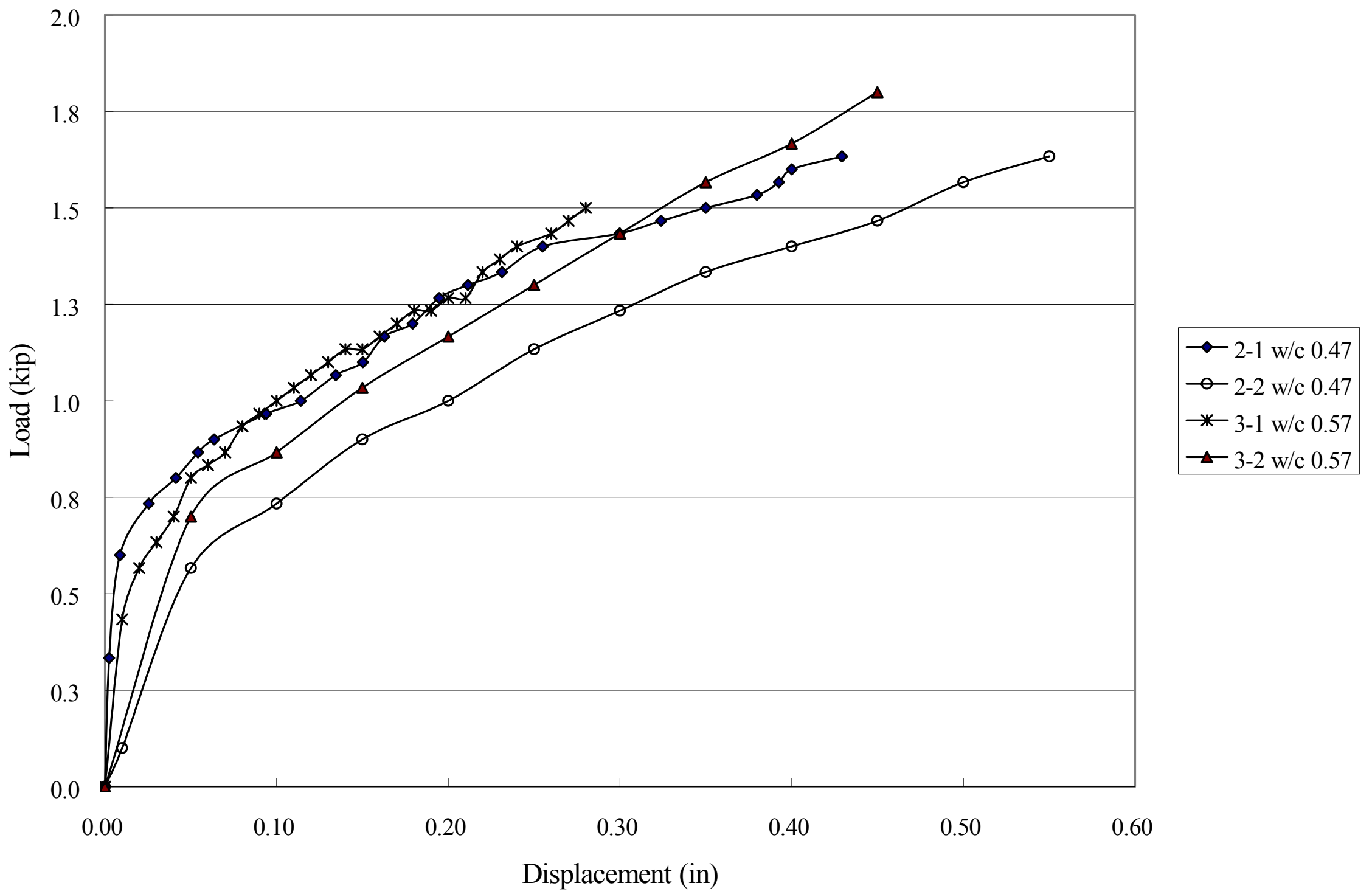

Figure 3.21 Push Test 2 and 3 (w/c Ratio Comparison) 


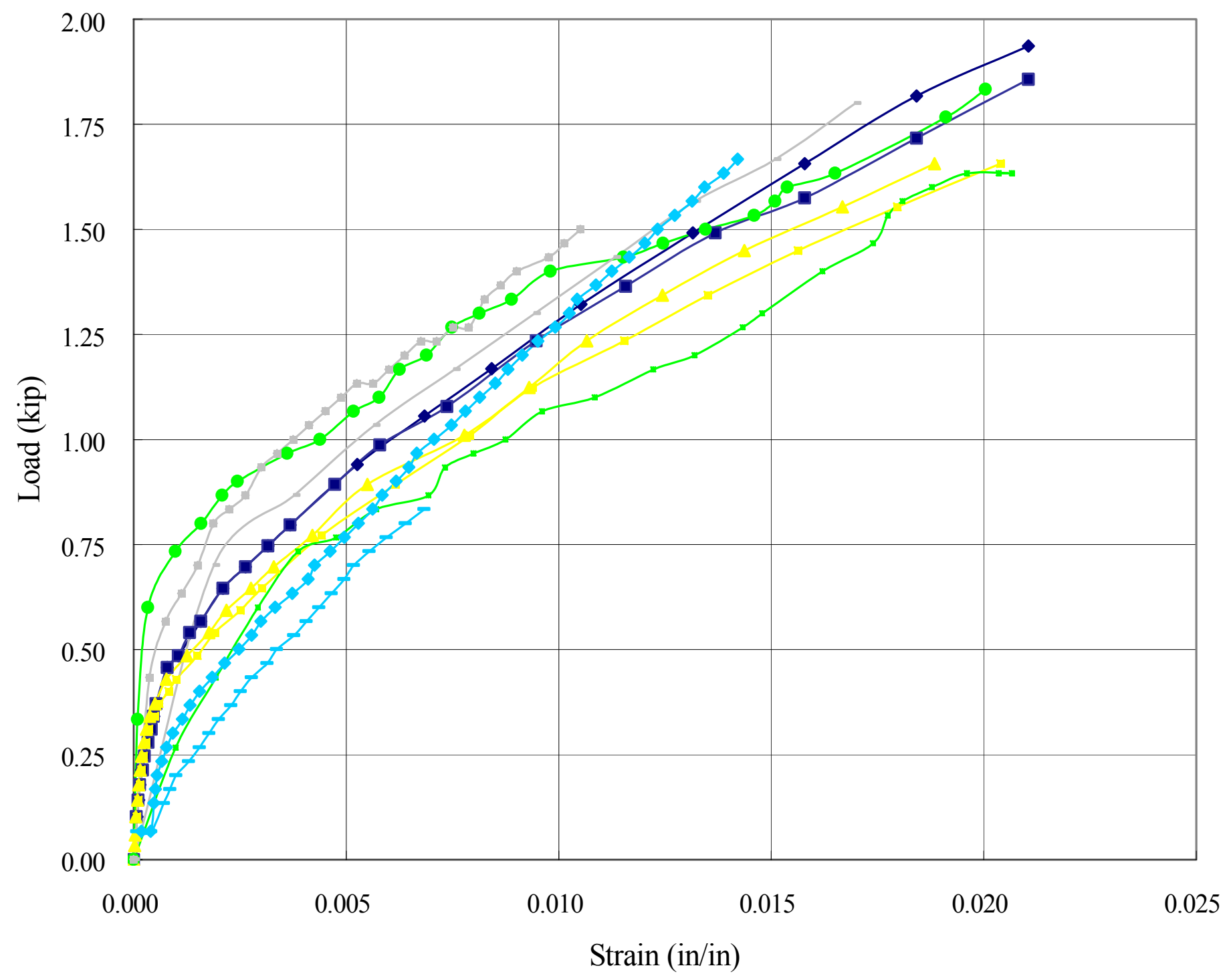

Test - Block

$$
\begin{aligned}
& \rightarrow-6-1 \\
& \rightarrow-6-2 \\
& -5-1 \\
& -5-2 \\
& --2-1 \\
& --2-2 \\
& --3-1 \\
& -3-2 \\
& -4-1 \\
& -4-2 \\
& \hline
\end{aligned}
$$

Figure 3.22 Push Test 2 to 6 (Comparison) 


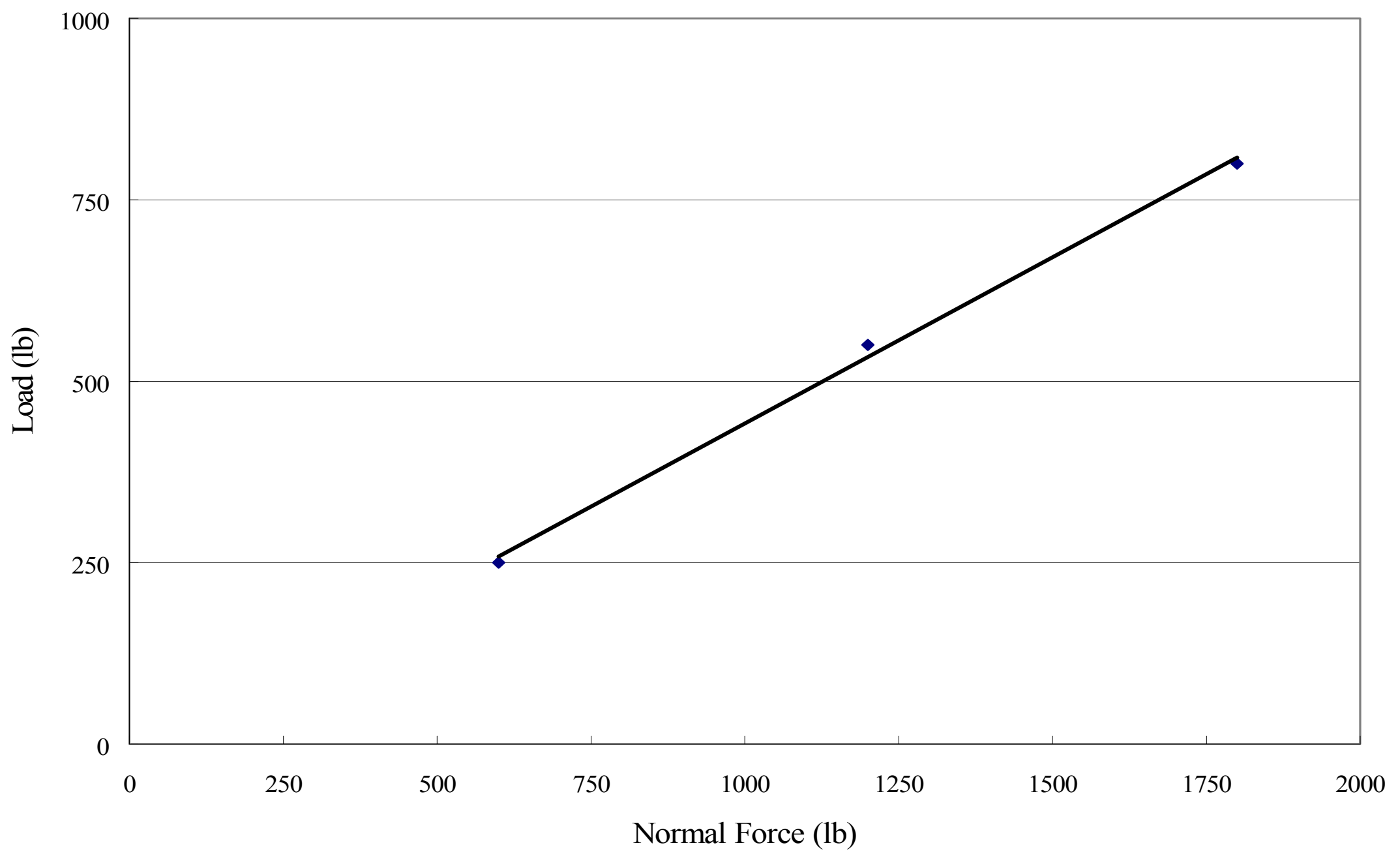

Figure 3.23 Frictional Resistance (Tendrain - 2 in Gravel; Test 2 and 3) 


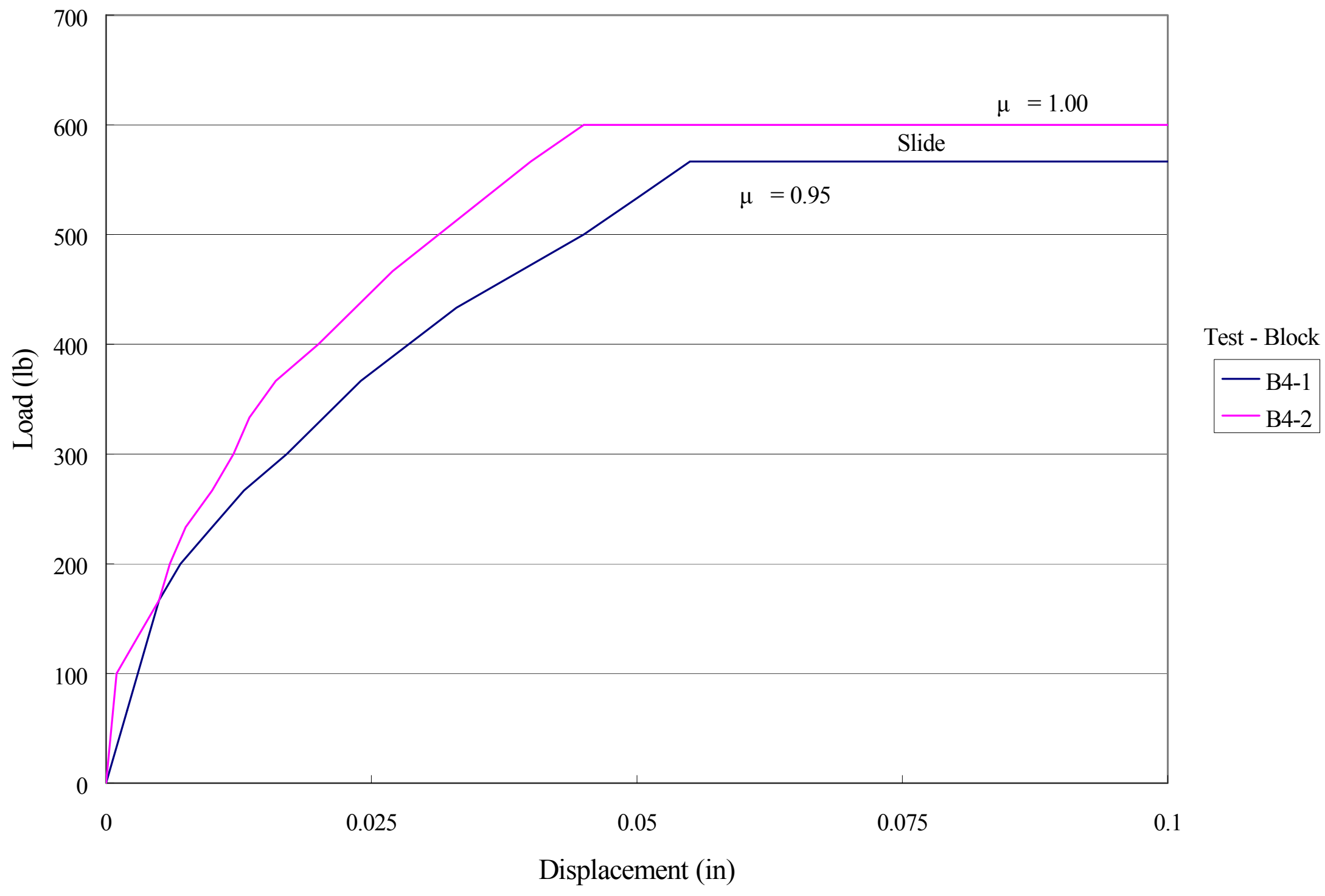

Figure 3.24 Frictional Resistance (Tendrain - 3 in Soil; Test 4) 


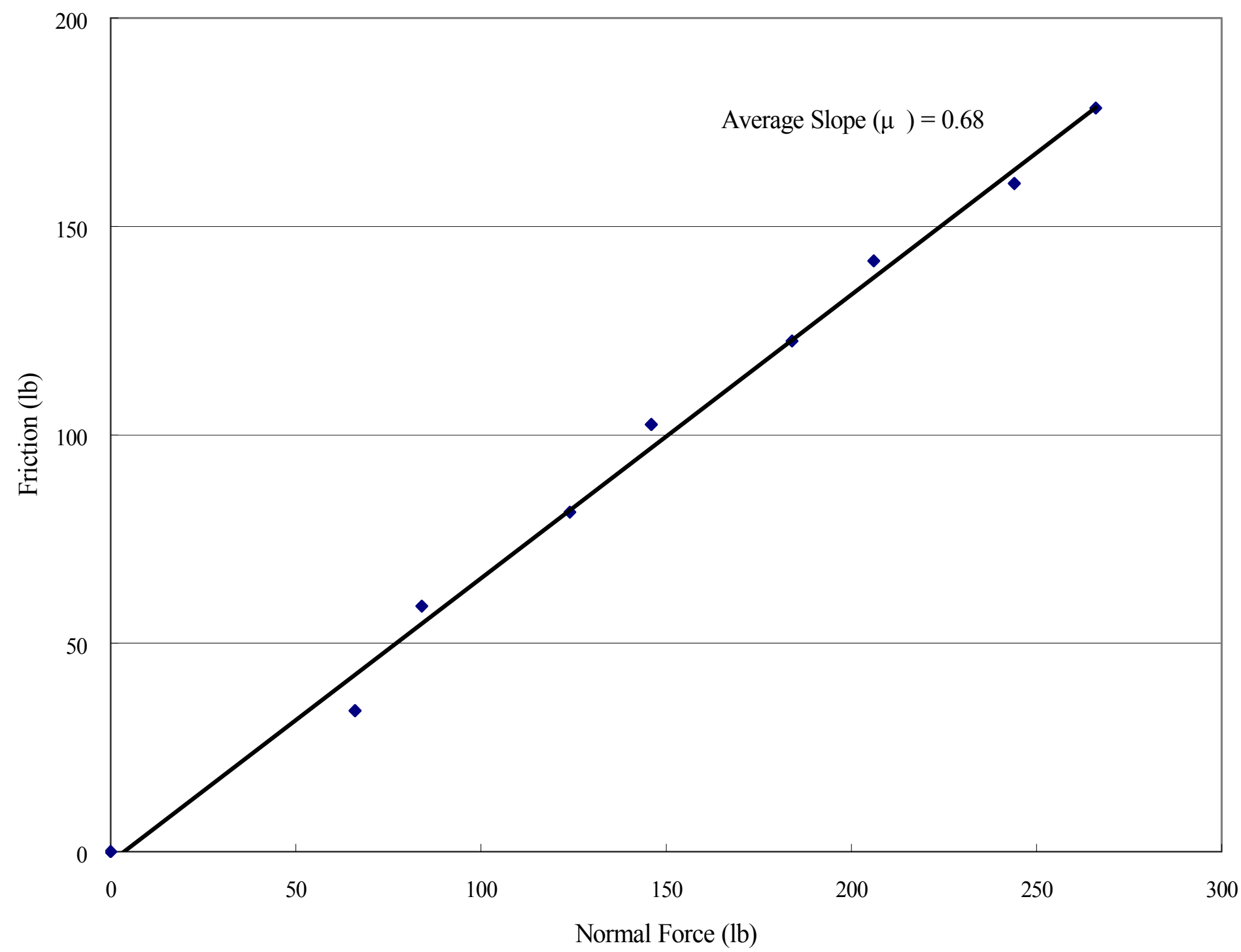

Specimens

6-1 to 6-5

Figure 3.25 Frictional Resistance (Tendrain - 12 in Gravel; Test 6-1a) 


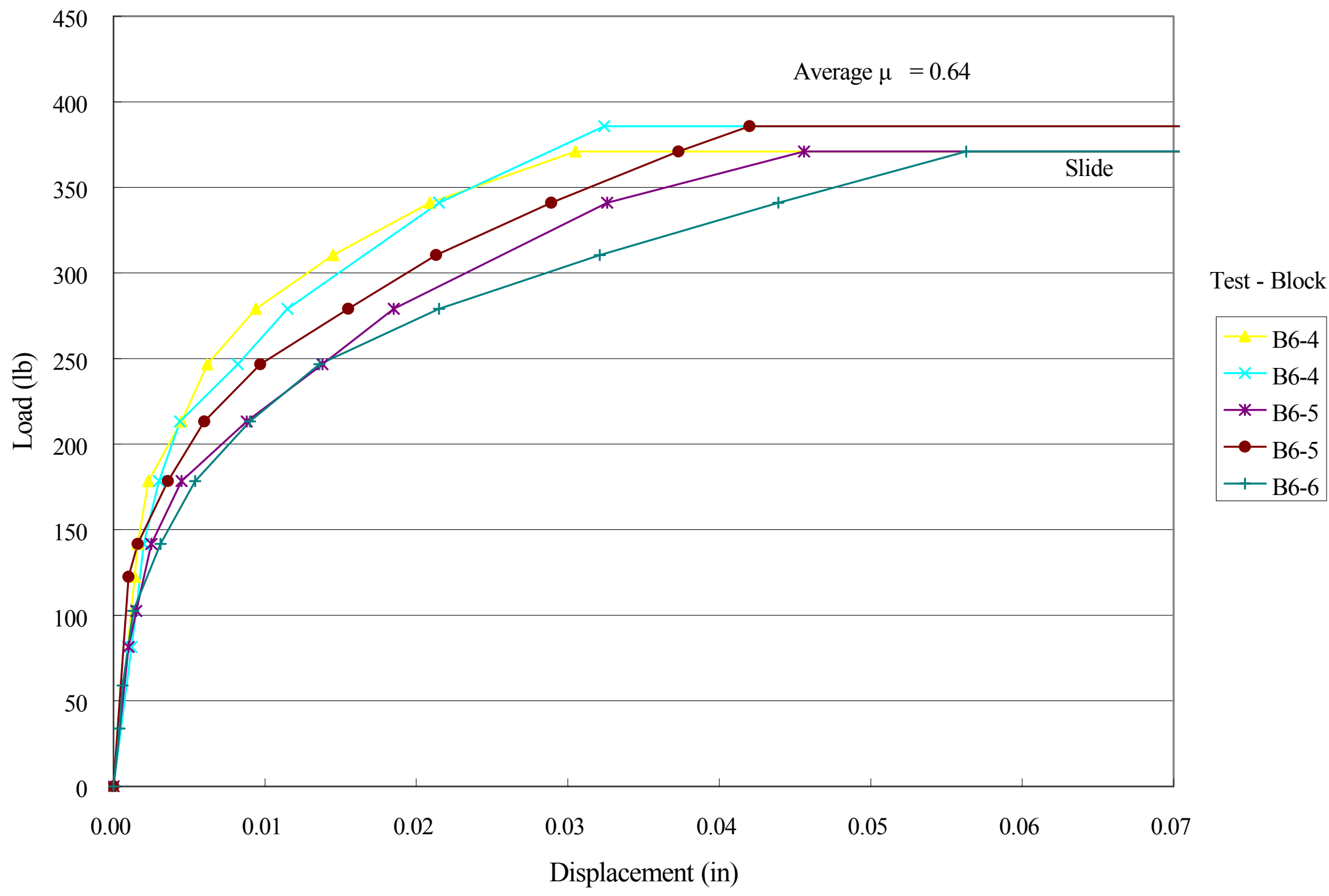

Figure 3.26 Frictional Resistance (Tendrain - 12 in Gravel; Test 6-1a) 


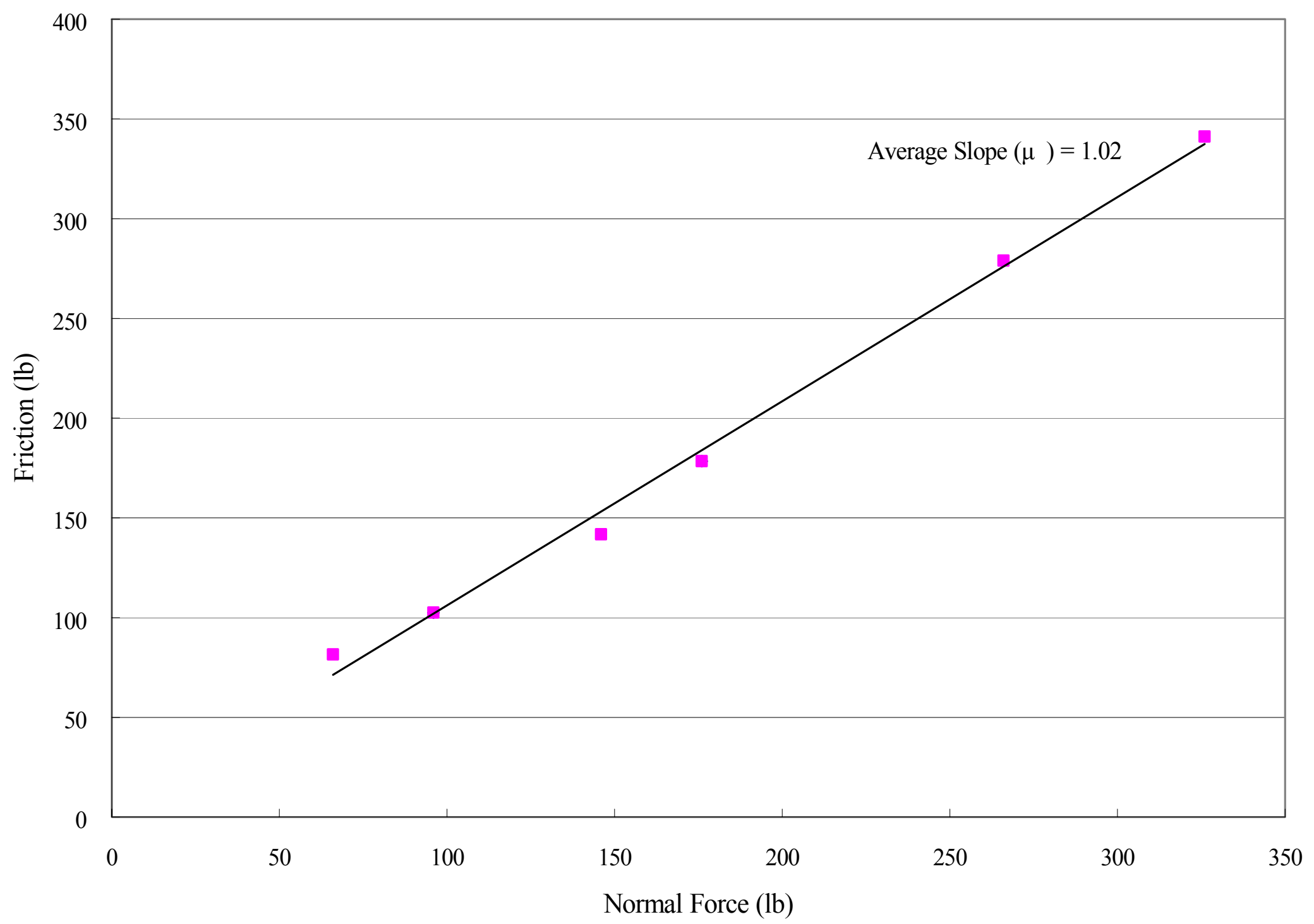

Figure 3.27 Frictional Resistance (Tendrain -3 in Soil; Test 6-1b) 


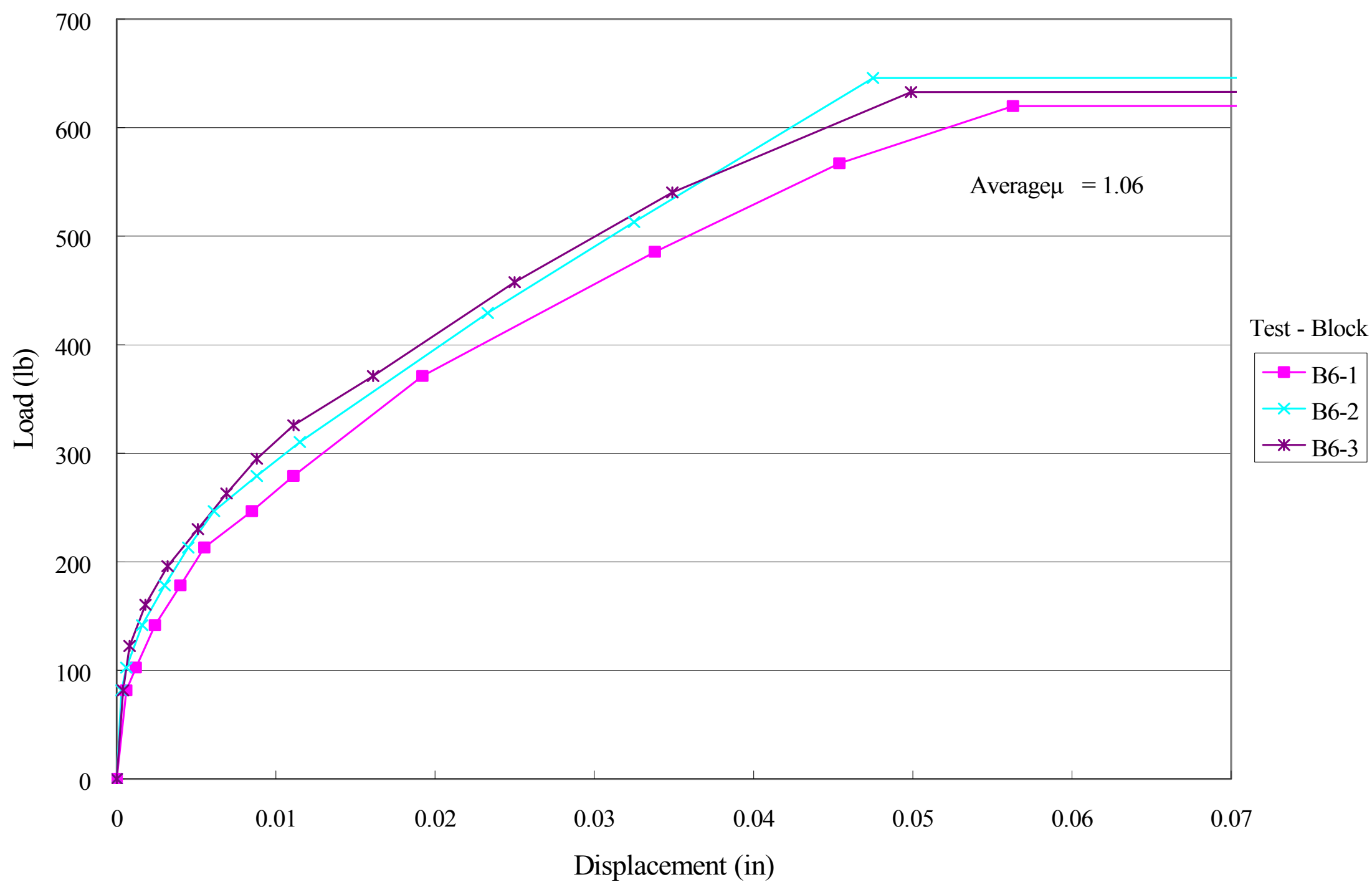

Figure 3.28 Frictional Resistance (Tendrain - 3 in Soil; Test 6-1b) 


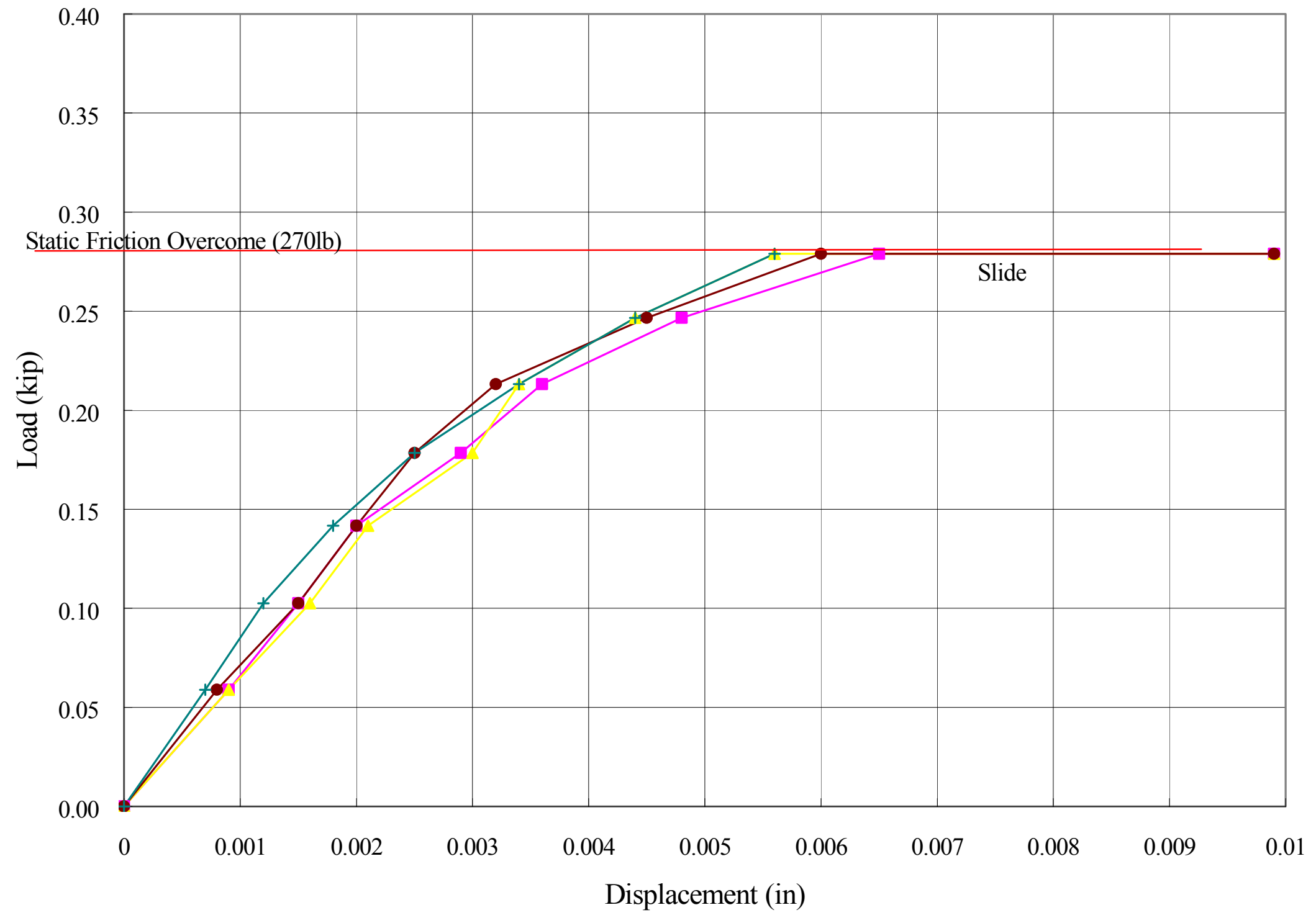

Figure 3.29 Plastic Frictional Resistance on Tendrain (Test 5 and 6) 


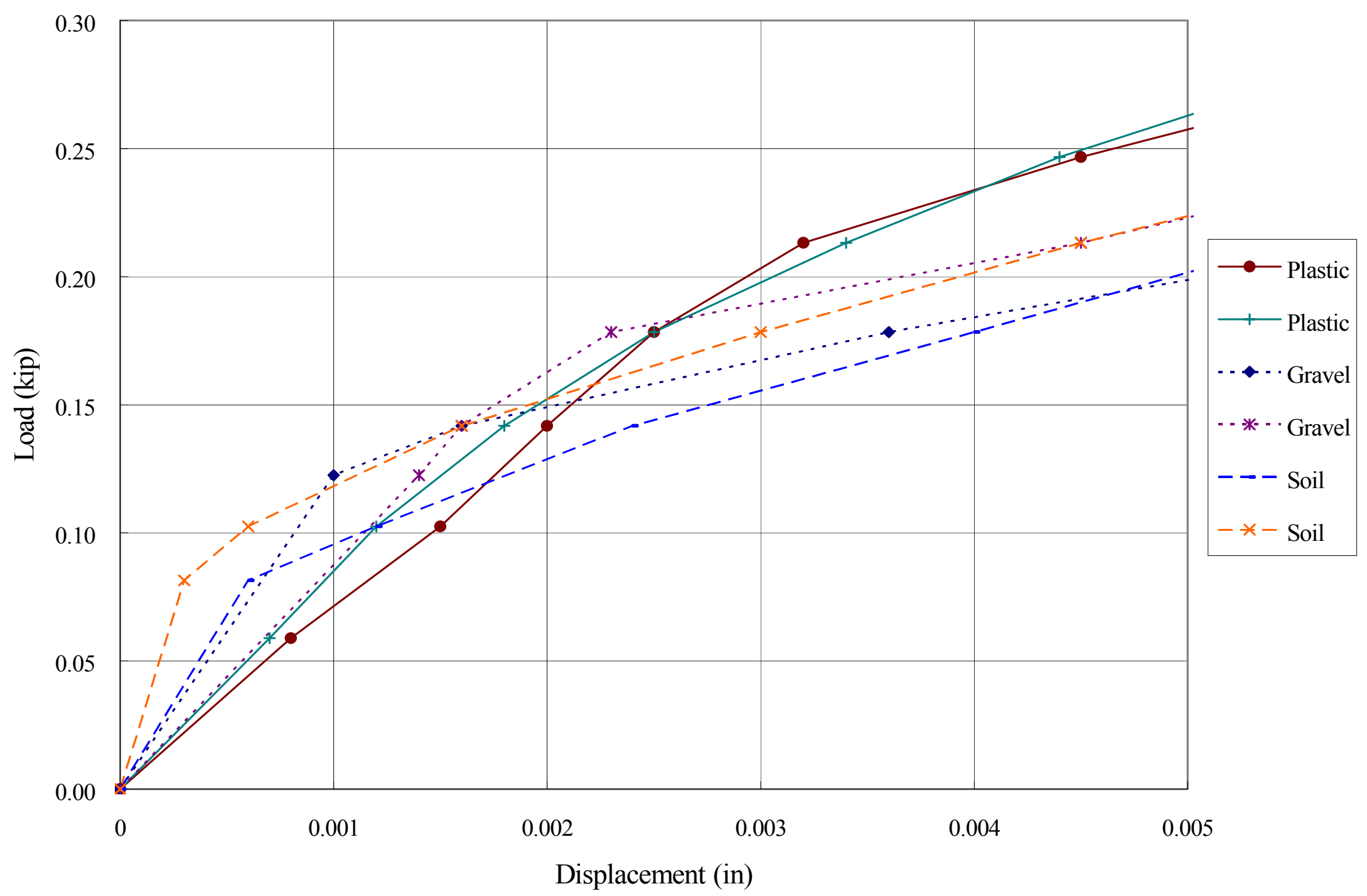

Figure 3.30 Frictional Resistances on Tendrain (Comparison) 


\section{CHAPTER 4}

\section{COMPRESSIVE STRENGTH TESTS}

\subsection{Overview}

The ultimate compressive strength of concrete is largely a function of the water cement ratio of the mixture. Tendrain possesses high drainage capabilities, which causes some seepage through the top layer of the Tendrain composite before the concrete has had an adequate time to set. This could affect the compressive strength of the concrete, since there is less water in the bottom portion of the concrete during the curing process.

To explore the possible effects of the above statements, several compressive tests were conducted. Three of which tests subject a compressive force to concrete cylinders and a fourth test which utilizes ultrasonic analysis for possible variation in strength.

\subsection{Test Procedure}

Within the first analysis twelve 6"dia. x 12 " specimens were subjected to compressive loading. Six of which were cast in standard compressive molds and six with the bottoms of the molds removed. The modified cylinders were placed and secured upon small sections of Tendrain. Using a Class B WVDOT concrete mixture with a w/c ratio of 0.47 , all cylinders were filled and proper curing procedures were taken. After the concrete had set, the molds were removed and the specimens were placed in the curing room for 14 and 28 days. Since the interest of the testing is on the initial loss of water, to the Tendrain, and the effect on the compressive strength, the Tendrain was removed after set also.

The second compressive analysis was conducted with the above procedures and mixture, but now with a concrete mixture possessing a w/c ratio of 0.57 . Besides using the $12-6$ " diameter 
cylinders, 8 - 3" diameter molds were used. This change in mold size reduces the cross section area to $7.07 \mathrm{in}^{2}$. These specimens cured for 28 days and then were tested. The third test is a repeat of the first test in procedure and materials, which also produced agreeable results.

Within the fourth assessment of compressive strength, an ultrasonic analysis was also conducted on the specimens. Two 6" diameter cylinders and two of the blocks from the push testing were used. The two cylinders were cast in normal molds, so they represent the non-Tendrain. The blocks from the push testing were cast on Tendrain and then removed. These specimens were tested using two sensors, an oscilloscope and a pulse generator. A short square pulse wave $(0.2$ us) is generated at one side of the concrete specimen and is received at the other end. The wave velocity through the test specimen, between the transmitting and receiving transducers, can be related to the modulus of elasticity. By determination of this modulus of elasticity of the concrete specimens the material strength was estimated. After the ultrasonic portion was complete, the two cylinders were then testing in compression until failure.

\subsection{Experimental Results}

The observation from all four tests is that the concrete cast on Tendrain seems to have little to no significant difference in compressive strength when compared with the standard concrete cylinders of the same mixture (refer to Table 4.1). The water seepage that occurs on the bottom of the concrete cylinder before the concrete was set has no obvious affect on the compressive strength of the concrete. The water loss on the bottom of the concrete interface is very localized, and has a negligible influence on the concrete strength for a typical $12 \mathrm{in.} \mathrm{depth} \mathrm{of} \mathrm{concrete} \mathrm{pavement.}$ 


\begin{tabular}{|c|c|c|c|c|}
\hline \multicolumn{5}{|c|}{ Compressive Test 1 (w/c 0.47) } \\
\hline \multirow{2}{*}{} & \multicolumn{2}{|c|}{ Tendrain } & \multicolumn{2}{c|}{ N/A } \\
\cline { 2 - 5 } & 14day (psi) & 28day (psi) & 14day (psi) & 28day (psi) \\
\hline $\mathbf{1}$ & 3979 & 3837 & 3643 & 4050 \\
\hline $\mathbf{2}$ & 3378 & 4050 & 4032 & 4421 \\
\hline $\mathbf{3}$ & 3395 & 4456 & 3961 & 4386 \\
\hline Average & $\mathbf{3 5 8 4}$ & $\mathbf{4 1 1 4}$ & $\mathbf{3 8 7 9}$ & $\mathbf{4 2 8 5}$ \\
\hline
\end{tabular}

\begin{tabular}{|c|c|c|}
\hline \multicolumn{3}{|c|}{ Compressive Test $2 \quad$ (w/c 0.57) } \\
\hline & Tendrain (psi) & N/A (psi) \\
\hline $\mathbf{1}$ & 3110 & 2690 \\
\hline $\mathbf{2}$ & 2650 & 3320 \\
\hline $\mathbf{3}$ & 2760 & 3150 \\
\hline $\mathbf{4}$ & 2900 & 2760 \\
\hline Average & $\mathbf{2 8 5 5}$ & $\mathbf{2 9 8 0}$ \\
\hline
\end{tabular}

\begin{tabular}{|c|c|c|}
\hline \multicolumn{3}{|c|}{ Compressive Test 3 (w/c 0.47) } \\
\hline & Tendrain (psi) & N/A (psi) \\
\hline $\mathbf{1}$ & 5092 & 5340 \\
\hline $\mathbf{2}$ & 5481 & 5623 \\
\hline $\mathbf{3}$ & 5375 & 5057 \\
\hline Average & $\mathbf{5 3 1 6}$ & $\mathbf{5 3 4 0}$ \\
\hline
\end{tabular}

\begin{tabular}{|c|c|c|c|}
\cline { 2 - 4 } \multicolumn{1}{c|}{} & Compressive Test & \multicolumn{2}{c|}{ Ultrasonics } \\
\cline { 2 - 4 } \multicolumn{1}{c|}{} & \multicolumn{2}{c|}{ N/A Cylinders (psi) } & Blocks on Tendrain (psi) \\
\hline $\mathbf{1}$ & 4598 & 4309 & 4562 \\
\hline $\mathbf{2}$ & 4668 & 4523 & 4327 \\
\hline Average & 4633 & 4416 & 4445 \\
\hline
\end{tabular}

Table 4.1 Compressive Strength Test Results 


\section{CHAPTER 5}

\section{DRYING SHRINKAGE TESTS}

\subsection{Overview}

Drying shrinkage refers to the change in length due to water loss in hardened concrete. It's basically strain produced by the loss of water of time. Inadequate design for the effects of drying shrinkage in concrete can lead to cracking or warping of structure members due to restraints present during shrinkage. To effectively design pavements or floor slabs on ground utilizing the Tendrain drainage system, a clear understanding of the effect that Tendrain has on concrete drying shrinkage has to be determined.

Within this study the change in the linear dimension of the test specimens was measured over a period of time. These measurements were acquired along the longitudinal axis. The specimens of this study consisted of a number of concrete blocks cast upon the standard base or the Tendrain subbase which will be compared with one another. The interest here is within the possible affect the Tendrain could have on the shrinkage of the concrete due to the bleeding of water from cement paste into the Tendrain.

\subsection{Specimens}

\subsubsection{Overview}

The preparation and curing of the shrinkage test specimens were done according to the methods set forth in ASTM C 490-89. These methods and procedures were followed for all of the shrinkage tests completed throughout the study. A total of five shrinkage tests were conducted. The concrete mixtures used within this test correspond to those of the push tests, 
discussed earlier. For example, Shrinkage Test 1 concrete mixture is from the same batch utilized in Push Test 1 and so on through Test 4.

\subsubsection{Concrete Mix Design}

To have a better representation of Tendrain behavior in actual pavement and slabs, a commonly used concrete mix design (WVDOT Class B) was chosen for these tests. This mix was prepared in accordance with WVDOT, DOH MCS\&T MP 711.03.023 and coincides to applicable subarticles of Section 601 Structural Concrete "West Virginia Department of Transportation, Division of Highways Standard Specifications - Roads and Bridges". Having a w/c ratio of 0.47 , this batch has an expected 28-day Compressive Strength of 4000 psi.

\subsubsection{Dimensions}

The dimensions of the specimens are in accordance to those set forth in ASTM-C 490-89. Using the standard mold referred to in the standard, specimens of dimensions 11 " x 3" x 3" are produced (refer to Figure 5.1). These blocks have steel shrinkage gage studs which are secured upon set of the concrete and are located along the longitudinal axis on each side. For proper preparation procedure, these studs extend into the concrete $0.625 \pm 0.025 \mathrm{in}$. and the distance between the inside ends of the studs were $10.00 \pm 0.10 \mathrm{in}$. The gage length within this analysis of 10 in. was used for determining length change. 


\subsubsection{Test Conditions}

Refer to 3.2.2 Test Conditions.

\subsection{Instruments and Equipment}

\subsubsection{Molds}

The shrinkage molds were constructed of smooth steel with a tight fitting assembly which allows no spreading or warping of the material. The mold has one compartment which will form a 3 by 3 by 11.25 in. concrete specimen. Two end plates secure gage studs which will be set 0.625 in. into the concrete upon cast. This creates a gage length for shrinkage calculations of $10 \mathrm{in}$ The equipment meets specifications for the ASTM C 490 standard.

\subsubsection{Apparatus for Measurement of Length Change}

The apparatus used for measurement of length change was the Length Comparator with Digital Indicator (H-3250D) manufactured by Humboldt Mfg. Co. of IL (refer to Figure 5.2). This piece of equipment consisted of three main components: a frame with base (upright and adjustable), a digital micrometer indicator with movable anvil, and a checking reference bar (Invar Test Bar for 10" effective gage length). This reference bar has a rubber sleeve cover the middle section to prevent the steel from changing length due to the temperature increase from the operator's hand. The digital indicator's resolution was set to 0.0001 in.

\subsection{Test Procedures}

\subsubsection{Mold Preparation}

All tests included six standard shrinkage forms; three of these had their bases removed and were place upon Tendrain, and three were standard mold setups (freebase). Special care was taken 
to prepare the molds in such a way to assure a quality specimen was produced within all the shrinkage testing. All components of the molds were cleaned and particle free. These pieces were then assembled with firm fittings to assure proper containment of the mix. Taking care to keep the studs clean and oil free they were set into end plate so $5 / 8 \mathrm{in}$. of the body remains outside for the concrete to bond with. The outside joints and contact lines were coated with a thin layer of microcrystalline wax of the material to prevent water or mix loss. The wax was not applied to the Tendrain, so these molds were weighted down and secured to prevent side losses. To prevent bond of the concrete with the interior of the molds, a thin coating of mineral oil is applied within, making sure not to apply any to the studs.

\subsubsection{Specimen Casting, Curing and Storage}

When the concrete (Class B) arrived at the laboratory, small amounts of the concrete mixture were distributed into the molds until half-full. Using a standard section of reinforcement bar, the concrete was tamped for air pocket removal and proper distribution within. The molds were then completely filled and tamped again. It was found that using the concrete vibrator on the sides of the molds helped to insure a proper specimen (having no voids and smooth sides). After leveling the tops, curing compound and wet burlap were applied to insure small water loss from the top. These specimens remained in the laboratory for one day and then were transferred into the storage lab. All specimens had the moldings removed and those cast with Tendrain subbase were peeled from the material after one day. The specimens were then placed upon a table for aging. 


\subsubsection{Measurement}

Measurement was accomplished by checking the specimen length against that of the reference bar at certain time intervals. The reference bar was first placed within the apparatus and the anvil is lower to secure its position. The digital gage was then zeroed with the bar in place using its length for a comparison to the specimens. This comparator measurement is done at the beginning and end of each specimen reading. After the ends of the studs were cleaned of any oil or dirt, the specimen was then placed in the apparatus for measurement. The specimen was then slowly rotated in the apparatus until the lowest reading was obtained. As the specimen was rotated, the reading shifted back and forth, varying up to 0.0003 in. The lowest value was recorded each time to insure the same length measurement was acquired. This was done for the next several weeks at varying time intervals. The specimens were always placed with the same end up during each of the readings.

\subsubsection{Calculation of Length Change}

Following the ASTM C 490 standards, the change in length is calculated for each new reading utilizing the following equation:

$$
L=\frac{(L x-L i)}{G} * 100
$$

where,

$\mathrm{L}=$ change in length at $\mathrm{x}$ age, $\%$,

$\mathrm{L}_{\mathrm{x}}=$ comparator reading of specimen at $\mathrm{x}$ age minus comparator reading of reference bar at $x$ age, 
$\mathrm{L}_{\mathrm{i}}=$ initial comparator reading of specimen minus comparator reading of reference bar at that same time

$\mathrm{G}=$ nominal gage length, $(10 \mathrm{in})$

\subsection{Experimental Results}

\subsubsection{Seepage and Bond}

Seepage of cement paste occurred in the Tendrain subbase specimens before concrete set, while the free base specimens had no bottom transfer of water or cement paste. As the specimens were being removed from the Tendrain, dampness on the top layer and within the Tendrain was noted. A moderate amount of force was required to remove the concrete specimens completely from the Tendrain. When all specimens were removed from the material, a moist spot with concrete fines remained on top. (Figure 5.3) The section of Tendrain was lifted to find moisture spots on the floor. This suggests that water seepage traveled to some extent through all three layers of Tendrain. After the Tendrain was allowed to fully dry, the top layer of fabric was removed for further observations. Though water penetrated the material before set, only an extremely small amount of powder was present in the interior (Figure 5.4).

\subsubsection{Shrinkage Comparison: Tendrain vs. Standard Specimens}

The specimens cast on Tendrain seem to have less shrinkage than those cast in the standard shrinkage forms. Within the first test (w/c 0.47), the standard and Tendrain-based specimens, on average, reached a final strain of 726.4 and $630.4 \mu \varepsilon$, respectively. The standard specimens (denoted as N/A in the Figures) have a higher rate of shrinkage during the first 30-40 days (refer to Figure 5.5). After this period, the 
Tendrain and standard specimens have the same rate of shrinkage.

Four more shrinkage experiments were undergone to determine if the preliminary observation of Tendrain specimens having less shrinkage was valid. Again, the WVDOT design mix for pavements $(0.47$ and $0.57 \mathrm{w} / \mathrm{c}$ ratios $)$ was utilized in the same shrinkage setup previously used. The same trend was observed in all sets of specimens (Figures 5.5 to 5.9). Initial shrinkage within the normal specimens has a greater rate of shrinkage than that of the Tendrain specimens, as seen by the difference in slopes. After a period of time, the shrinkage within both sets possess approximately the same rate, as seen by the parallel curves. For comparison results of the final shrinkage difference of all the tests refer to Table 5.2. Concrete cast on Tendrain, on average, has about $9 \%$ less shrinkage than that of concrete cast with freebase. It should be noted that concrete pavement cast on regular drainage base will also have different drying shrinkage behavior in comparison with concrete cast on freebase. Moreover, at different depth in side the concrete pavement, the concrete drying shrinkage could also be different due to initial water loss from the drainage layer as well as the water loss from the pavement surface. 


\begin{tabular}{|c|c|c|c|c|c|c|c|}
\hline TEST & $\begin{array}{l}\text { w/c } \\
\text { ratio }\end{array}$ & Lab Temp.(C) & $\begin{array}{c}\text { Lab } \\
\text { Humidity }\end{array}$ & $\begin{array}{l}\text { Concrete } \\
\text { Mixture }\end{array}$ & $\begin{array}{c}\text { Specimen } \\
\text { Dimensions (in) }\end{array}$ & $\begin{array}{c}\text { Storage } \\
\text { Temp.(C) }\end{array}$ & $\begin{array}{c}\text { Storage } \\
\text { Humidity }\end{array}$ \\
\hline 1 & 0.47 & $26.4^{\circ}$ & $50 \%$ & \multirow{5}{*}{ Class B } & \multirow{5}{*}{ 11" x 3" x 3" } & \multirow{5}{*}{$23^{\circ} \mathrm{C}$} & \multirow{5}{*}{$55 \%$} \\
\hline 2 & 0.47 & $23.1^{\circ}$ & $52 \%$ & & & & \\
\hline 3 & 0.57 & $23.5^{\circ}$ & $61 \%$ & & & & \\
\hline 4 & 0.47 & $25.2^{\circ}$ & $57 \%$ & & & & \\
\hline 5 & 0.47 & $23.6^{\circ}$ & $55 \%$ & & & & \\
\hline
\end{tabular}

Table 5.1 Shrinkage Test Properties

\begin{tabular}{|c||c|}
\hline Test (w/c ratio) & Final Shrinkage Difference (Tendrain/NA) \\
\hline \hline $1(0.47)$ & $13.2 \%$ \\
\hline $2(0.47)$ & $10.4 \%$ \\
\hline $3(0.57)$ & $8.4 \%$ \\
\hline $4(0.47)$ & $8.0 \%$ \\
\hline $5(0.47)$ & $5.5 \%$ \\
\hline Total Average & $9.09 \%$ \\
\hline
\end{tabular}

Table 5.2 Average Shrinkage Results Comparison 


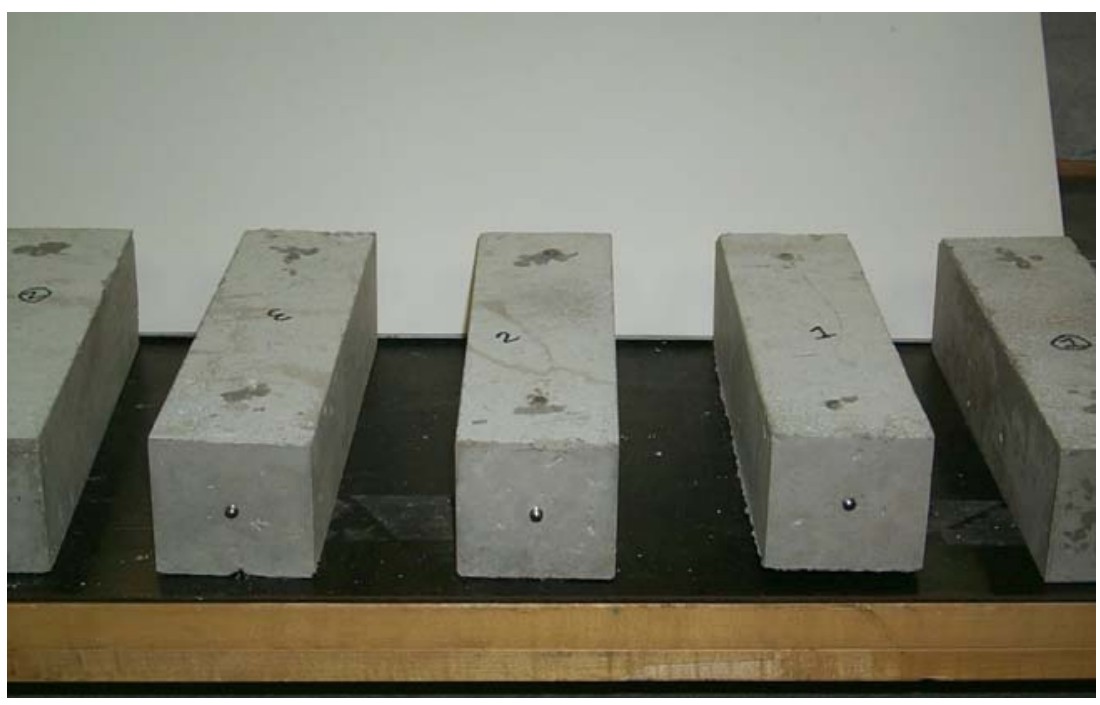

Figure 5.1 Shrinkage Specimens

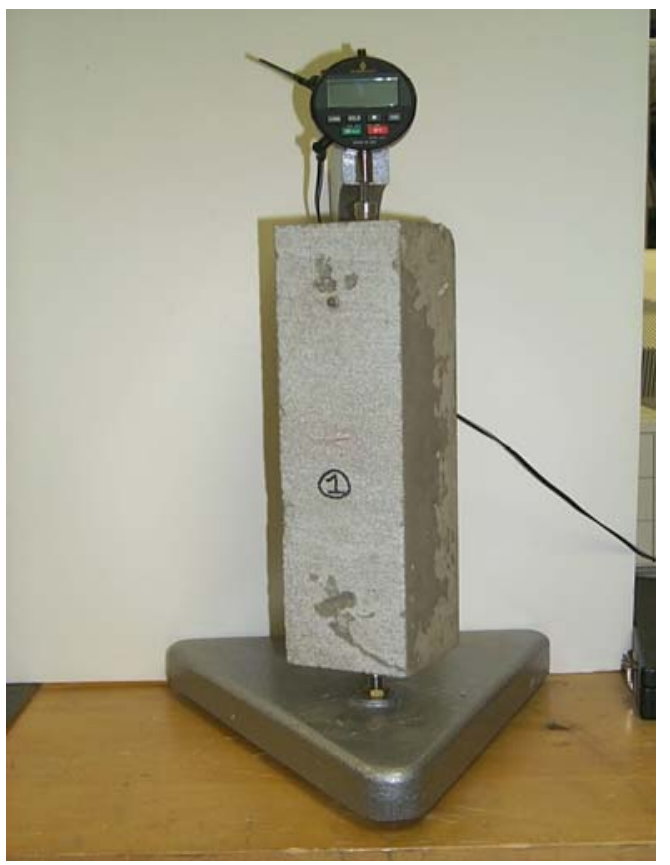

Figure 5.2 Apparatus for Measurement of Length Change 


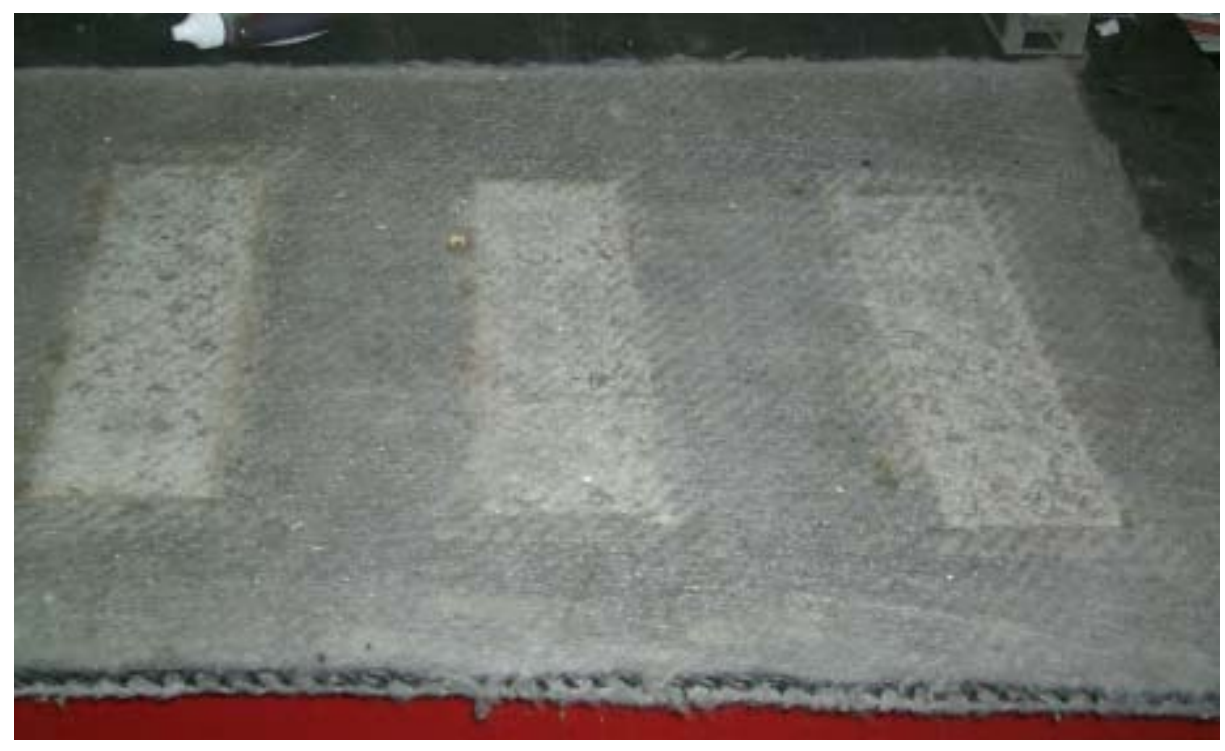

Figure 5.3 Shrinkage Specimens Removed from Tendrain

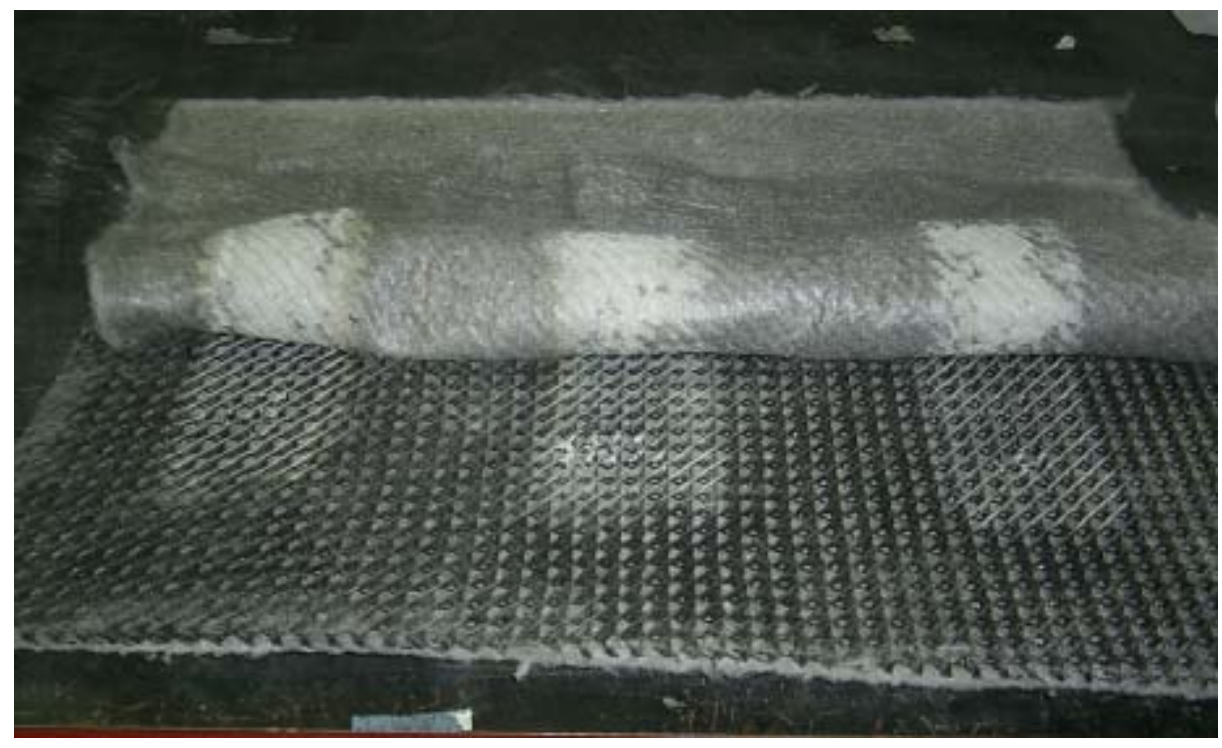

Figure 5.4 Cement Paste Residues from Shrinkage Specimens 


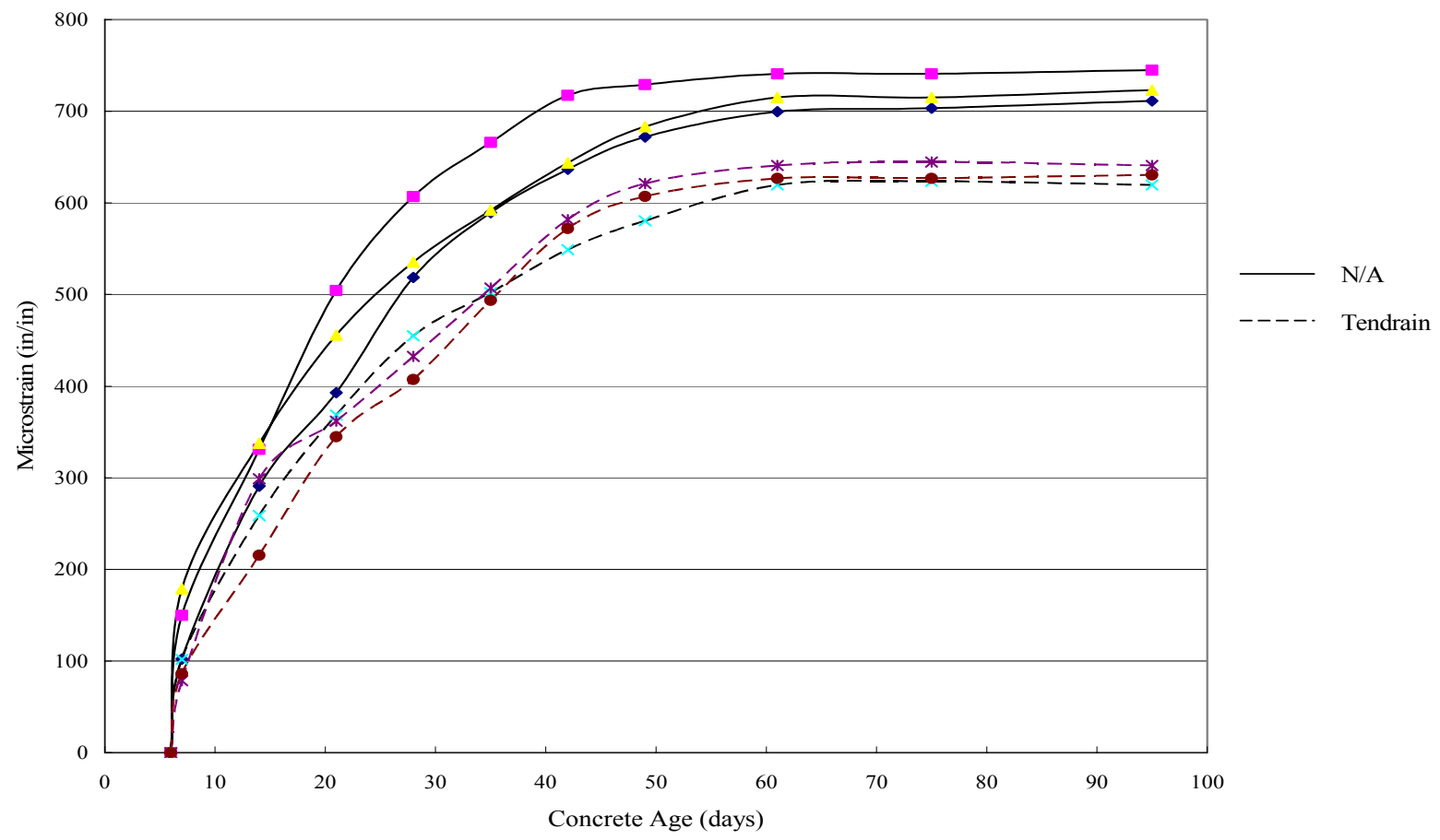

Figure 5.5 Test 1: Shrinkage vs. Time (w/c ratio 0.47)

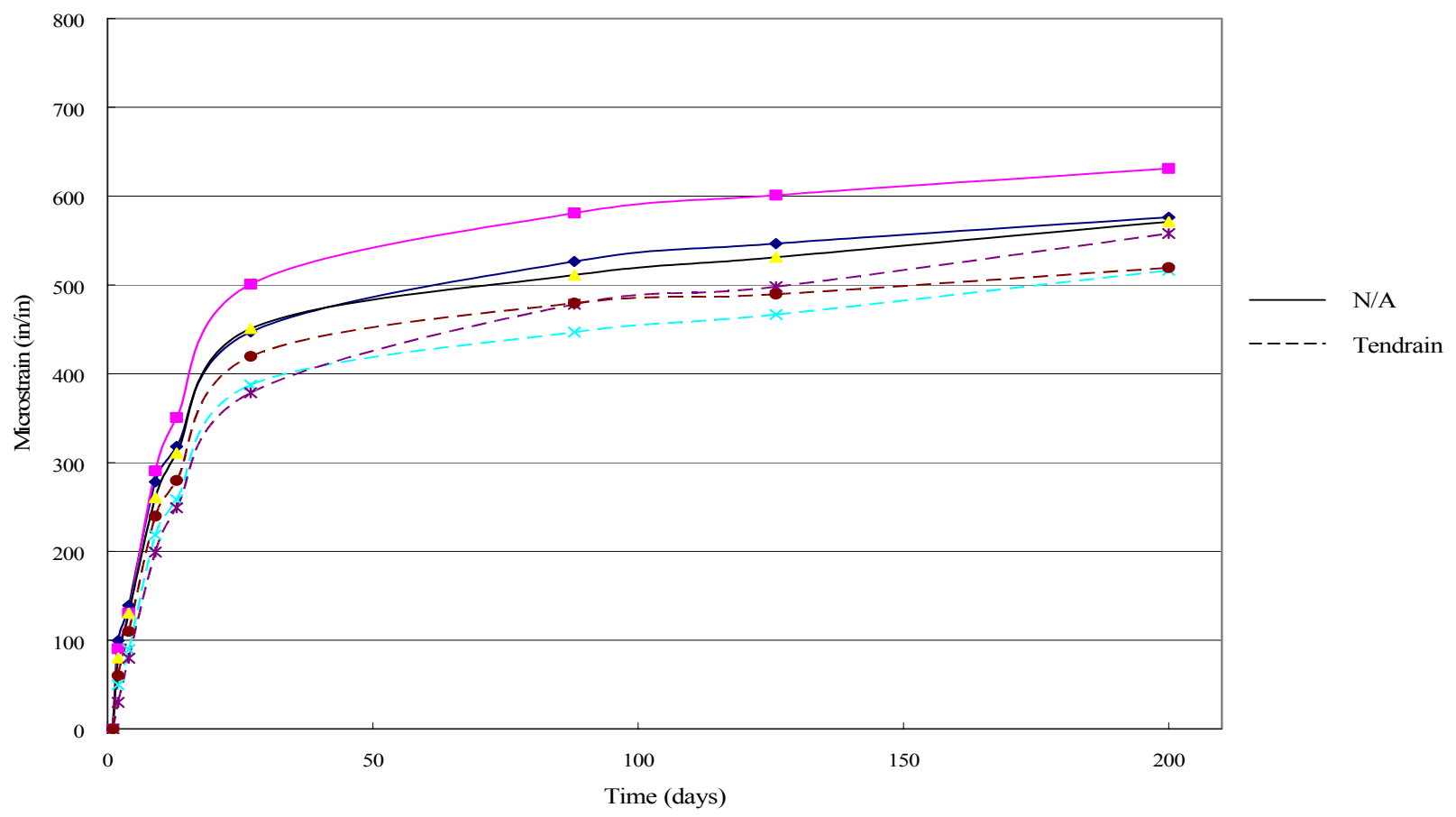

Figure 5.6 Test 2: Shrinkage vs. Time (w/c ratio 0.47) 


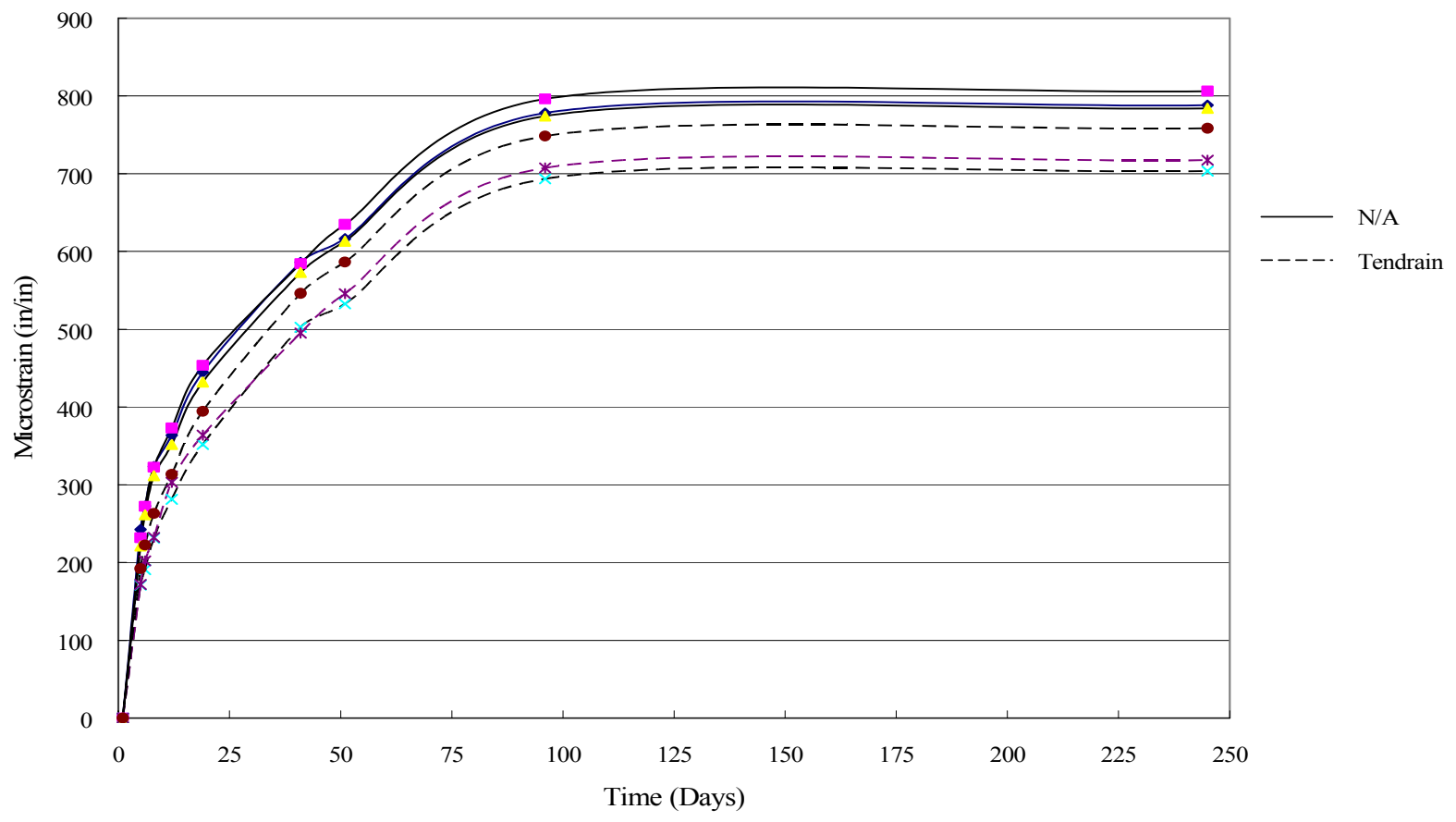

Figure 5.7 Test 3: Shrinkage vs. Time (w/c ratio 0.57)

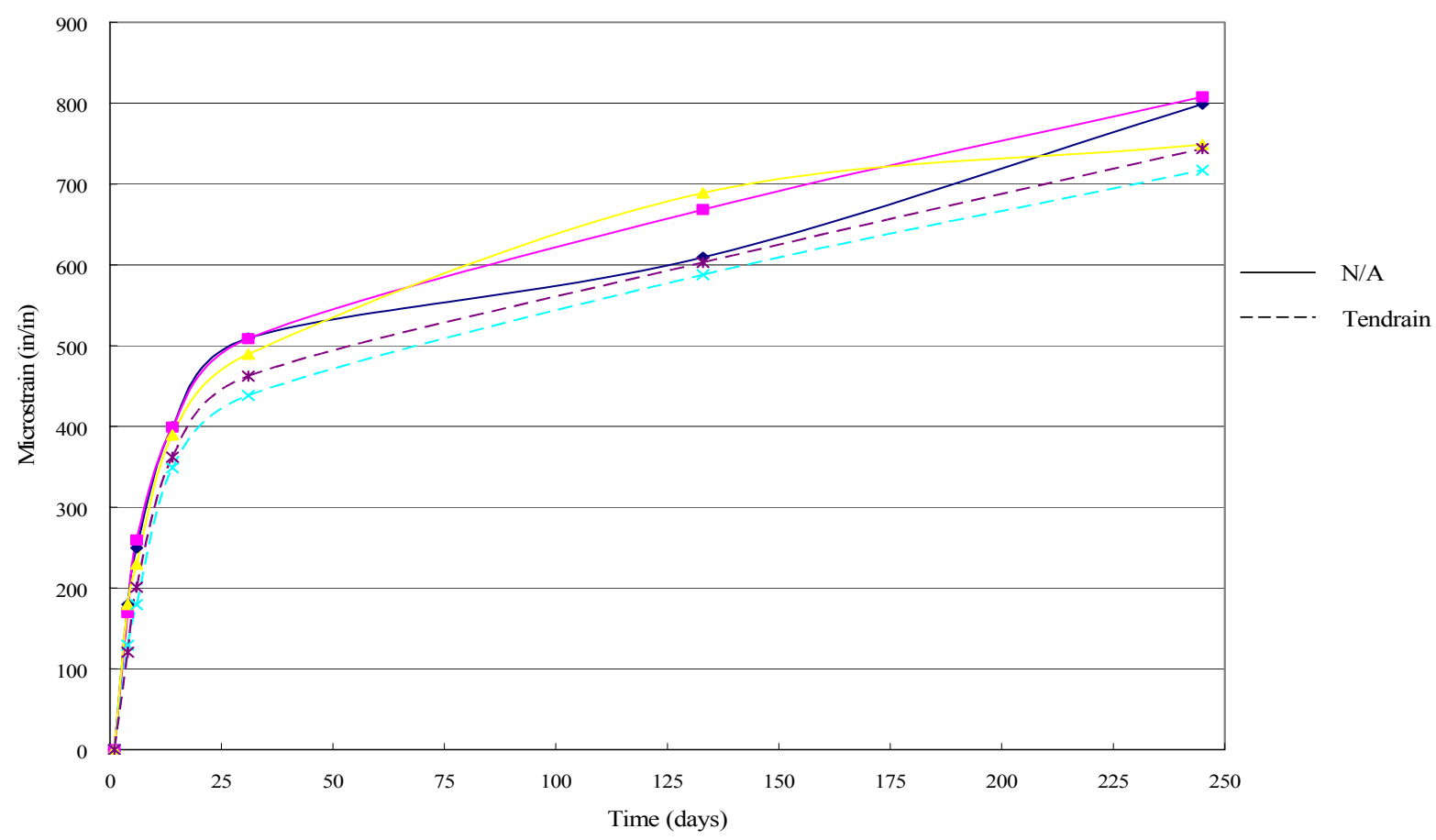

Figure 5.8 Test 4: Shrinkage vs. Time (w/c ratio 0.47) 


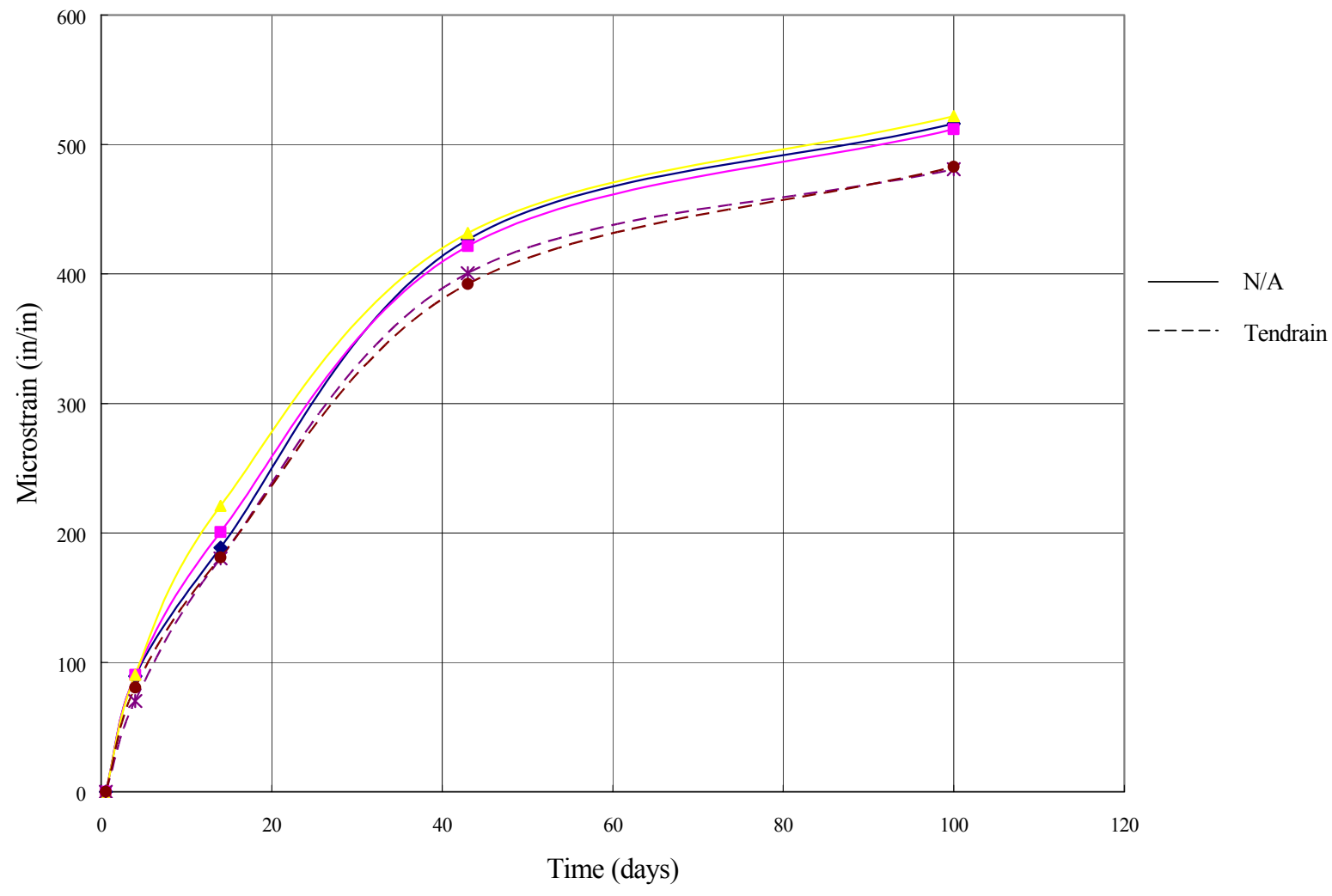

Figure 5.9 Test 5: Shrinkage vs. Time (w/c ratio 0.47) 


\section{CHAPTER 6}

\section{WATER LOSS TESTS}

\subsection{Overview}

An interest of the Tendrain is to see if concrete has a noticeable loss of weight during the curing process and during the aging of the specimen, due to water seepage into the Tendrain. This can be achieved by comparing the concrete cast on Tendrain to that of concrete which is only exposed on the top while curing. Since there is a difference in the shrinkage over time of the two types of specimens, theoretically, there should be a difference in weight loss. This loss should also be proportional to the difference in the shrinkage.

\subsection{Test Procedure}

\subsubsection{Test Setup}

Two experiments were conducted for the analysis of water / weight loss in relation to the presence of Tendrain. Within the first experiment twelve standard 3-in. diameter by 6-in. height concrete cylinder molds were utilized, six of which had their bottoms removed and six cylinders were standard specimens (Figure 6.1). Seven 7 in. $x 7$ in. sections of Tendrain were cut from the continuously woven material roll. Six were used within the casting setup, while one section was used for environment control. This section was weighed and allowed to fully dry find the amount of water that was already within the material, which is the normal amount of water absorbed from the testing room. The measured weight loss was then used to find out the amount within the other specimens before casting. Experiment 2 consisted of the same setup, but changed the specimens to 
six 4-in. diameter by 4.5-in. height concrete cylinder molds. This increased the area exposed to the Tendrain (Table 6.1).

\subsubsection{General Test Procedure}

After the molds and Tendrain sections were weighed, the six modified cylinders were placed and secured on the sections of Tendrain material. Note that the weight measurements were taken with great care since the weight losses are in very small percentage. Twelve 3 -in. diameter by 6-in. height cylinders were used in this test. After producing a concrete mix of $0.57 \mathrm{w} / \mathrm{c}$, the material was poured into the cylinders and agitated for air loss. Care was taken not to loose concrete from the bottom side due to tilt or movement or to get any of the mixture on the sides of the mold or on the material. Proper amounts of curing compound were applied to the tops. Total weights of the component specimens were measured. These total weights included molds, concrete and Tendrain for the modified specimens and the molds and concrete for the standard specimens.

After one day of curing the component specimens were weighed again, specimens cast on Tendrain had the material removed and were weighed again. A portion of water loss could still be held within the fabric pieces, so the material sections were separately massed and than heated to find the amount of water held within. This weight was added to the change in component specimen weight to find the total day 1 loss for the Tendrain specimens. Total day 1 losses for the

standard specimens were calculated by subtracting the initial and day 1 weights. Molds were removed and the concrete only was weighed through the next several weeks. 


\subsection{Experimental Results}

\subsubsection{Overview}

The concrete specimens cast on Tendrain were noticeably lighter in color on the bottoms and sides. A water mark of gray color was left on the Tendrain's surface where cement paste had penetrated the top fabric layer. Some of the specimens seemed to have bled water through all three Tendrain layers. The specimen bottoms had a hint of dampness upon visual inspection.

In Experiment 1 the initial water loss is greater in the Tendrain specimens because of the loss due to seepage before the concrete set, 1.07 percent loss compared to 0.78 percent in the standard specimens (Figure 6.2$)$. After the concrete set ( $\sim 8 \mathrm{hrs})$ the greater loss over time is with the normal cast concrete specimens. On average the percent weight loss for the Tendrain and normal specimens was 3.36 and 3.20, respectively, a difference of 4.8 percent (Table 6.3). If initial loss isn't included, comparison with shrinkage differences can be made. On average the percent weight loss for the Tendrain specimens without initial loss and the normal specimens without initial water loss was 2.28 and 2.42, respectively, a difference of 5.79 percent (Figure 6.3). This agrees with the shrinkage results.

Experiment 2 was conducted to increase the surface area and weight for better resolution of the results. The bottom surface area was increased to cause more seepage / loss of water through the Tendrain, while the total surface area was increased to cause more loss over time. The trend remains present with the results of the second experiment (Figure 6.4). The Tendrain specimens and standard specimens had an average initial loss of 1.22 percent and 0.74 percent, respectively. On average the percent weight loss for the Tendrain and normal specimens was 5.42 and 5.22, respectively, a difference of 3.7 percent. On average the percent weight loss for the Tendrain 
specimens without initial loss and the normal specimens without initial loss was 4.20 and 4.48 , respectively, a difference of 6.25 percent (Figure 6.5).

\subsubsection{Shrinkage Tests Comparison}

The results present a trend in both experiments which agrees with that of the shrinkage measurements. Initial water loss within the Tendrain specimens is greater than that of the normal specimens. Drying shrinkage is the strain caused by water loss within hardened concrete over time and the Tendrain specimens posses less water to loose over time and therefore have less shrinkage. Also, as with shrinkage, the weight loss seems to have a high initial rate after set and then an equal rate after a certain period of time. Though resulting values are very close, the trend seems evident.

Since shrinkage measurements were done after the initial loss and set of the concrete, the water loss was also calculated after initial loss for comparison. The weight loss and shrinkage experiments results in terms of Tendrain - NA differences which are close. The average final difference in weight loss for Exp 1 and Exp2 were 5.79 and 6.25 percent, respectively, compared to that of 9.1 percent for the average shrinkage results. Shrinkage Test 5 closely agrees with the water loss results, having a value of 5.5 percent.

The weight loss due to water seepage into Tendrain was quantified. The higher initial weight loss was observed in the concrete specimen cast on Tendrain. The Tendrain specimens also show less long-term water loss in comparison with the normal specimens. This explains why the concrete specimens cast on Tendrain would have less long-term drying shrinkage than the normal specimen as observed in Chapter 5. 


\begin{tabular}{|c|c|c|}
\hline Properties & Experiment 1 & Experiment 2 \\
\hline Concrete Specimen & $3^{\prime \prime}$ dia x 6" & $4^{\prime \prime}$ dia x 4. 5" \\
\hline Specimen Surface Area & 71 in $^{2}$ & 82 in $^{2}$ \\
\hline Bottom Area Exposed to Tendrain & 7.1 in $^{2}$ & 12.6 in $^{2}$ \\
\hline Lab Temperature & $25^{\circ} \mathrm{C}$ & $25^{\circ} \mathrm{C}$ \\
\hline Lab Humidity & $51 \%$ & $51 \%$ \\
\hline Concrete Specimens Weight & $1680 \mathrm{~g}$ & $2143 \mathrm{~g}$ \\
\hline Number of Specimen & 2 sets of 6 & 2 sets of 3 \\
\hline w/c ratio & \multicolumn{2}{|c|}{0.57 hand mix } \\
\hline
\end{tabular}

Table 6.1 Experiment Properties

\begin{tabular}{|c|c|c|c|c|}
\cline { 2 - 5 } \multicolumn{2}{c|}{} & \multicolumn{2}{c|}{ Experiment 1 } & \multicolumn{2}{c|}{ Experiment 2 } \\
\hline Result & Tendrain & N/A & Tendrain & N/A \\
\hline Average Initial Weight Loss & $1.08 \%$ & $0.79 \%$ & $1.24 \%$ & $0.75 \%$ \\
\hline Final Weight Loss (w/ out initial*) & $2.28 \%$ & $2.42 \%$ & $4.20 \%$ & $4.48 \%$ \\
\hline Fina1 Wt. Loss Difference \\
$\begin{array}{c}\text { Tendrain/NA) } \\
\text { Final Shrinkage Difference } \\
\text { (Tendrain/NA) }\end{array}$
\end{tabular}

* Having shrinkage test start after initial loss, initial loss is left out here for comparison of difference

Table 6.2 Experimental Results 


\begin{tabular}{|c|c|c|c|c|c|c|c|c|c|c|c|c|}
\hline \multirow[b]{2}{*}{ Weight (g) } & \multicolumn{6}{|c|}{ Tendrain Specimen } & \multicolumn{6}{|c|}{ Normal Specimen } \\
\hline & 1 & 2 & 3 & 4 & 5 & 6 & 1 & 2 & 3 & 4 & 5 & 6 \\
\hline TENDRAIN & 53.71 & 41.46 & 49.31 & 50.37 & 57.16 & 51.66 & \multicolumn{6}{|c|}{$\mathrm{N} / \mathrm{A}$} \\
\hline CYLINDER（clean） & 66.01 & 66.00 & 66.07 & 65.95 & 65.49 & 65.81 & 74.02 & 74.06 & 74.33 & 73.95 & 74.35 & 73.71 \\
\hline CYLINDER（oiled） & 66.47 & 66.91 & 66.59 & 66.59 & 66.08 & 66.51 & 75.29 & 75.81 & 75.54 & 75.22 & 75.45 & 75.02 \\
\hline (TEN), CYL, CONC & 1849.9 & 1811.8 & 1862.40 & 1838.00 & 1841.10 & 1867.00 & 1757.90 & 1761.90 & 1762.60 & 1761.80 & 1759.80 & 1758.10 \\
\hline \multirow[t]{2}{*}{$\begin{array}{l}\text { (TEN), CYL, CONC + } \\
\text { CURING COM. }\end{array}$} & 1850.8 & 1812.1 & 1862.60 & 1838.60 & 1841.70 & 1867.50 & 1758.50 & 1762.50 & 1763.10 & 1762.40 & 1760.30 & 1758.50 \\
\hline & \multicolumn{12}{|c|}{ Day 1} \\
\hline (TEN), CYL, CONC & 1836.00 & 1797.40 & 1845.40 & 1821.00 & 1826.10 & 1847.70 & \multirow{2}{*}{$\begin{array}{l}\text { Control } \\
\text { Tendrain }\end{array}$} & \multirow{5}{*}{\multicolumn{5}{|c|}{$\mathrm{N} / \mathrm{A}$}} \\
\hline TENDRAIN & 66.33 & 50.91 & 67.10 & 63.25 & 67.39 & 64.92 & & & & & & \\
\hline TENDRAIN (clean) & 65.34 & 50.29 & 65.96 & 62.26 & 66.68 & 64.02 & 39.79 & & & & & \\
\hline TENDRAIN (ovened) & 63.28 & 48.87 & 63.77 & 60.38 & 65.30 & 62.10 & 39.70 & & & & & \\
\hline Water in TENDRAIN & 1.94 & 1.33 & 2.08 & 1.77 & 1.25 & 1.80 & 0.0023 & & & & & \\
\hline CYL, CONC & 1769.50 & 1746.30 & 1778.10 & 1757.60 & 1758.60 & 1782.50 & 1749.40 & 1745.00 & 1747.10 & 1750.40 & 1747.20 & 1747.60 \\
\hline CONCRETE & 1698.00 & 1674.90 & 1704.30 & 1683.90 & 1688.50 & 1704.80 & 1665.20 & 1667.80 & 1665.90 & 1670.70 & 1665.30 & 1669.90 \\
\hline TOTAL WATER LOSS & 16.74 & 16.03 & 19.28 & 19.39 & 16.85 & 21.60 & 9.10 & 17.50 & 16.00 & 12.00 & 13.10 & 10.90 \\
\hline Initial Concrete Wt & 1714.74 & 1690.93 & 1723.58 & 1703.29 & 1705.35 & 1726.40 & 1674.30 & 1685.30 & 1681.90 & 1682.70 & 1678.40 & 1680.80 \\
\hline \begin{tabular}{|c|} 
Average Initial Water \\
Loss
\end{tabular} & \multicolumn{6}{|c|}{18.31} & \multicolumn{6}{|c|}{ 13. 10} \\
\hline$\%$ & 0.98 & 0.95 & 1.12 & 1.14 & 0.99 & 1.25 & 0.54 & 1.04 & 0.95 & 0.71 & 0.78 & 0.65 \\
\hline$\%$ & \multicolumn{6}{|c|}{1.07} & \multicolumn{6}{|c|}{0.78} \\
\hline
\end{tabular}

Table 6.3 Water Loss Exp 1 Results 


\begin{tabular}{|c|c|c|c|c|c|c|c|c|c|c|c|c|}
\hline & \multicolumn{6}{|c|}{ Tendrain Specimen } & \multicolumn{6}{|c|}{ Normal Specimen } \\
\hline & \multicolumn{12}{|c|}{ Day 4} \\
\hline & 1 & 2 & 3 & 4 & 5 & 6 & 1 & 2 & 3 & 4 & 5 & 6 \\
\hline CONCRETE & 1669.3 & 1643 & 1676.3 & 1655.4 & 1662.2 & 1676.4 & 1633.4 & 1638.4 & 1639.7 & 1640.6 & 1633.3 & 1640.9 \\
\hline$\%$ & 2.65 & 2.83 & 2.74 & 2.81 & 2.53 & 2.90 & 2.44 & 2.78 & 2.51 & 2.50 & 2.69 & 2.37 \\
\hline \multirow[t]{2}{*}{$\%$ Average } & \multicolumn{6}{|c|}{2.74} & \multicolumn{6}{|c|}{2.55} \\
\hline & \multicolumn{12}{|c|}{ Day 7} \\
\hline CONCRETE & 1664. 7 & 1638.5 & 1671.9 & 1651.1 & 1657.5 & 1672 & 1629 & 1633.6 & 1634. 7 & 1635.5 & 1628.2 & 1636.3 \\
\hline$\%$ & 2.92 & 3.10 & 3.00 & 3.06 & 2.81 & 3.15 & 2.71 & 3.07 & 2.81 & 2.81 & 2.99 & 2.65 \\
\hline \multirow[t]{2}{*}{$\%$ Average } & \multicolumn{6}{|c|}{3.01} & \multicolumn{6}{|c|}{2.84} \\
\hline & \multicolumn{12}{|c|}{ Day 12} \\
\hline CONCRETE & 1658.8 & 1632.7 & 1666. 2 & 1645.8 & 1651.7 & 1666.4 & 1623.9 & 1628.2 & 1629 & 1629.6 & 1622.3 & 1630.8 \\
\hline$\%$ & 3.26 & 3.44 & 3.33 & 3.38 & 3.15 & 3.48 & 3.01 & 3.39 & 3.15 & 3.16 & 3.34 & 2.97 \\
\hline \multirow[t]{2}{*}{$\%$ Average } & \multicolumn{6}{|c|}{3.34} & \multicolumn{6}{|c|}{3.17} \\
\hline & \multicolumn{12}{|c|}{ Day 25} \\
\hline CONCRETE & 1658.2 & 1632.3 & 1666 & 1645.5 & 1651.1 & 1666.3 & 1623.7 & 1627.6 & 1628.4 & 1628.8 & 1621.9 & 1630.5 \\
\hline$\%$ & 3.30 & 3.47 & 3.34 & 3.39 & 3.18 & 3.48 & 3.02 & 3.42 & 3.18 & 3.20 & 3.37 & 2.99 \\
\hline$\%$ Average & \multicolumn{6}{|c|}{3.36} & \multicolumn{6}{|c|}{3.20} \\
\hline
\end{tabular}

Table 6.3 Water Loss Exp 1 Results (continued) 


\begin{tabular}{|c|c|c|c|c|c|c|}
\hline & \multicolumn{3}{|c|}{ Tendrain Specimen } & \multicolumn{3}{|c|}{ Normal Specimen } \\
\hline Weight (g) & 1 & 2 & 3 & 1 & 2 & 3 \\
\hline TENDRAIN & 41.03 & 42.18 & 56.21 & & & \\
\hline CYLINDER (clean) & 81.67 & 86.14 & 81.85 & 107.34 & 108.18 & 107.89 \\
\hline (TEN), CYL, CONC & 2458.81 & 2234.51 & 2211.98 & 2174.38 & 2203.88 & 2287.17 \\
\hline CONCRETE & 2336.11 & 2106.19 & 2073.92 & 2067.04 & 2095.70 & 2179.28 \\
\hline \multicolumn{7}{|c|}{ Day 0.83} \\
\hline (TEN), CYL, CONC & 2437.81 & 2209.52 & 2187.26 & \multirow{2}{*}{$\begin{array}{c}\text { Control } \\
\text { Tendrain }\end{array}$} & & \\
\hline TENDRAIN & 47.43 & 48.04 & 63.70 & & & \\
\hline TENDRAIN (clean) & 46.03 & 46.66 & 62.15 & 39.79 & & \\
\hline TENDRAIN (ovened) & 43.51 & 44.17 & 59.44 & 39.70 & & \\
\hline Water in TENDRAIN & 2.61 & 2.59 & 2.84 & 0.0023 & & \\
\hline CYL, CONC & 2381.90 & 2122.84 & 2160.72 & 2159.40 & 2188.73 & 2270.25 \\
\hline CONCRETE & 2299.33 & 2034.26 & 2068.87 & 2047.46 & 2075.81 & 2156.59 \\
\hline TOTAL WATER LOSS & 23.61 & 27.58 & 27.56 & 14.98 & 15.15 & 16.92 \\
\hline Initial Concrete wt. & 2322.94 & 2061.84 & 2096.43 & 2062.44 & 2090.96 & 2173.51 \\
\hline$\%$ Loss per total mass & 1.02 & 1.34 & 1.31 & 0.73 & 0.72 & 0.78 \\
\hline Average Initial Water Loss & \multicolumn{3}{|c|}{1.22} & \multicolumn{3}{|c|}{0.74} \\
\hline
\end{tabular}

Table 6.4 Water Loss Exp 2 Results 


\begin{tabular}{|c|c|c|c|c|c|c|}
\hline & \multicolumn{3}{|c|}{ Tendrain Specimen } & \multicolumn{3}{|c|}{ Normal Specimen } \\
\hline Weight (g) & 1 & 2 & 3 & 1 & 2 & 3 \\
\hline \multicolumn{7}{|c|}{ Day 1.83} \\
\hline CONCRETE & 2242.77 & 1982.51 & 2012.89 & 1990.33 & 2018.05 & 2094.67 \\
\hline Loss & 80.17 & 79.33 & 83.54 & 72.11 & 72.91 & 78.84 \\
\hline$\%$ Loss per total mass & 3.45 & 3.85 & 3.98 & 3.50 & 3.49 & 3.63 \\
\hline Average Water Loss & \multicolumn{3}{|c|}{3.76} & \multicolumn{3}{|c|}{3.54} \\
\hline \multicolumn{7}{|c|}{ Day 3.92} \\
\hline CONCRETE & 2233.58 & 1974.42 & 2004.44 & 1982.16 & 2010.27 & 2086.8 \\
\hline Loss & 89.36 & 87.42 & 91.99 & 80.28 & 80.69 & 86.71 \\
\hline$\%$ Loss per total mass & 3.85 & 4.24 & 4.39 & 3.89 & 3.86 & 3.99 \\
\hline Average Water Loss & \multicolumn{3}{|c|}{ 4. 16} & \multicolumn{3}{|c|}{3.91} \\
\hline \multicolumn{7}{|c|}{ Day 6} \\
\hline CONCRETE & 2228.9 & 1970.22 & 2000 & 1977.91 & 2006.11 & 2082.46 \\
\hline Loss & 94.04 & 91.62 & 96.43 & 84.53 & 84.85 & 91.05 \\
\hline$\%$ Loss per total mass & 4.05 & 4. 44 & 4. 60 & 4. 10 & 4.06 & 4. 19 \\
\hline Average Water Loss & \multicolumn{3}{|c|}{4.36} & \multicolumn{3}{|c|}{ 4. 12} \\
\hline
\end{tabular}

Table 6.4 Water Loss Exp 2 Results (continued) 


\begin{tabular}{|c|c|c|c|c|c|c|}
\hline & \multicolumn{3}{|c|}{ Tendrain Specimen } & \multicolumn{3}{|c|}{ Normal Specimen } \\
\hline Weight (g) & 1 & 2 & 3 & 1 & 2 & 3 \\
\hline \multicolumn{7}{|c|}{ Day 23} \\
\hline CONCRETE & 2213.58 & 1956.49 & 1985.67 & 1963.6 & 1992.11 & 2067.47 \\
\hline Loss & 109.36 & 105.35 & 110.76 & 98.84 & 98.85 & 106.04 \\
\hline$\%$ Loss per total mass & 4.71 & 5.11 & 5.28 & 4.79 & 4.73 & 4.88 \\
\hline Average Water Loss & \multicolumn{3}{|c|}{5.03} & \multicolumn{3}{|c|}{4.80} \\
\hline \multicolumn{7}{|c|}{ Day 42} \\
\hline CONCRETE & 2209.15 & 1952.33 & 1981.36 & 1959.07 & 1987.08 & 2062.35 \\
\hline Loss & 113.79 & 109.51 & 115.07 & 103.37 & 103.88 & 111.16 \\
\hline$\%$ Loss per total mass & 4.90 & 5.31 & 5.49 & 5.01 & 4.97 & 5.11 \\
\hline Average Water Loss & \multicolumn{3}{|c|}{5.23} & \multicolumn{3}{|c|}{5.03} \\
\hline \multicolumn{7}{|c|}{ Day 70} \\
\hline CONCRETE & 2205.04 & 1948.54 & 1977.37 & 1955. 17 & 1983.54 & 2057.97 \\
\hline Loss & 117.90 & 113.30 & 119.06 & 107.27 & 107.42 & 115.54 \\
\hline$\%$ Loss per total mass & 5.08 & 5.50 & 5.68 & 5.20 & 5.14 & 5.32 \\
\hline Average Water Loss & \multicolumn{3}{|c|}{5.42} & \multicolumn{3}{|c|}{5.22} \\
\hline
\end{tabular}

Table 6.4 Water Loss Exp 2 Results (continued) 

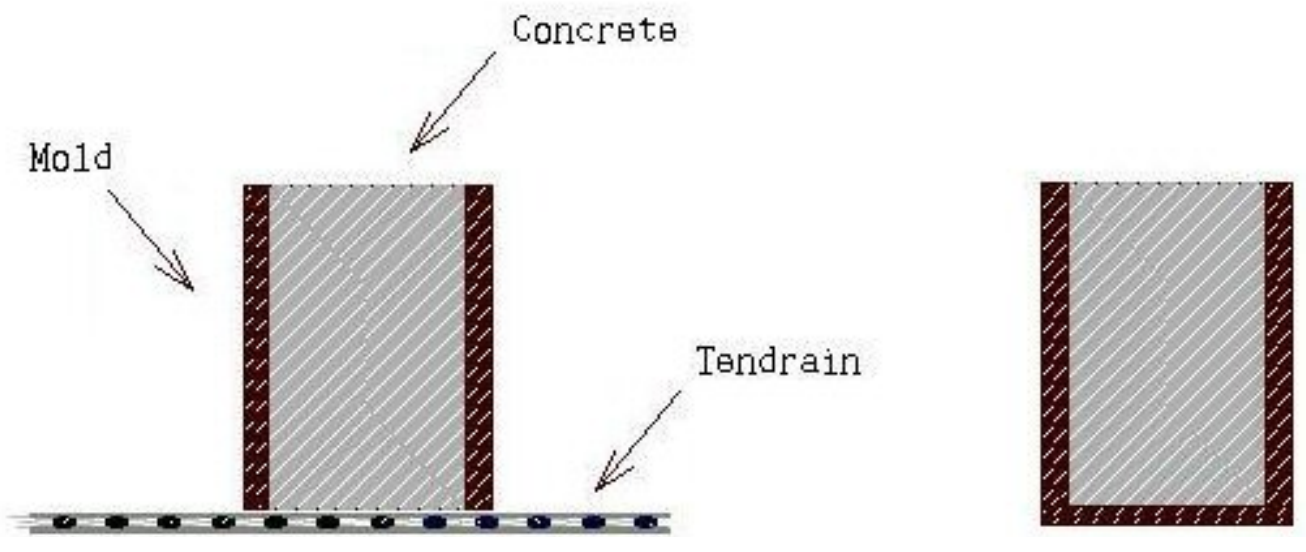

Tendrain Specimen

Standard Specimen

Figure 6.1 Experiment Setup 
Water Loss Experiment 1

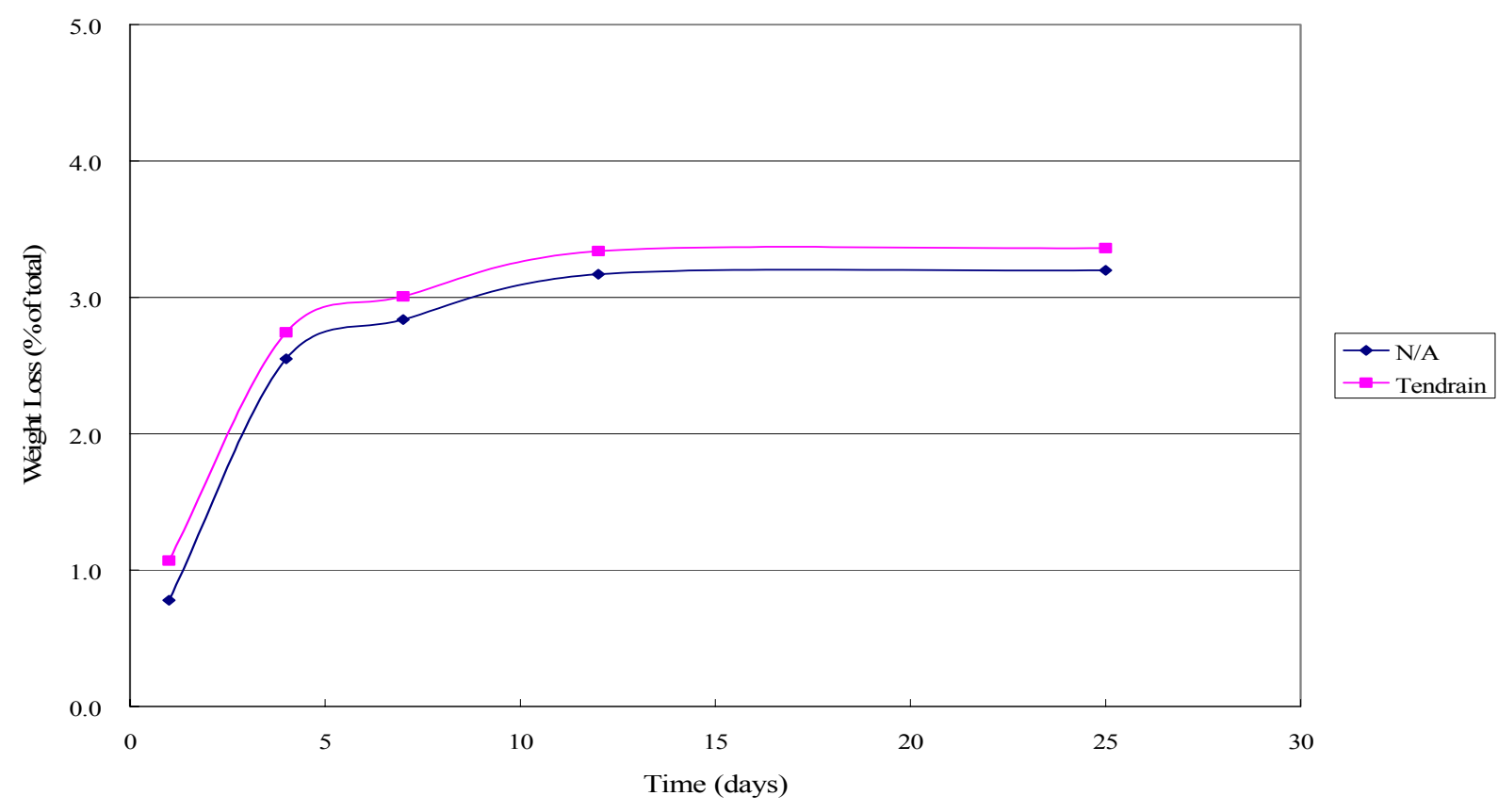

(a)

Water Loss Experiment 1

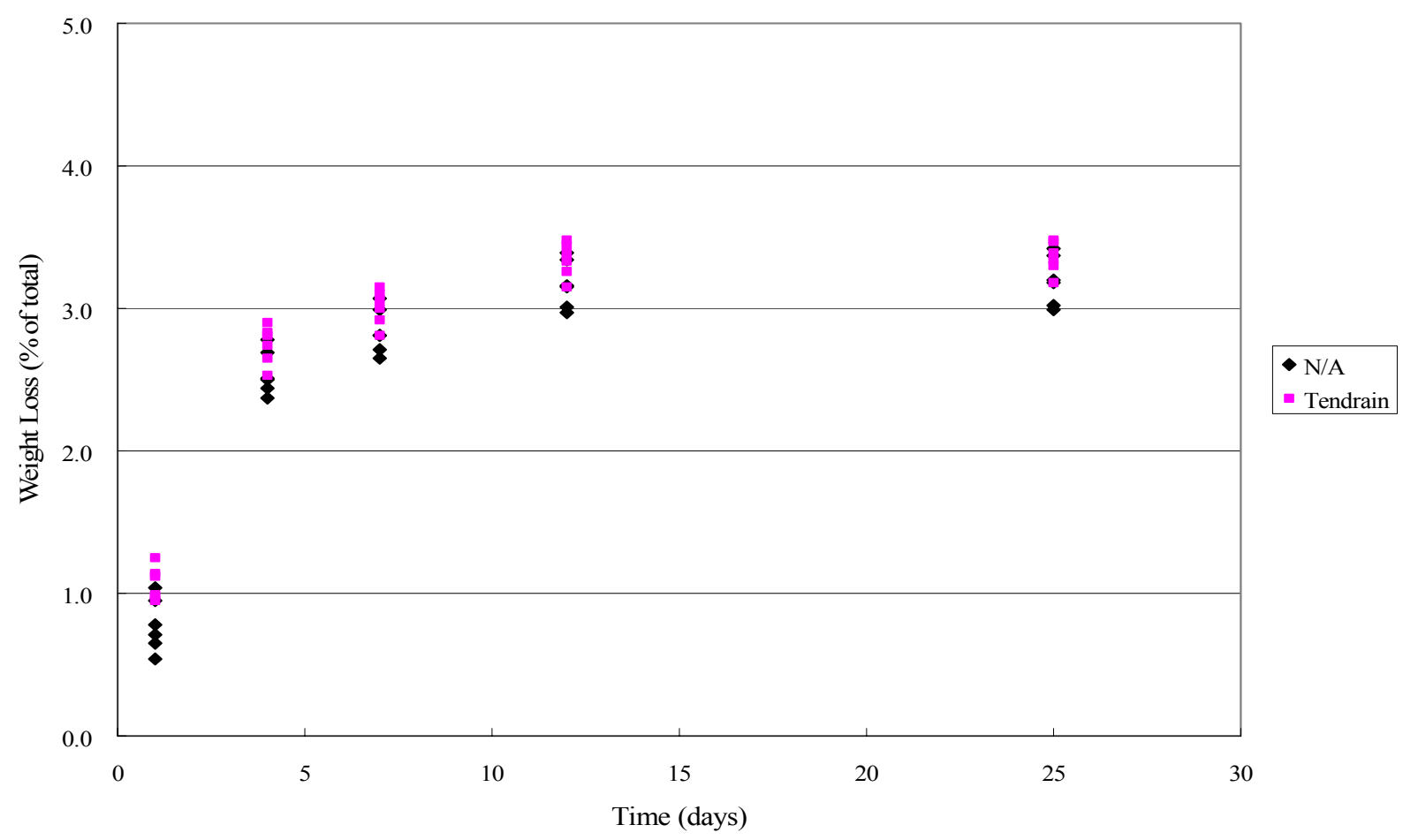

(b)

Figure 6.2 Weight Loss vs. Time (a) averages (b) individual 
Water Loss Experiment 1

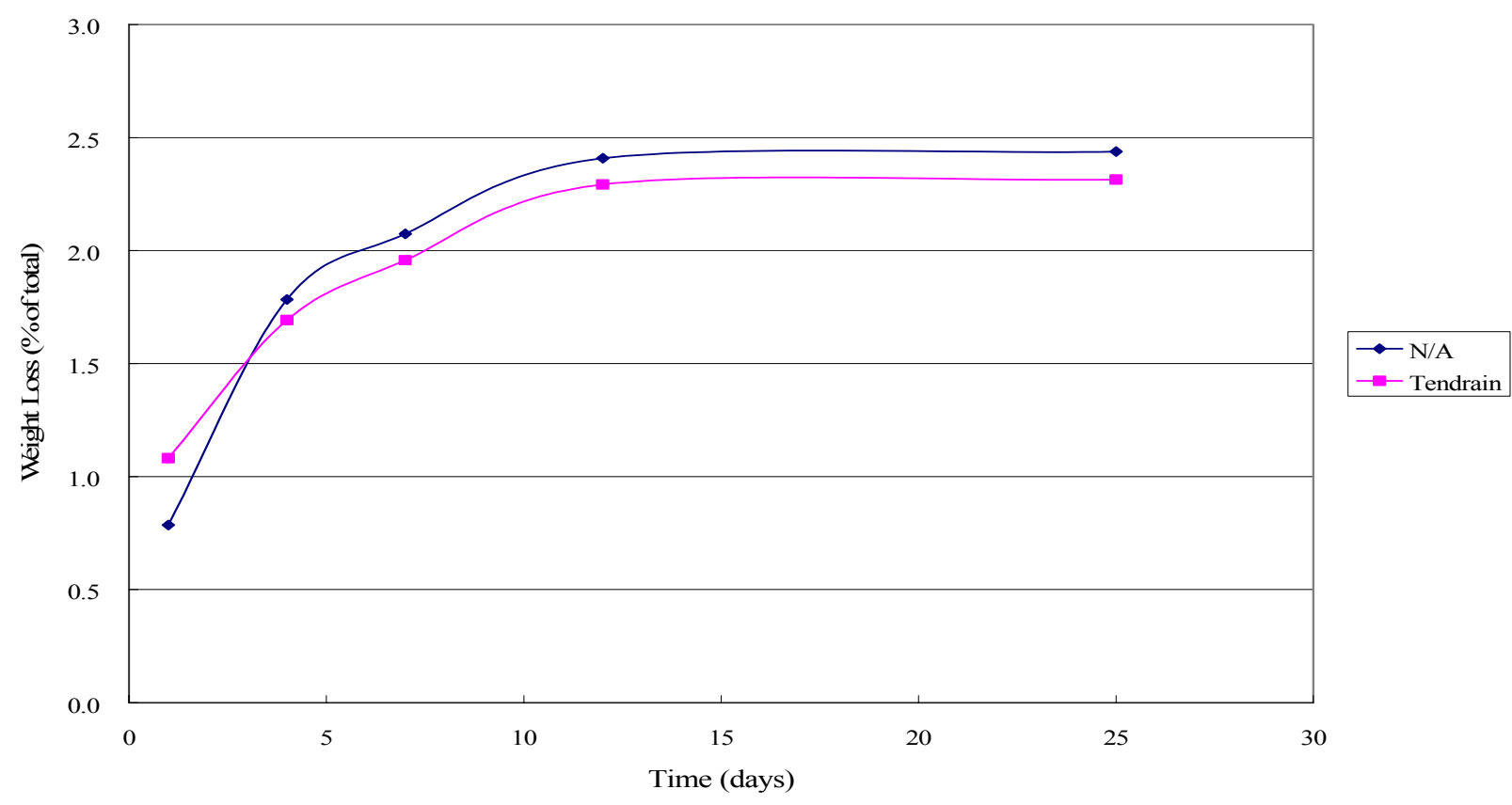

(a)

Water Loss Experiment 1

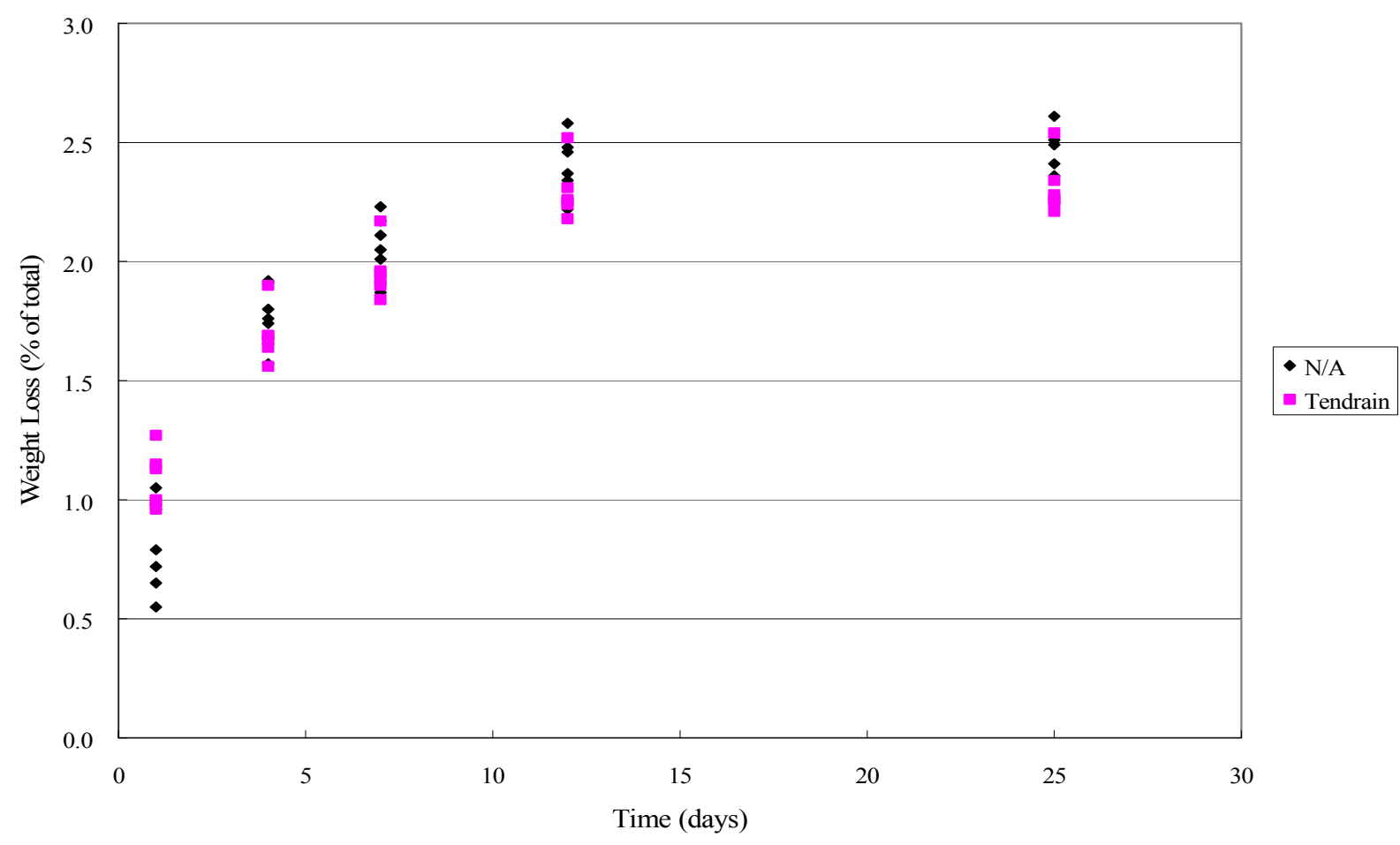

(b)

Figure 6.3 Weight Loss (w/ initial loss) vs. Time (a) averages (b) individual 
Water Loss Experiment 2

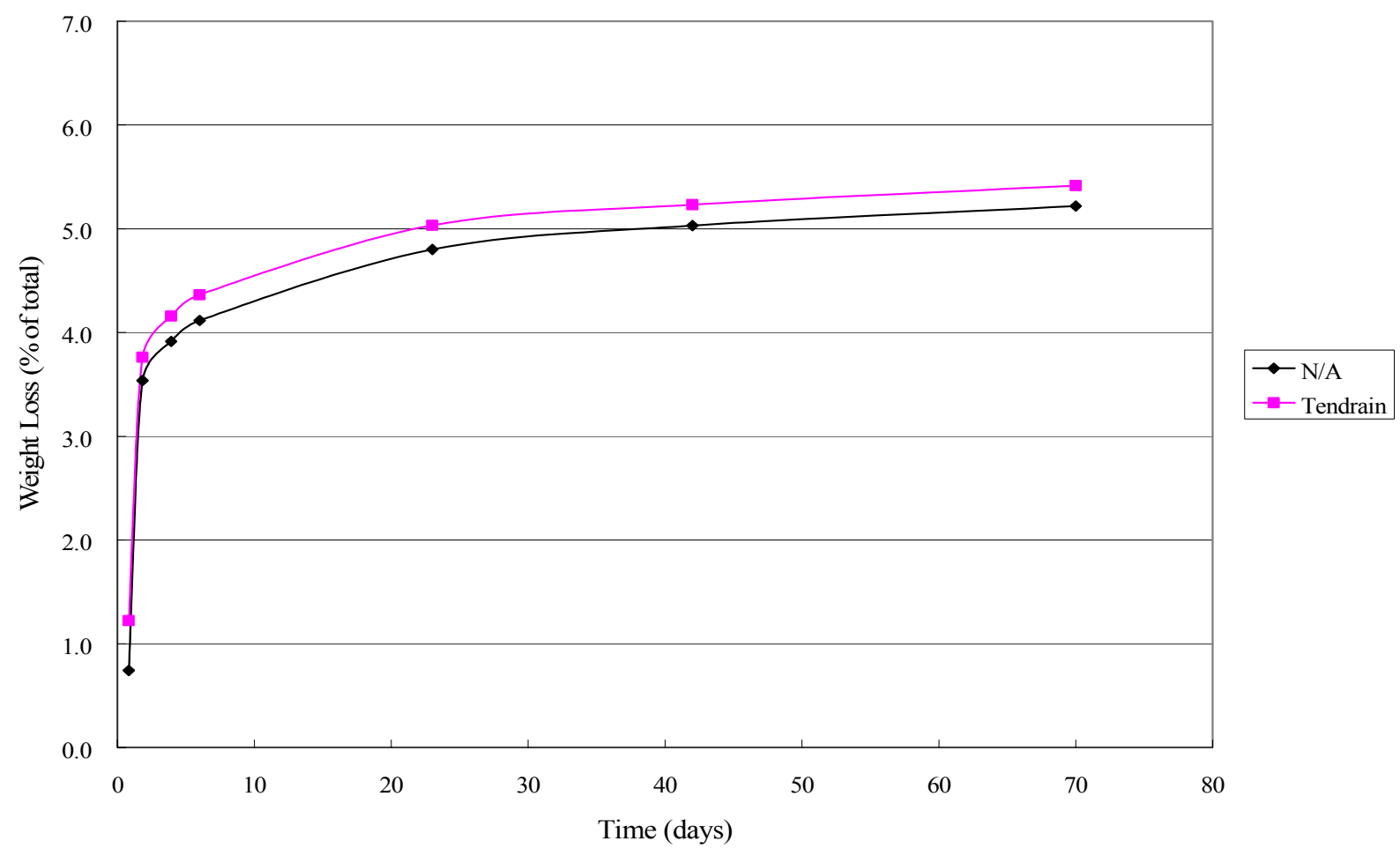

(a)

Water Loss Experiment 2

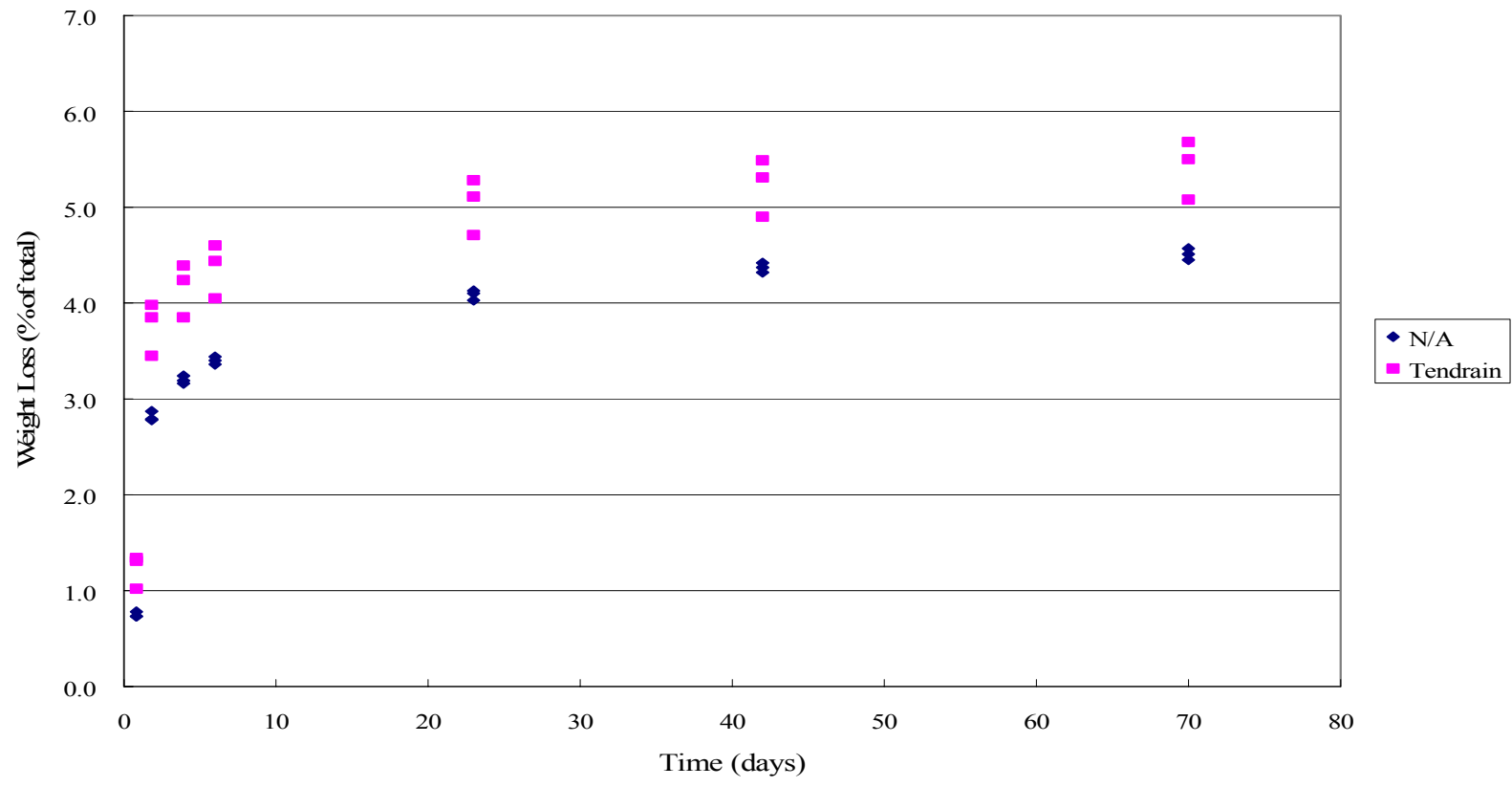

(b)

Figure 6.4 Water Loss vs. Time (a) averages (b) individual 
Water Loss Experiment 2

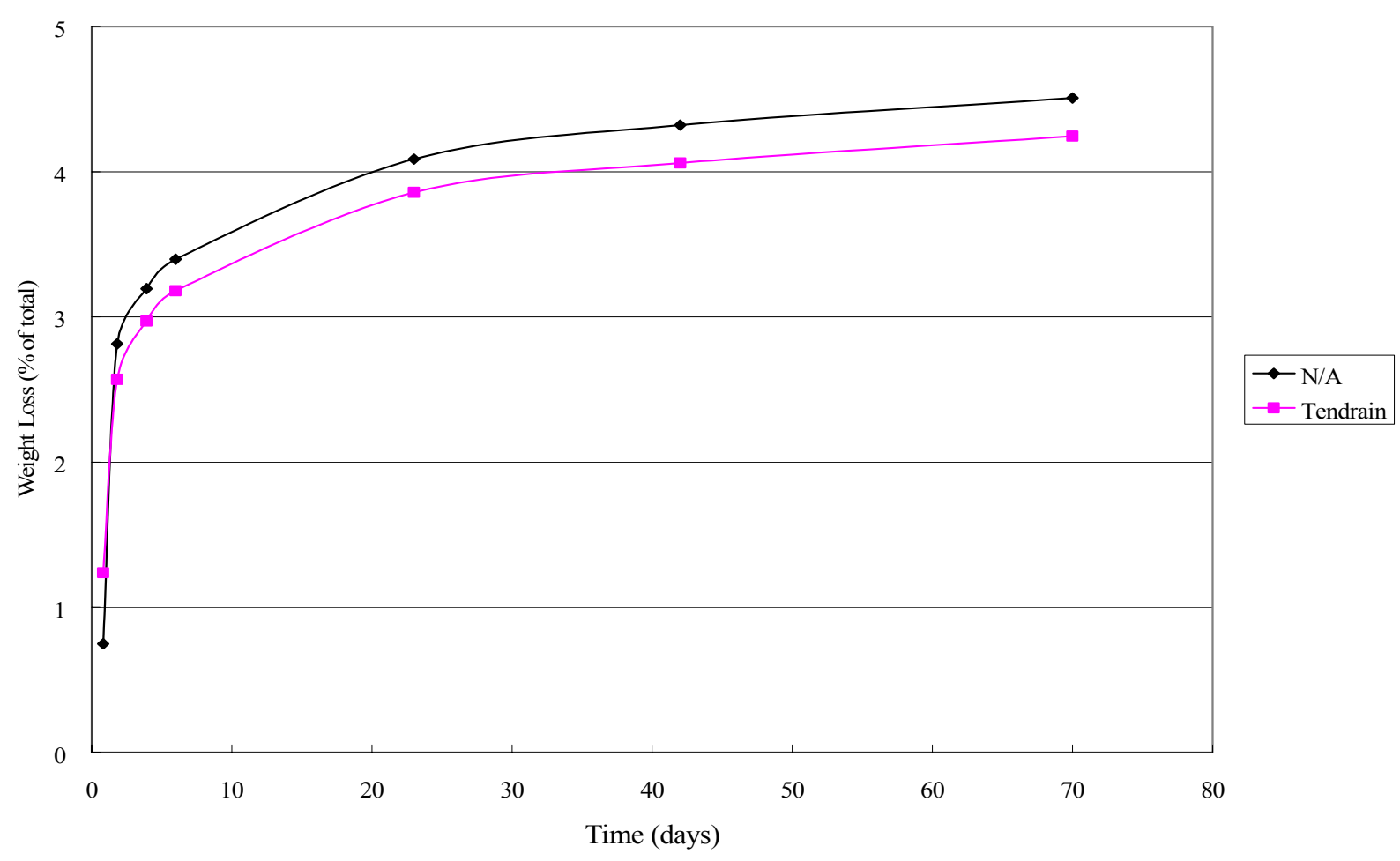

(a)

Water Loss Experiment 2

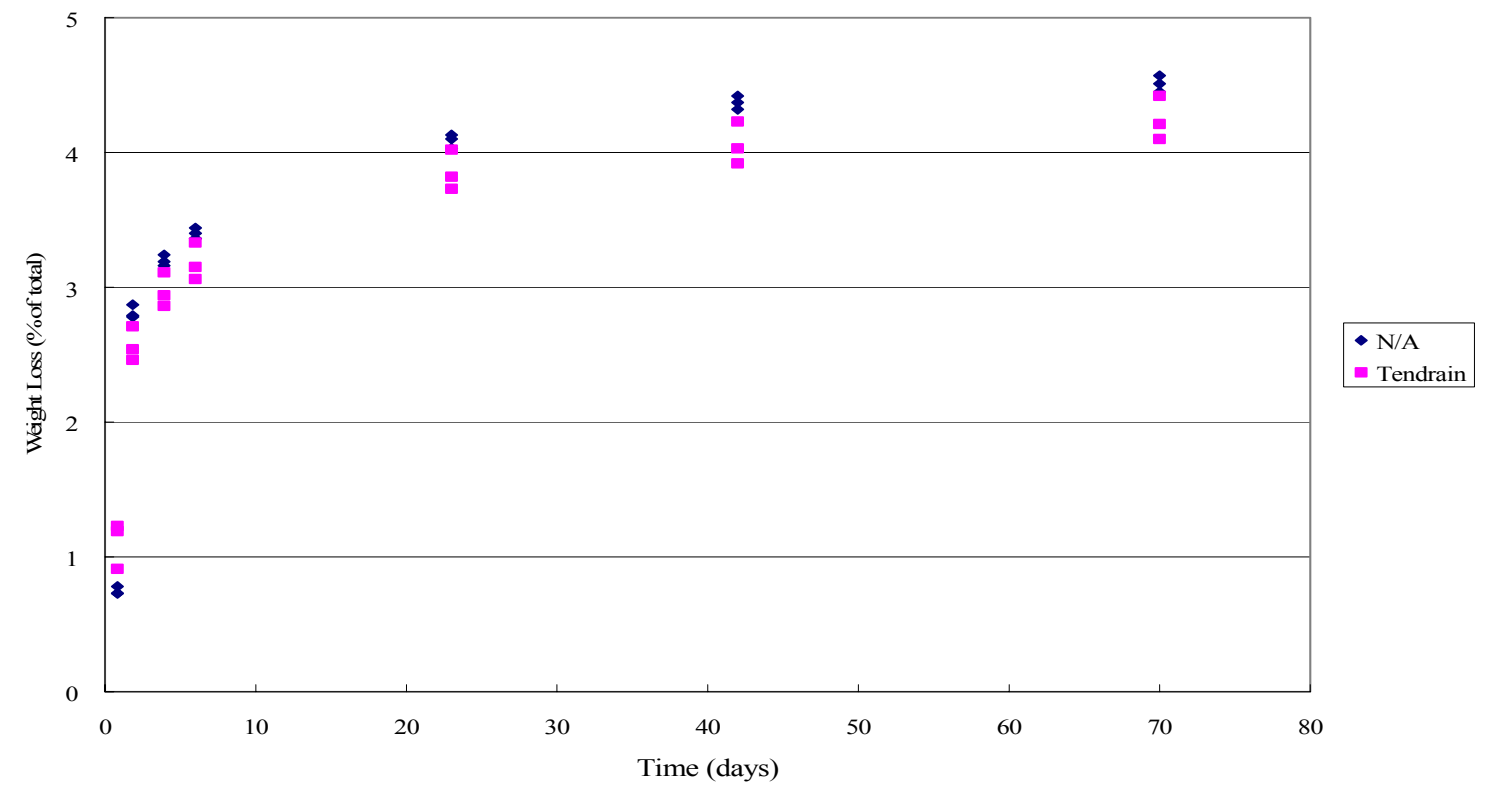

(b)

Figure 6.5 Water Loss (w/ out initial loss) vs. Time (a) averages (b) individual 


\section{CHAPTER 7 \\ CONCLUSIONS AND APPLICATIONS}

\subsection{Conclusions}

The following are the specific conclusions attained from this research:

Friction Study:

1. There seems to be no significant difference in the performance of the frictional resistance when $\mathrm{w} / \mathrm{c}$ ratio is varied from 0.47 to 0.57 .

2. The bond between the concrete and Tendrain is developed early in the setting process. Push tests were conducted at concrete age from 8 hours to 21 days and no significant difference in frictional resistance was observed.

3. During small displacements $(0$ in. $\sim 0.03$ in. $)$ within these Push Tests, resistance depends on the deformation of the Tendrain and the friction between Tendrain and the subbase. Tendrain's tensile stiffness comes into play after loading surpasses the frictional value.

4. Regardless of the subbase material, Tendrain follows the same trend after loading surpasses the frictional value offered by the subbase. By knowing the coefficient of friction of Tendrain and its subbase, one can predict the behavior of total horizontal resistance of concrete on Tendrain.

5. The coefficient of friction between Tendrain - \#57 limestone, and Tendrain - soil are 0.68 and 1.1 respectively.

6. The gray Tendrain with the continuously woven required on average about half the force of that required to peel-off the black Tendrain. 
Compressive Tests Study:

1. The conclusion from all four tests is that the concrete cast on Tendrain seems to have little to no significant difference in compressive strength when compared with the standard concrete cylinders of the same mixture. The statement is also true for varying $\mathrm{w} / \mathrm{c}$ ratios of 0.47 and 0.57 . The water seepage that occurs before the concrete has set has no affect on the overall compressive strength of the concrete.

Drying Shrinkage and Water Loss Study:

1. Initial drying shrinkage within the normal specimens has a greater rate than that of the Tendrain specimens. After a period of time, the drying shrinkages within both sets possess approximately the same rate.

2. On average concrete cast on Tendrain has about $9 \%$ less drying shrinkage than that of concrete cast with standard shrinkage specimen mold.

\subsection{Applications}

The experimental results and conclusions made from them can be applied in the following applications.

1. The traditional subgrade-drag formula for determining amount of distributed Steel in CRCP and floor slabs dictates:

$$
\text { As }=\text { FLw } / 2 \mathrm{fs}
$$

where,

$$
\begin{aligned}
& \text { As }=\text { cross-sectional area of steel } \\
& F=\text { coefficient of subgrade friction. } \\
& \mathrm{L}=\text { slab length } \\
& \mathrm{W}=\text { weight } \text { of slab }
\end{aligned}
$$


fs $=$ allowable working stress of reinforcement

Designers use $\mathbf{F}=\mathbf{1 . 5}$ for concrete floors on ground; $\mathbf{1 . 1}$ and $\mathbf{0 . 6 4}$ can be used for concrete floors with Tendrain on soil and on gravel, respectively. This reduces the amount of temperature and shrinkage reinforcement by 27 and 57 percent, respectively. However, care should be taken to satisfy minimum amount of reinforcement requirement.

2. The test results from this study can be compared with other push-off test data ${ }^{3,14}$ from example slabs (Figure 7.1). $\quad$ Failure planes for the different types of layers in Figure 7.1 are within the subbase layer, not at the interface of the slab and subbase layer. The Tendrain test's sliding interface is between the subbase and the material. Table 7.1 contains a summary of other push-off test data and Tendrain's results.

3. Even with good jointing uneven shrinkage can cause curling of the slab. Curling occurs mainly due to the differences in moisture between the top and bottom surfaces of the concrete slab. New slabs dry from the surface down creating a moisture gradient and therefore a differential in shrinkage ${ }^{13}$. One of the practice noted to help minimize the potential for curling was: take precautions to avoid excessive bleeding by placing concrete on an absorptive/damp subgrade so that all the bleed water wouldn't force to the top $^{16}$. The presence of Tendrain could help reduce the shrinkage allowing water loss from the bottom portion of the slab.

4. Slab moisture can cause problems with floor-coverings, such as tile and sheet flooring, which require adhesion with the concrete ${ }^{14}$. Due to restrictions on volatile emissions on the products, the adhesives used with the coverings are normally water-sensitive. The manufacturers often require moisture emission from hardened concrete slab be less than a 
certain value before installation of their product. Tendrain's presence might be able to help reduce the amount of residual moisture in the slab, in turn producing a shorter drying period.

\subsection{Recommendations}

Laboratory test on larger scale specimens for continued investigation into the vertical stiffness characteristics of pavement which utilizes Tendrain for drainage is needed. Practically all designs for concrete pavements and floors-on-grade are based on the composite modulus of subgrade reaction $\mathrm{k}$, which is defined as the pressure necessary to produce a unit deformation of the subgrade. Substantial pavement studies have shown that elastic deflections and stresses of the concrete slab can be predicted reasonably well when using an appropriate modulus $k$ to represent the subgrade response.

It is also of interest to determine if the presence of Tendrain has an affect on the freeze thaw cycle and temperature gradient of the concrete. 


\begin{tabular}{|c|c|c|c|c|c|}
\hline Subbase Type & $\begin{array}{c}\text { Peak } \\
\text { Frictional } \\
\text { Resistance } \\
\text { (psi) }\end{array}$ & $\begin{array}{c}\text { Horizontal } \\
\text { Movement at } \\
\text { Sliding } \\
\text { (in) }\end{array}$ & $\begin{array}{c}\text { Slab } \\
\text { Depth } \\
\text { (in) }\end{array}$ & $\begin{array}{c}\text { Initial } \\
\text { Resistance up } \\
\text { to 0. 002" } \\
\text { (psi/in) }\end{array}$ & $\begin{array}{c}\text { Peak } \\
\text { Resistance } \\
\text { up to slide } \\
\text { (psi/in) }\end{array}$ \\
\hline Asphalt-stabilized & $1.6,2.2$ & $\begin{array}{c}0.030, \\
0.038\end{array}$ & $3.5,7$ & 600,576 & $53.3,57.9$ \\
\hline Cement-stabilized & $15.4+$ & $0.001+$ & 3.5 & 12791 & 15400 \\
\hline Lime-treated clay & $1.6,1.7$ & $\begin{array}{c}0.011, \\
0.012\end{array}$ & $3.5,7$ & 375,400 & $\begin{array}{c}745.5, \\
142.7\end{array}$ \\
\hline Untreated clay & $.6,1.1$ & $\begin{array}{c}0.030, \\
0.052\end{array}$ & $3.5,7$ & 167,352 & $20,21.1$ \\
\hline Tendrain - Soil & 1.15 & 0.051 & 12 & 130 & 22.5 \\
\hline Tendrain - Gravel & 0.71 & 0.041 & 12 & 130 & 17.3 \\
\hline
\end{tabular}

Table 7.1 Push-off Test Comparison

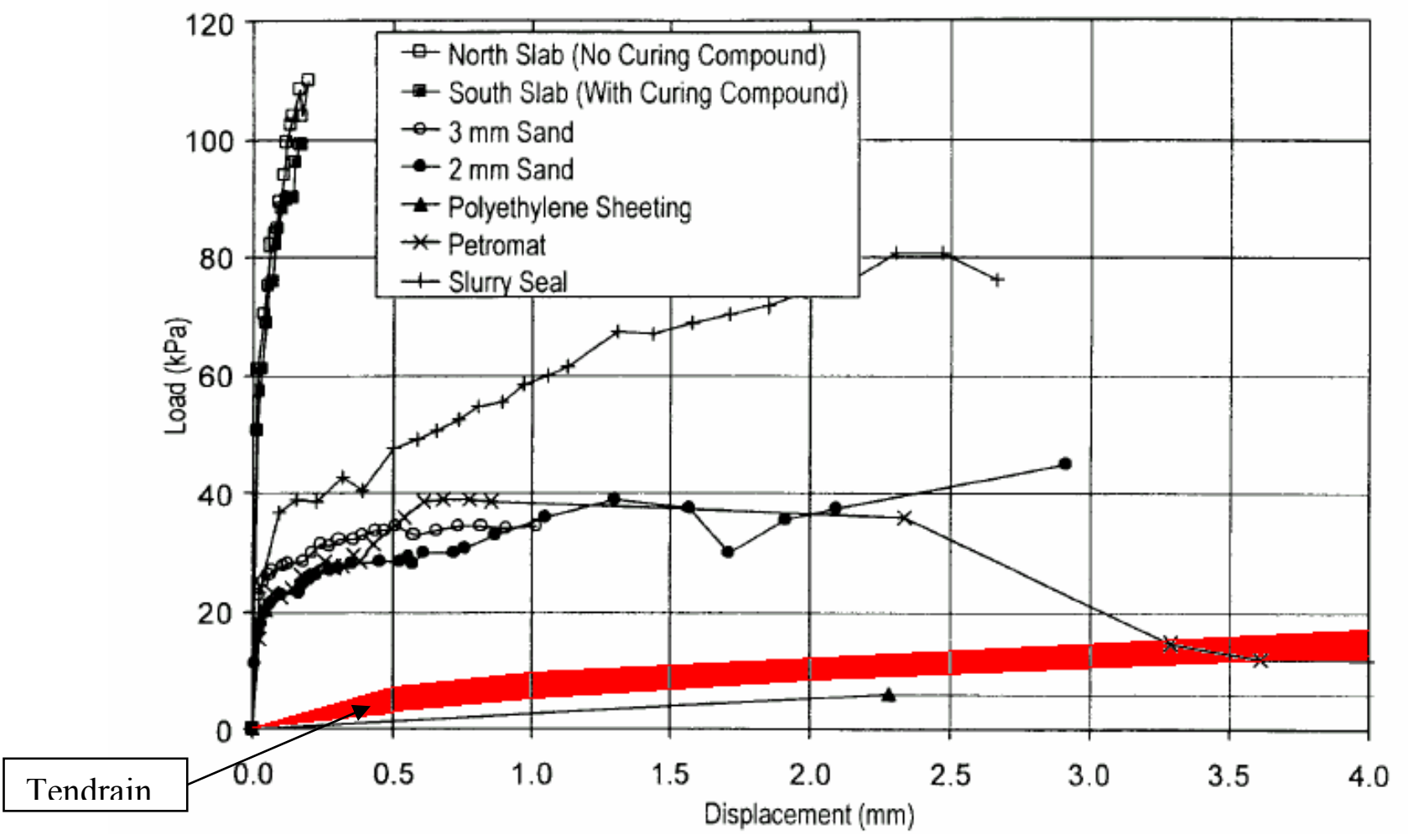

Figure 7.1 Plots of push-off test data from example slabs in Rasmussen and Rozycki Study 


\section{References}

1. Goldbeck, A.T. Friction Tests for Concrete on Various Subbabes. American Concrete Institute Proceedings, Vol. 8, 1917.

2. Goldbeck, A.T. Friction Tests for Concrete on Various Subbabes. Public Roads, Vol. 5 No. 5, United States Department of Agriculture, Washington, D.C., July 1924.

3. Rasmussen, R.O. and Rozycki D.K., "Characterization and Modeling of Axial Slab-Support Restraint”. TRB Paper Number 01-2948, Committee A2B02, 2001.

4. "Guide for Design of Pavement Structures", American Association of State Highway and Transportation Officials, Washington, D.C., 1986.

5. Neville, Adam M., "Properties of Concrete", 3 rd edition, Pitman Publishing Inc., Massachusetts, 1981.

6. Gilbert, R. I., "Time Effects in Concrete Structures”, Elsevier Science Publishing Company Inc., New York, 1988.

7. Ropke, John C., "Concrete Problems: Causes and Cures”, McGraw-Hill Inc., New York, 1982

8.. "Guide for Concrete Floor and Slab Construction", ACI 302.1 R American Concrete Institute, Farming Hills, MI. 1996.

9. “Concrete slab surface defects: Causes, prevention, repair", Portland Cement Association, (EB096.01D), pp. 4-5, 1997.

10. "Pavement Design", Transportation Research Record 1207, National Research Council, Washington, D.C., p.44, 1988.

11. Springfield, J., Mailvaganam, N.P. and Taylor, D.A. "Curling in new and repaired industrial floors", Proceedings of annual conference of Canadian Society of Civil Engineers, Vol. 2b, pp. 727-38, 1996.

12. "Concrete Floors on Ground", Portland Cement Association, EBO 75, Skokie, IL., 2001.

13. Suprenant, B., "Moisture Movement through Concrete Slabs", Concrete Construction, November 1997.

14. "Understanding Concrete Floors and Moisture Issues", Portland Cement Association, CDO14, Skokie, IL., 200 
15. Won, M., Hankins, K., and McCullough B., "Mechanistic Analysis of Continuously Reinforced Concrete Pavements Considering Material Characteristics, Variability, and Fatigue", Center for Transportation Research, Report 1169-2, March 1991.

16. Holland, J. and Walker, W., "Controlling Curling and Cracking in Floors to Receive Coverings", Concrete Construction, www.worldofconcrete.com, July 1998.

17. Wesevich, J., McCullough, B. and Burns, N., "Stabilized Subbase Friction Study for Concrete Pavements". Research Report 459-1. Center for Transportation Research, The University of Texas at Austin, April 1987 


\section{Appendix A Tendrain ${ }^{\mathrm{TM}}$ Geocomposite Properties}

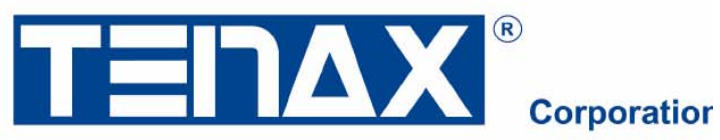

\section{TENDRAIN 770-2 \\ Double-Sided Geocomposite}

The drainage geocomposite is comprised of a tri-axial geonet structure consisting of thick supporting ribs with diagonally placed top and bottom ribs and with a thermally bonded, non-woven high UV resistant Ultra Vera geotextile on both sides. The product is capable of providing high Transmissivity in a soil environment under high normal loads and will have properties conforming to the values and test methods listed below.

\begin{tabular}{|c|c|c|c|c|c|}
\hline Property & Test Methods & Units & Value & Qualifier & Test Frequency \\
\hline \multicolumn{6}{|l|}{ Resin } \\
\hline - Density & ASTM D 1505 & $\mathrm{~g} / \mathrm{cm}^{3}$ & 0.94 & MAV & lot \\
\hline - Melt Flow Index & ASTM D 1238 & $\mathrm{~g} / 10 \mathrm{~min}$ & 1.0 & Max & lot \\
\hline \multicolumn{6}{|l|}{ Geonet Core $^{3}$} \\
\hline Structure & & & Tri-axial & & \\
\hline - Tensile Strength-MD & ASTM D 4595 & $\mathrm{lb} / \mathrm{ft}(\mathrm{kN} / \mathrm{m})$ & \multirow{2}{*}{$\begin{array}{c}1200(17.5) \\
1.2\end{array}$} & MAV & $50,000 \mathrm{sf}$ \\
\hline - Creep Reduction Factor ${ }^{1}$ & GRI-GC8 & - & & & \\
\hline - Thickness ${ }^{2}$ & ASTM D 5199 & $\operatorname{mil}(\mathrm{mm})$ & $300(7.6)$ & MAV & $50,000 \mathrm{sf}$ \\
\hline - Carbon Black & ASTM D 4218 & $\%$ & $2-3$ & range & $50,000 \mathrm{sf}$ \\
\hline \multicolumn{6}{|l|}{ Top Filter Geotextile ${ }^{34}$} \\
\hline - U.V. Resistance (500 hrs) & ASTM G 154 & $\%$ & 95 & MAV & Per formula \\
\hline - AOS & ASTM D 4751 & US Std. Sieve (mm) & $70(0.212)$ & MaxARV & $500,000 \mathrm{sf}$ \\
\hline - Mass/Unit Area & ASTM D 5261 & $\mathrm{oz} / \mathrm{yd}^{2}\left(\mathrm{~g} / \mathrm{m}^{2}\right)$ & $6(203)$ & MARV & $100,000 \mathrm{sf}$ \\
\hline - Permittivity & ASTM D 4491 & $\mathrm{Sec}^{-1}$ & 0.5 & MARV & $500,000 \mathrm{sf}$ \\
\hline - Puncture Resistance & ASTM D 4833 & $\operatorname{lbs}(\mathrm{N})$ & $56(250)$ & MARV & $100,000 \mathrm{sf}$ \\
\hline - Tear Strength & ASTM D 4533 & $\operatorname{lbs}(\mathrm{N})$ & $56(250)$ & MARV & $100,000 \mathrm{sf}$ \\
\hline - Grab Tensile & ASTM D 4632 & $\operatorname{lbs}(\mathrm{N})$ & $157(700)$ & MARV & $100,000 \mathrm{sf}$ \\
\hline \multicolumn{6}{|l|}{ Bottom Friction Geotextile ${ }^{3}$} \\
\hline - U.V. Resistance (500 hrs) & ASTM G 154 & $\%$ & 95 & MAV & Per formula \\
\hline - Mass/Unit Area & ASTM D 5261 & $o z / y^{2}\left(g / m^{2}\right)$ & \multirow{2}{*}{$6(203)$} & AVE & $100,000 \mathrm{sf}$ \\
\hline - Grab Tensile & ASTM D 4632 & $\operatorname{lbs}(\mathrm{N})$ & & MARV & $100,000 \mathrm{sf}$ \\
\hline \multicolumn{6}{|l|}{ Geocomposite } \\
\hline - Peel Adhesion ${ }^{5}-\mathrm{MD}$ & F904 Modified & $\mathrm{lb} / \mathrm{in}(\mathrm{g} / \mathrm{in})$ & $1.0(454)$ & MAV & $100,000 \mathrm{sf}$ \\
\hline - Labeling & \multicolumn{5}{|c|}{ Product code, geotextile type, roll dimensions, finished product lot and roll number. } \\
\hline \multicolumn{6}{|c|}{ Hydraulic Behavior of Geocomposite } \\
\hline \multicolumn{6}{|l|}{ - Transmissivity $^{6}$ - MD } \\
\hline \multicolumn{6}{|l|}{ Gradient / Load } \\
\hline 0.1 & $\begin{array}{l}\text { ASTM D } 4716 \\
\text { GRI - GC } 8\end{array}$ & $\mathrm{~m}^{2} / \mathrm{sec}$ & $1.8 * 10^{-3}$ & MAV & $200,000 \mathrm{sf}$ \\
\hline
\end{tabular}

$\begin{array}{llll}\text { Qualifiers: } & \text { MARV }=\text { Minimum Average Roll Value (MARV) } & \text { MAV }=\text { Minimum Average Value } & \text { MAX }=\text { Maximum Value } \\ & \text { MaxARV }=\text { Maximum average roll value } & \text { AVE }=\text { Average value } & \end{array}$

NOTES:

1. Creep Reduction Factor is based on 10,000 hour test duration, extrapolated to 30 years and using a compressive load of 25,000 psf.

2. Thickness measured by manufacturer per ASTM D5199 with a 2.22 in. diameter presser foot and 2.9 psi pressure.

3. Geotextile and geonet properties listed are prior to lamination.

4. Top filter geotextile meets ASSHTO Standard Specification M 288-00 strength requirements of class 2 and the highest filter requirements.

5. Peel Adhesion is tested by the manufacturer per modified ASTM F904, with a 2 inch wide ( 5 longitudinal ribs) by 10 inch long strip. The geotextile bonded to either side of the geonet is pulled apart at a peeling rate of $12 \mathrm{in} / \mathrm{min}$., for at least 4 inches of peeling distance. The reported value for each laminated side is the average of the "peak" values from 5 tested samples. The 5 samples are cut evenly distributed along the roll width with a 1 foot margin from both edges of the roll.

6. Geocomposite transmissivity measured by manufacturer per ASTM D4716 with testing boundary conditions as follows: steel plate / uniform sand / geocomposite / 60 mil HDPE geomembrane / steel plate, and seating period of 100 hours according to GRI-GC8.

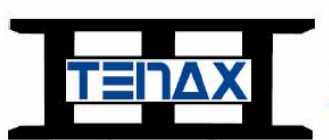

Engineered for Life

() 2002, Tenax Geotextiles are manufactured by Tenax, LLC., Evergreen, AL. Printed in the U.S.A. The information contained herein has been carefully compiled by Tenax Corporation and to the best of our knowledge accurately represents Tenax product. Final determination of the suitability of any information or material for the use contemplated and its manner of use is the sole responsibility of the user. 


\section{Vita}

Joshua Bryan Cook was born and raised March 3, 1980 in Charleston, West Virginia. He graduated in the top twenty percent of the Capital High School class of 1998. In August 1998, he entered West Virginia University, and earned a Bachelor of Science in Civil Engineering degree in May 2002. In the same year he passed the FE exam to become an EIT. He entered the graduate program with a specialty in structures in August 2002. In May 2004 he met all requirements for the degree of Master of Science in Civil Engineering. 